\title{
POLITICALLY (DIS)EMPOWERED: THE EFFECT OF SYSTEMIC RACISM AND COLORBLINDNESS ON MINORITY YOUTH
}

\author{
A Thesis submitted to the faculty of \\ San Francisco State University \\ In partial fulfillment of \\ the requirements for \\ the Degree
}

Master of Arts
In
Political Science

by

Sarah Bouabibsa

San Francisco, California

August 2020 
Copyright by

Sarah Bouabibsa

2020 


\section{CERTIFICATION OF APPROVAL}

I certify that I have read Politically (Dis)Empowered: The Effect of Systemic Racism and Colorblindness on Minority Youth by Sarah Bouabibsa, and that in my opinion this work meets the criteria for approving a thesis submitted in partial fulfillment of the requirement for the degree Master of Arts in Political Science at San Francisco State University.

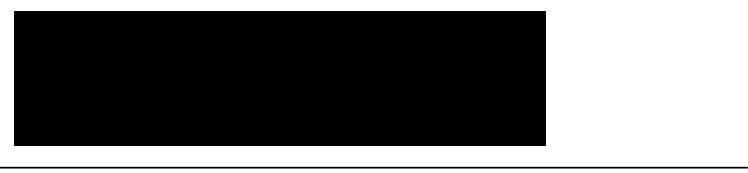

Francis Neely, Ph.D.

Associate Professor

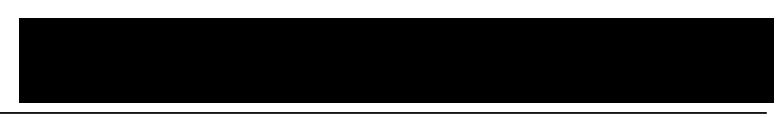

Marcela Garcia-Castanon, Ph.D.

Associate Professor 


\title{
POLITICALLY (DIS)EMPOWERED: THE EFFECT OF SYSTEMIC RACISM AND COLORBLINDNESS ON MINORITY YOUTH
}

\author{
Sarah Bouabibsa \\ San Francisco, California
}

2020

\begin{abstract}
This project takes up the question, why do minority youth lack political empowerment? To answer this, I use Joe Feagin's Systemic Racism Theory and Edward Bonilla-Silva's Theory of Color-Blind Racism to examine institutional and social structures of racism. I apply both theories as socio-environmental context for ethnic and racial identity formation to examine their developmental implications. I adopt Albert Bandura's Social Cognitive Theory to present social media as an agency-building tool that can mitigate the effects of institutional and social structures of disempowerment. I test whether the institutional and social structures of racism disproportionately impact minority youth and whether social media can positively impact a sense of empowerment using a two-wave survey of youth that examines their digital presence and sense of efficacy, which serves as a stand-in for empowerment. I find that non-White youth are more likely to view racism as a major problem. In addition, both White and non-White respondents have lower levels of political efficacy when they report viewing racism as a significant problem. Finally, social media use suggests a positive impact on efficacy, with a stronger impact for non-Whites.
\end{abstract}

I certify that the Abstract is a correct representation of the content of this thesis.

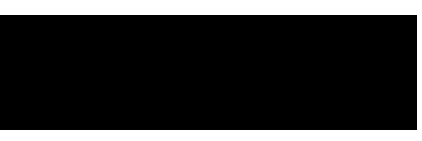

Chair, Thesis Committee

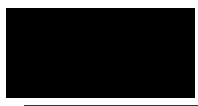

Date 


\section{ACKNOWLEDGEMENTS}

This project could not have been finished without the guidance and patience of my committee chair, Dr. Francis Neely, and committee member Dr. Marcela Garcia-Castanon, whose mentorship throughout the graduate program has been so appreciated. Additionally, major thank you to Dr. Jason McDaniel for his mentorship. I am also grateful for my cohort friends who have been a tremendous source of support. To my parents: thank you for instilling in me a sense of love for learning, and for supporting me throughtout this process. To my husband: you've provided me so much support and encouragement. Thank you for being my mentor, my best friend, and everything in between. 


\section{TABLE OF CONTENTS}

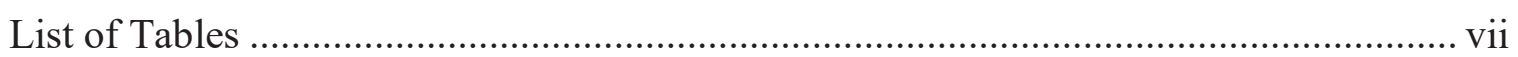

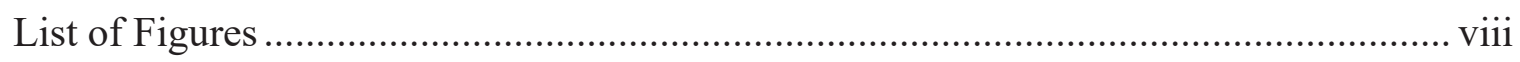

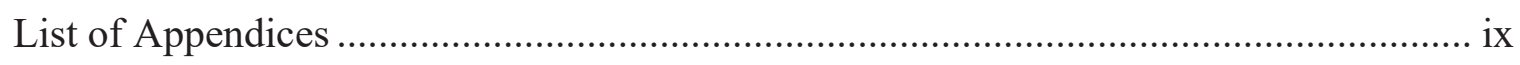

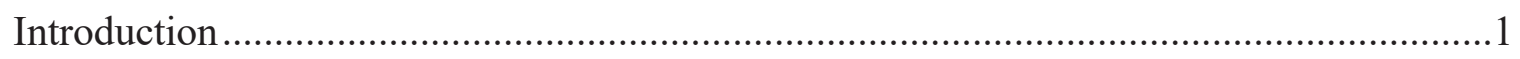

Ch. 2 Institutional and Social Structures of (Dis)Empowerment ...................................

Institutional Structures: Systemic Racism Theory ............................................ 7

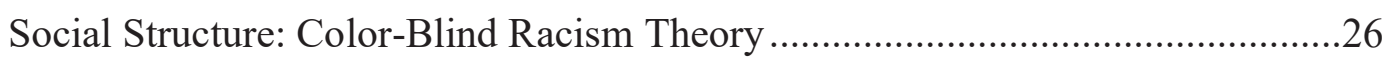

Ch. 3 Ethnic and Racial Identity Formation: Implications and Possibilities for Gaining

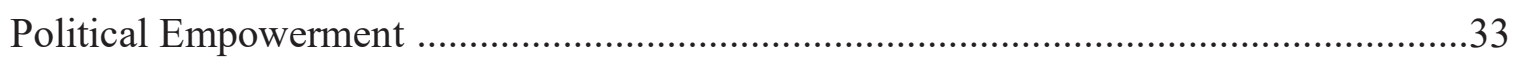

Ethnic and Racial Identity Formation: In Context ..........................................40

Social Cognitive Theory - A Theory of Agency ............................................49

Applying SCT: Social Media Use to Grow Political Efficacy and

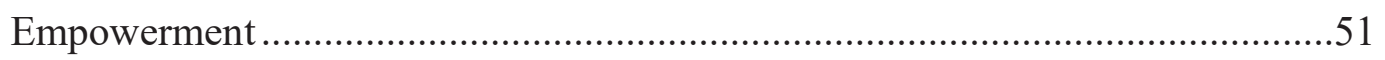

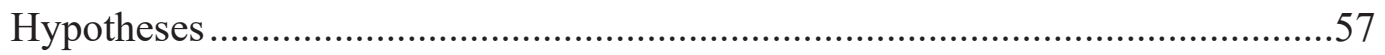

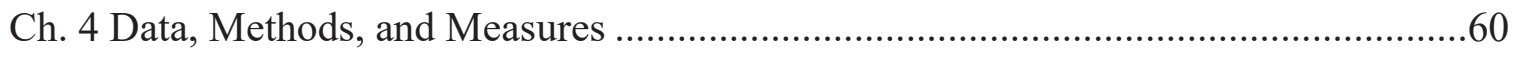

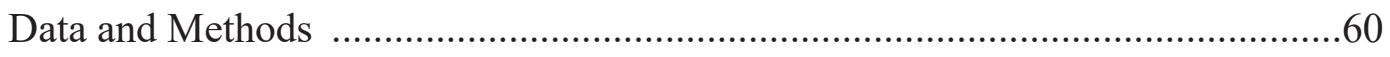

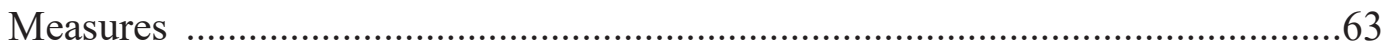

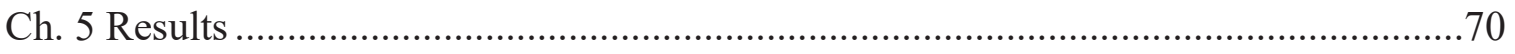

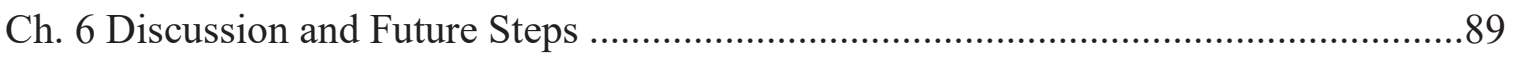

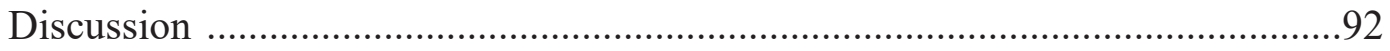

Limitations and Future Steps ................................................................ 100

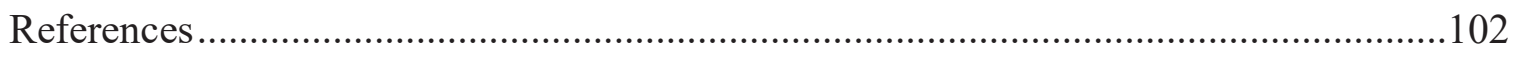

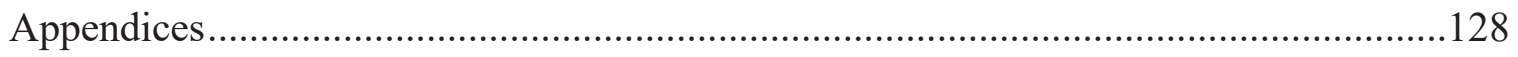




\section{LIST OF TABLES}

Table Page

1. Table 1. Survey Respondents by Race and Age, Wave 2 ..............................62

2. Table 1.1 Survey Respondents by Race and Age Wave 3 ..............................62

3. Table 2. Belief that Racism is a Major Problem by Race Wave 2..................64

4. Table 2.1. Belief that Racism is a Major Problem by Race Wave 3..............64

5. Table 3. Belief that Racism is a Major Problem Based on Respondent

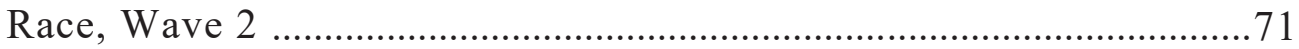

6. Table 4. Impact of Viewing Racism as a Major Problem on Political

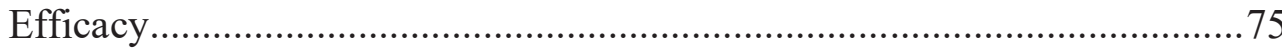

7. Table 5. Interaction of Attitudes about Racism and Race: Impact on

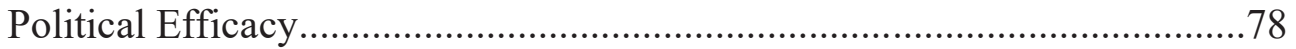

8. Table 6. Political Efficacy Levels by Social Media Use.................................80

9. Table 7. Efficacy Level Based on Social Media Usage with Split Sample by Race.

10. Table 7.1. Efficacy Level Based on Social Media Usage with Split Sample by Race 


\section{LIST OF FIGURES}

Figures $\quad$ Page

1. Figure 1. Percentage of U.S. Residents and Men in Prison or Jail, by Age, Race, and Education, 1980, 2000 Source: Webster, 2007. ............................................22

2. Figure 2. ERI Development Timeline. Source: Umana-Taylor et. al)....................35

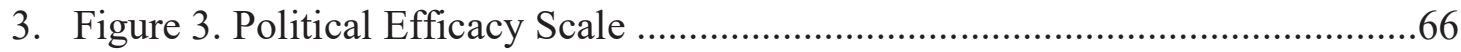

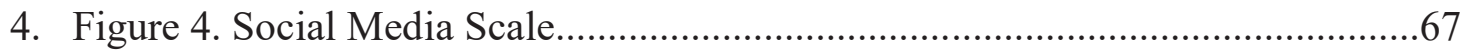

5. Figure 5. Estimated Effects of Social Media Usage on Political Efficacy)............81

6. Figure 6. Political Efficacy Levels Based on Social Media Usage by Race)..........86 


\section{LIST OF APPENDICES}

Appendix Page

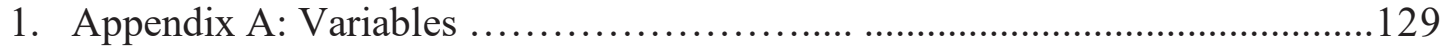

2. Appendix B: Descriptive Statistics .. .................................................133 


\section{CHAPTER ONE}

\section{Introduction}

Young people have traditionally been depicted as apathetic and disengaged from politics (Zukin et. al, 2006, 66-69). A growing body of research, however, suggests that youth feel shut out from and unrepresented in the political process (Gniewosz, Noack, and Buhi, 2009). The absence of a portion of the citizenry from political participation has long-term implications for the health of democratic engagement. Literature on political participation states that lack of participation from youngsters is natural as they have yet to gain experiences that form the habit of voting (Wolfinger and Rosenstone 1980;

Ronsenstone and Hansen 1993; Gerber et. A1 2003). In addition to this, non-Whites also have a lower propensity to participate politically (Wolfinger and Rosenstone 1980).

These two findings coupled with the increasing diversification of younger generations provide insight into their noticeable absence and the potential for it to become worse as the more diverse, young cohorts enter the electorate.

The compounded effects of age and ethnic identity on an individual's propensity to engage in the political process is an important area to study. The literature on political participation and engagement is vast; however, studies that specifically examine minority youth's capacity for political engagement in an increasingly polarizing context is yet to be extensively studied. With the election of the first Black president, Barack Obama, openly racist behavior and reactions to his presidency grew throughout his eight-year 
presidency. The rise of white nationalism during Obama's administration exposed longstanding, hidden sentiments about minorities and Black people more specifically. To understand how these realities affect minority youth, we have to examine the mechanisms in place that support and reinfornce these realities.

This project examines the extent of the role of age and race on political engagement, asking, why are non-white youth not politically empowered? I argue that the institutional and social structures of racism impact minority youth during critical developmental periods, keeping them politically disempowered. I propose social media as a tool for increasing political efficacy, a core component of empowerment. In what follows, I outline the project roadmap.

Chapter two lays the theoretical argument of the institutional and social structures of disempowerment. Using the Theory of Systemic Racism (Feagin, 2006), I detail how racism is interwoven into the economic, education, housing, healthcare, and policing institutions. I examine how these institutions work in tandem to maintain racial domination over minorities. Next, I use the Theory of Color-Blind Racism (Bonilla-Silva 2017) to analyze how the post-Civil Rights Era of color-blind racism affects non-Whites in social settings. I use Bonilla-Silva's four frames of abstract liberalism, naturalization, cultural racism, and minimization of racism to document how White Supremacy is upheld.

Chapter three follows the process of ethnic and racial identity development. I use a framework proposed by the Ethnic and Racial Identity in the $21_{\text {st }}$ Century Study Group 
(Umana-Taylor et. al, 2014). Their process examines identity formation at the intersection of cognitive development and socio-environmental context. I use this to analyze the extent of the negative impact of institutional and social structures of racism on empowerment. I then use Albert Bandura's Social Cognitive Theory (1986) to propose that social media can be an agency-building tool that increases political empowerment.

Chapter four lays out the hypotheses, data, and methods used to test the arguments proposed. I test whether non-Whites are more likely to believe that racism remains a major problem in society as a means of testing the theoretical argument about the effects of racism on identity. Next, I claim that viewing racism as a major problem will be negatively related to political efficacy. I then hypothesize that the negative relationship between viewing racism as a major issue and political efficacy will be stronger for non-Whites. I then turn to social media and hypothesize that social media will be positively related to political efficacy. Finally, I expect that the positive relationship between social media use and political efficacy to be stronger for nonWhites. To test the hypotheses, I use panel data from 2013 and 2015 from the Youth Participatory Politics Survey, a nationally representative survey that oversamples for nonWhites. I use logistic and OLS regression to test the hypotheses. Finally, I present the measures that are used in the regression models.

Chapter five presents the findings. I find that non-Whites are more likely to view racism as a major issue. Next, I find that attitudes about racism are negatively related to political efficacy, but only for one period. I also find that the effect of attitudes about 
racism on political efficacy is the same for Whites and non-Whites. Turning to social media, I only find a positive effect of social media use for political efficacy in the second period. Finally, I find that the relationship between social media use and efficacy is only significant for non-Whites (Garcia-Castanon, Rank, and Barreto, 2011). In both periods, the positive relationship between social media use and political efficacy is significant for non-Whites. Meanwhile, this relationship is non-significant for Whites in both periods.

Chapter six first discusses the findings in chapter five. The first finding that shows attitudes about racism are informed by race. This supports the theoretical arguments presented in chapter two that detail how institutional and social structures disempower minority groups. In addition, it is consistent with chapter three's arguments about the salience of racism in the identity formation process. The second finding that illustrates attitudes about racism are negatively related to political efficacy for the first period of analysis stems from research on the relationship between the state of one's community and political efficacy. However, this finding is only significant for one moment in time and is not found in the second period. Next, the finding for the test on the third hypothesis shows that the relationship between attitudes about racism and political efficacy is the same for Whites and non-Whites runs contrary to the literature on how political efficacy is affected by racism. This points to a limitation in the study that stems from a lack of a more thorough political efficacy measure. Next, the positive relationship between social media use and political efficacy only being significant for the second period is consistent with findings about the positive impact of social media use on 
efficacy. The findings here are limited, especially as the study only captures two moments in time. This finding however is on par with the lack of conclusive findings in the social media literature suggesting the need for more consistent measures for political efficacy in the realm of social media. Finally, social media use being significantly positively related to political efficacy for non-Whites only is in line with chapter three's argument that using Social Cognitive Theory, we can better understand how social media can build a sense of efficacy.

The concluding remarks in chapter six present an overview of the project as a whole. Chapter two presents the core theoretical argument that minority youth are not politically empowered because the institutional and social structures within they operate are constructed to maintain racial inequality. The Theory of Systemic Racism (Feagin, 2006) and Color-blind Racism Theory (Bonilla-Silva 2017) are essential frameworks for understanding the structural mechanisms that protect and enforce racism and White Supremacy. To understand the effects of these structures as socio-environmental contexts, the ethnic and racial identity formation process presented by the 21 st Century Study Group (Umana-Taylor et. al, 2014) reveals their negative impact during critical cognitive and emotional developmental periods for minority youth. Next, to explore the potential of social media as a tool for empowerment, Social Cognitive Theory is used to argue that social media can build a sense of efficacy which is a core component of empowerment. Results and theoretical implications are discussed. Future areas of 
improvement are highlighted including the need for an expanded period of analysis and a more uniform conceptualization of political empowerment. 


\section{CHAPTER TWO}

\section{The Institutional and Social Structures of Disempowerment}

The struggle for equality has been long-standing--its feasibility remains

questionable, despite four-hundred years of pushback from Slavery until today. To grasp

the full effect of the mechanisms of disempowerment, an in-depth analysis of how racial oppression is a core pillar of institutional foundations is required. Here, Joe Feagin's (2006) Theory of Systemic Racism presents a useful framework for understanding the how racial oppression and disempowerment function. Turning to the social structures of disempowerment, I adopt Edward Bonilla-Silva's 2017 Theory of Color-Blind Racism to detail how White Supremacy operates on an individual level.

Institutional Structure: Theory of Systemic Racism

The Theory of Systemic Racism, conceptualized by Joe Feagin, provides a theoretical structure for understanding injustice and oppression in the United States. Feagin's theory states that because oppression has been embedded in U.S. institutions, in this way, racism is systemic by nature (Feagin, 2006, 9). The oppression of people of color in the United States has afforded Whites hegemonic power over all institutions. The subjugation of people of color, according to Feagin, is sowed into the legal and political fabric of the United States. Feagin's theory situates racism and oppression into the political systemthe primary source of legal doctrines, policies, and initiatives for maintaining White power (Feagin 1978, 19-37; 2006, 2-50; Feagin and Elias 2013; Omi and Winant 1994, viiii). As the context for oppression in institutions, the political system, mainly through 
laws, will remain a key component of the analysis of the major institutions Feagin discusses. Using Feagin's Theory of Systemic Racism, I will lay out the ways in which non-Whites' oppression is maintained in various institutional spheres.

The institutional structures of oppression and domination in the United States are complex creations that are self and socially reinforced. The self-reinforced nature of these institutions is a result of centuries-long efforts to build racial oppression into the very institutional and social schema of the United States (Feagin 1978, 19-37; 2006, 1-6; Feagin and Elias 2013). These institutions do not exist in silos-rather they are interconnected and often rely upon each other to maintain collective domination over non-Whites, and African Americans in particular (Feagin 2006, 42). These institutions are the economic, education, housing, healthcare, and policing institutions (Feagin 2006, 9). Each institution was built for the specific empowerment of White Americans and the subsequent subjugation of people of color. While these institutions overlap in their roles, they each serve to uphold a racist system in differing ways.

\section{Economic}

The economic institution(s) of the United States is the most critical of the institutions as it affects every aspect of society. The economic institution of the United States can be dated back to the 1600s wherein Indigenous land was stolen for use by European settlers (Salisbury 1982, 2-15). While land was ample, labor was not, mainly due to the mass killing of Indigenous peoples (Salisbury 1982, 2-15). Here, European settlers forcefully brought African slaves to serve as the main form of labor for centuries (Feagin 2006, 1- 
10). The profit and fiscal value of land generated from slave labor are in trillions of dollars (Huston 2003, 25-29). The use of slave labor was so critical to the profit and success of the United States economy, that it was inscribed into the Constitution, and later fought over in the Civil War. The use of Black bodies for the benefit of White Americans was ingrained into legal, political, and social institutions, lasting until today (Darity 2005, 14-16; Lively 1992, 2-6). In this way, racial subordination has been cemented as an intrinsic factor for the success of our economic institutions.

The historical building of the economic institution as incumbent upon racial subordination is critical to understanding the significant differences in wealth and socioeconomic standing between Whites and non-Whites (Shapiro and Kenty-Drane 2005, 175-181; Shapiro, Meschede and Osoro 2013). The profit from slave labor, coupled with centuries of reinforcing White access and privilege to economic opportunities has resulted in upward mobility for Whites. Conversely, slavery and legal segregation, coupled with restricted movement and access to economic opportunities have resulted in an inter-generational wealth gap, namely for African Americans, and other people of color (Darity 2005, 14-16; Feagin 2006, 42; Shapiro 2004, 31). It is in this way that racial subordination in the economic institution has served to maintain power, privilege, and an overall better socio-economic standing and wealth distribution for Whites (Shapiro and Kenty-Drane 2005, 175-181).

While wealth is passed on generationally, institutionalized racism in employment plays an important role in the continued socio-economic differences between Whites and 
non-Whites. Discrimination in hiring decisions has been well documented (Mason 2005, 141-149; Turner et. Al 1991; Cain 1993; Bertrand and Mullainathan 2004; Pager 2007; Pager and Shepherd 2007), and studies on involuntary unemployment suggest that nonWhites, especially African American males, experience a higher rate of involuntary unemployment (Wilson, Tienda, and Wu 1995; Tomaskovic-Devey, Thomas, and Johnson et. Al 2005; Pager and Shepherd 2007). Further, research on income by race and gender suggests that White men earn significantly higher incomes in comparison to every other race and gender (Pew Research). Through race-based discriminatory practices and historical inequality, our economic institutions continue to oppress non-Whites.

Economic resources affect all aspects of life including educational quality, housing, and lifelong success. Economic success in many ways relies on educational background. However, systemic racism in the educational institution promotes economic disparities by maintaining racial inequality in schooling.

\section{Education}

Institutionalized racism in the educational system has been well documented. Prior to the Civil Rights Act of 1965 and the decision in Brown v. Board of Education of 1954, African Americans were segregated in schooling. After the decision in Brown v. Board, racism in the educational system morphed into what is today-- an inequitable allocation of financial and educational resources in predominately non-White areas, problematic standardized testing, and discrepancies in educational quality between Whites and nonWhites (Furumoto 2005; Smith 1995, 54-57). Systemic Racism theory asserts that access 
to a good-quality education is institutionalized in such a way that privileges Whites (Feagin 2006, 37). An important component of systemic racism in the institution of education is that it relies on White educators to uphold it (Picower 2009). One form of upholding systemic racism is in the disparate application of discipline for White and nonWhite students. Non-White students are more likely to be disciplined, and schools are more likely to weave law enforcement into such disciplinary moments (Kim, Losen, and Hewitt 2010). The shift to including law enforcement into the educational system has seen greater rates of non-White students' educations being disrupted through suspensions, expulsions, and arrests for in-school disciplinary issues (Fuentes 2013).

Exclusionary punishment as a form of discipline functions as a tool for social control in educational settings - it does so by reinforcing inequality in the quality of education, and by decreasing the likelihood of student success (Polakow-Suransky 2001; Heitzeg 2016 p. 10). While disciplinary action has occurred under the guise of improving student behavior, especially in low-income schools, the effect of such action has merely pushed 'misbehaving' students out of school (Heitzeg 2016). The adoption of the No Child Left Behind Act (2001), an act aimed at increasing funding to impoverished schools, has led to a wave of punitive action against low-performing students as a means of retaining funds (Heitzeg 2016). The No Child Left Behind Acts stipulates that test scores are the measure of a schools' success, thus, schools with lower test scores see their funding reduced as a punitive and incentivizing measure (Furumoto 2005; Rentschler 2005). This approach has served to uphold institutional racism through reinforcing 
education quality gaps by increasing the likelihood of non-Whites' failure in the educational setting.

Education remains a starting point for lifelong inequality. Disparities in school funding and resource allocation disproportionately affect minorities. This is because in many instances, quality education is tied to housing. Affleunt neighborhoods often have greater resources and support for students whereas low-income schools tend to have lower resources, higher levels of exclusionary punishment, and less student support. Racism in housing reinforces these disparities and maintains racial inequality.

\section{Housing}

Discrimination in housing dates back to slavery where African Americans were barred from adequate housing. Following emancipation, Black individuals and families were heavily discriminated against, especially in being allowed choice in housing (Dimsky and Mason 2005, 151-156). In 1930, the FDR administration created the Federal Home Loan Bank Board (FHLB) which then created Residential Security Areas (RSA) that colorcoded neighborhoods either recommending lending or not (Kantor and Nystuen 1982). In these RSAs, Black residential neighborhoods were all coded "red", effectively barring all home loans to individuals in those areas or planning to move to those areas (Kantor and Nystuen 1982). This practice came to be known as redlining, and today, despite bills aimed at uncovering ongoing practices 1 , redlining still exists (Kantor and Nystuen 1982).

\footnotetext{
${ }^{1}$ The Home Mortgage Disclosure Act of 1975 requires financial institutions to disclose their lending practices to expose any discriminatory actions (Kantor and Nystuen 1982). One drawback of this Act is that
} 
Many studies, over time, have found that racial and ethnic background still affects likelihood to be approved for a home loan (Kain and Quigley 1970, 72; Weinberg 1978; Schafer 1979; Lang and Nakamura 1993; Hernandez 2009; Mitchell and Franco 2018). Over time, redlining has affected the wealth gap between Whites and non-Whites, especially between Whites and African Americans (Dimsky and Mason 2005, 151-156). The effects of redlining expand beyond the direct impact felt by individuals — they negatively affect neighborhoods, leading to a greater chance of business divestment and deterioration.

Discrimination in housing extends beyond home loans - the racial composition of neighborhoods is in part due to previous legal segregation and (more-so in recent times) individuals' choices. Multiple studies suggest that when minorities enter a White neighborhood, there is a tipping point (of an increase in the minority population in the neighborhood) that leads Whites to move away and into another White neighborhood (Crowder 2000; Trounstine 2016). The individual choices of Whites to move from a neighborhood as it becomes increasingly racially diverse impacts neighborhood value, as the evidence from redlining suggests that neighborhoods with predominantly minority populations are redlined, leading to a higher chance of neighborhood deterioration (Urban

it does not require financial institutions to disclose which neighborhoods were denied loans, nor the reasons for denials. To remedy this, some states, such as Michigan, have passed one form of an anti-redlining law (Kantor and Nystuen 1982). The Fair Housing Act of 1968 also specifically addresses redlining and requires the federal government to take affirmative action in instances where discrimination is uncovered (Kantor and Nystuen 1982). 
Institute 2019). In addition to White mobility out of integrated neighborhoods and into White neighborhoods, attempts to provide more inclusive housing in regions where neighborhood and quality of life are better have seen pushback.

Community development efforts, especially those to build affordable housing or multi-family housing complexes in neighborhoods with higher-quality schools, access to transit, and facilities for families, have seen pushback from predominantly affluent Whites in suburban neighborhoods. Opposition from these individuals revolves around inclusionary developments in their neighborhoods for fear of crime, lowered property values, and a sentiment similar to that of pushback against desegregation (Maney and Abraham 2008, 66-82). Multi-income properties in affluent neighborhoods, which include a portion of affordable housing units are consistently pushed-back against by residents, the majority of whom are White (Esaiasson 2014). Opposition to inclusionary development often cites a fear for their safety and property, evoking speech that is coated in ambiguous racial stereotypes (Mother Jones 2019; Scally and Tighe 2015; Tighe 2012; Tighe and Goetz 2019). Opposition to community development is not a new phenomenon, however, it continues to exacerbate inequities in neighborhood, mobility, and educational resources that disproportionately affect non-Whites (Tighe 2012; Tighe and Goetz 2019).

Institutional racism in housing, as Theory of Systemic Racism points out, is designed in a complex, multi-faceted way that relies upon individual and institutional behavior to reinforce inequality. The intent behind individual behavior aside, the effects 
of redlining are still felt today because of Whites' mobility out of browning neighborhoods, opposition to inclusive development, and differences in lending practices where neighborhoods have predominantly minority residents.

The quality of housing and neighborhood environment have longterm effects on health. Low income and urban neighborhoods have a negative impact on health (Ellen, Mijanovich, and Dillman, 2016). Limited neighborhood resources and lower environmental quality trigger stress and health issues (Chaix 2009). Finally, the social construction of neighborhoods has also enforced inaccessibility to hospitals and healthcare (Chitewere et. al, 2017). Institutionalized racism in healthcare weaves in racism in employment and housing.

\section{Healthcare}

Institutionalized racism in healthcare dates back to the founding of the United States. Establishing the 'inferiority' of African Americans and later on, Asian, and Latino immigrants, was a powerful tool for maintaining the legitimacy of oppression and inequality (Byrd and Clayton 2001). Views of non-Whites as biologically inferior was a persistent narrative from the 17 th to the early 20 th century until objective scientific methods disproved these notions (Belkhir and Duyme 1998). Prior to the 20th century, African Americans were also utilized as test subjects for medical experiments (Feagin 2006, 24; Washington 2006, 157-189). African American (Washington 2006, 189-215), Native American, and Puerto Rican women have also been found to have been unknowingly sterilized. Occurrences such as the ones mentioned here have reinforced the 
domination of the state over Black bodies, and this domination is continuously reinforced in subtler ways (Byrd and Clayton 2001; Washington 2006, 25-25).

Quality and access to healthcare in the United States are often hinged upon socioeconomic resources, education, and geography. Socioeconomic status and the ability to obtain a job with health insurance is closely linked to education. In a study of non-Whites in rural areas, researchers found that non-Whites in rural areas were twice as likely to not have a high school diploma (Probst et. al 2004; Hale, Bennett, and Probst 2010 ). If access to health insurance is tied to one's ability to obtain a "good" job that provides health coverage, non-Whites in rural areas were less likely to have access to such jobs, and as a result, access to private health insurance (Probst et. al 2004; Hale, Bennett, and Probst 2010 ). Of the non-Whites who were insured, it was through public health insurance, which also usually translated into less healthcare coverage and diminished quality of healthcare (Probst et. al 2004; Hale, Bennett, and Probst 2010 ). The compounded effects of low education and low income often leave non-Whites in rural areas with diminished or no healthcare coverage (Probst et. Al 2004). Although nonWhites in urban and suburban areas experience such effects to a lesser extent, it still makes for systemic disparities.

Disparities in access to healthcare cover complex, connected relationships between environment, housing, and income. The physical environment plays an important role in an individual's health. The physical environment provides context for two key aspects of health and healthcare: access to nutritional food and natural spaces 
like parks, and proximity to healthcare. Access to nutritional food sources is dependent on the income of a neighborhood. Low-income neighborhoods are more likely to be food deserts (Hilmers, Hilmers, and Dave 2012; Larson, Story, and Nelso 2009). When access to nutritional food becomes difficult, based on geography and income, nutrition becomes a critical source of health issues, especially as diet and nutrition interact with pre-existing health conditions (Larson, Story, and Nelso 2009). Thus, as non-Whites are more likely to live in low-income, food desert areas, they are also more likely to experience adverse health effects due to the physical environment (Dubary and Lebrun 2012; Hilmers, Hilmers, and Dave 2012).

The physical environment of low-income, majority non-White neighborhoods also contains higher levels of allergens and pollutants which have adverse health effects (Dubary and Lebrun 2012). In addition, the absence of safe recreational spaces also leaves many individuals without proper physical activity (Richardson and Norris 2010). These factors, working in tandem, present disproportionate effects for non-Whites. However, the physical environment and access to healthcare explain one aspect of nonWhites' diminished access to quality healthcare. The relationship between healthcare providers and health outcomes for non-Whites provides additional context (Sabin et. Al 2009).

Healthcare providers' quality of care can have life-altering effects on a patient. In a study of operative mortality, one study found evidence that African Americans had higher mortality risks on the operating table than their White counterpart, mostly due to 
the quality of the hospital and physician themselves (Lucas et. al 2006). Outside the realm of quality of the facility, evidence also suggests that non-Whites receive a lower portion of protocol treatments than Whites do (Jha et. Al 2007). Further, in hospitals providing care for low-income, non-White individuals, evidence suggests that the patients are viewed as dishonest and attempting to extract undeserved resources from the hospital, leading to hostile interactions between hospital staff and patients (Bridges 2011, p. 210216). Discrimination and hostility in healthcare facilities have been shown to harm health (Major, Mendes, and Dovidio 2013).

Incidents of perceived discrimination have also illustrated higher rates of health complications such as hypertension and cardiovascular disease (Penner and Hagiwara 2014). Further, implicit bias tests conducted on medical doctors illustrated implicit bias for Whites over non-Whites (Sabin et. Al 2009). Studies have also highlighted that disparate treatment effects exist between Whites and non-White patients (Nelson 2002; Johnson et. Al 2004; Flores, Olson, and Tomany-Korman 2005; Canino et. al 2009; Hambidge et. Al 2007; Penner et. Al 2014).

The effects of systemic theory in health outcomes are felt collectively by nonWhites. The success of systemic racism in the healthcare institution relies on interaction with inequalities in economic, educational, and housing institutions. The inequality in each institution subsequently informs and reinforces inequality in other institutions. Related to these, the policing institution acts as a legal enforcer of inequalities. Policing is a cornerstone of systemic racism as it retains the capacity for 'lawful' violence 


\section{Policing}

Systems of policing in the United States are characterized by extreme violence against Black Americans. Policing during slavery was in the form of slaveowners and White enforcers ensuring continued oppression over slaves. Community policing during slavery was in the form of Whites assisting in the search for fugitive slaves (Feagin 2006, 24, 32, 55, 70). Since the uprising by Nat Turner and other African Americans in 1830, a response in the form of repressive police has continued until today (Feagin 2006, 24). Unsurprisingly, the legacy of violence in the U.S. has been carried out generationally by law enforcement officers. Taking on different forms, the policing remains a source of extreme stress and uncertainty for non-Whites, especially African Americans. The different forms of violence in policing include police brutality against African Americans and the racialization and criminalization of immigrants.

Police brutality against African Americans has spanned centuries, and it continues to pose a threat against the livelihood of the Black Americans. Under Jim Crow, antiBlack riots in the South were often reinforced by police, who partook in violence (Feagin 2006, 138-139; Messer 2011). In the 1980s, Broken Windows policing and Stop and Frisk policies racially profiled and harassed Latinos and African Americans (White and Fradella 2016, 1-15).2 The subjective nature of Broken Windows and Stop and Frisk

2 Broken Windows Policing was first coined by political scientist James Q. Wilson and criminologist George L. Kelling in an Atlantic Monthly article title "Broken Windows: Police and the Neighborhood". In this article Wilson and Kelling asserted that "unaddressed disorder is a sign that no one cares and invites both further disorder and more serious crime." (New York City Police Department 1994). The Broken Windows theory was employed by then (1994) New York City mayor, Rudy Giuliani, under a "quality-of- 
allocates a greater degree of power to individual law enforcement officers. Because these two policies rely on perception, police officers are granted the primary authority on which individuals appear, at face value, to be suspicious (Alpert, Macdonald, and Dunham 2005).

Data on Broken Windows and Stop and Frisk illustrates a disproportionate effect on African American and Hispanic/Latino males (White and Fradella 2016, 1-15, 117-145). Further, investigations into the misuse of Stop and Frisk by including officer quotas for such stops and their disproportionate effect on non-Whites have resulted in a court-imposed review of this policy (Floyd v. New York). Outside of New York, a majority of states have adopted some form of Stop-and-Frisk policies. However, most of these policies are known as Terry stops, taking after the name of the U.S. Supreme Court case Terry v. Ohio 1968. The ruling stated that there is no violation of the Fourteenth Amendment right against unreasonable search and seizure when stop-and-frisks occur without probable cause or warrant, if a police officer suspects that an individual has, is in the process of, or is going to commit a future crime (Terry v. Ohio 1968). Many scholars have cited that this critical ruling has laid the groundwork for the mass infringement of civil rights, especially for non-Whites. The Terry ruling is a manifestation of systemic racism in the policing institution as a form of instilling fear and violence in non-Whites (Bellin 2014).

life initiative" and pushed for aggressive policing of quality of life misdemeanors such as public urination, public drinking, turnstile jumping, etc. (Harcourt 2001). 
Police violence against African Americans has gained traction as incidents are increasingly filmed and uploaded onto social media platforms. Several notorious cases of police brutality have prompted investigations into African Americans' rate of death by police officers. Data from the Mapping Police Violence project shows that Black men are three times more likely to be killed by police than White men (Mapping Police Violence 2019). In addition, eight of the largest police precincts in the nation have a higher kill rate than the national murder rate (Mapping Police Violence 2019). Police brutality remains one of the biggest threats to the Black community's livelihood.

The construction of a "Black male predator", a myth rooted in historical justification for using violence against Black men, is a core component of systemic racism. This myth is ingrained in the nation's consciousness, so when incidents of police brutality occur, the violence is instantly justified (Nelson 2001; White and Fradella 2016, 17-40). Police brutality and violence are foundational components of institutionalized racism - they are built into the core of police training, management, and culture (Lawrence 2000). The creation of hostile, predatory actors eases the process of justifying action and violence against said actors.

Establishing Black and brown individuals as hostile predators allow for their funneling into the prison industrial complex. Black and non-White Hispanic males are significantly more likely to be arrested and convicted than their White male counterparts (Alexander 2011). Rates of incarceration amongst this population have dramatically increased since the 1980s, especially as efforts for aggressive policing were popularized 
on the federal, state, and local levels. Aggressive enforcement, particularly in non-White neighborhoods stems from racist notions that violence is an innate characteristic of Black and brown communities (White and Fradella 2016, 17-40). Figure 1 (Western 2007, 3036) highlights the steep growth in non-Whites' imprisonment between 1980 and 2000. Within two decades, the proportion of non-White men in prisons or jails has at least doubled, and as education level decreases, the rate triples for Black men between ages 20-40. While the era of overt citizen violence targeting Black and brown people has ceased to a great extent, law enforcement agencies have maintained police-sanctioned brutality. Terry stops, and mass incarceration have served the same purpose - to maintain the racial subjugation of non-Whites and to uphold White supremacy.

Figure 1

Percentage of U.S. Residents and Men in Prison or Jail, by Age, Race, and Education, 1980, 2000

\begin{tabular}{lcc}
\hline All U.S. Residents, Men Aged 18-65 & 1980 & 2000 \\
\hline All U.S. Residents & $0.2 \%$ & $0.7 \%$ \\
Men Aged 18-65 & & \\
$\quad$ All & 0.7 & 2.1 \\
White & 0.4 & 1.0 \\
$\quad$ Hispanic & 1.6 & 3.3 \\
$\quad$ Black & 3.0 & 7.9 \\
Men Aged 20-40 & & \\
$\quad$ White & 0.6 & 1.6 \\
$\quad$ Hispanic & 2.1 & 4.6 \\
Black & 4.8 & 11.5 \\
Non-College Men Aged 20-40 & & \\
$\quad$ White & 0.9 & 3.2 \\
$\quad$ Hispanic & 2.6 & 5.5 \\
$\quad$ Black & 6.0 & 17.0 \\
High-School-Dropout Men Aged 20-40 & & \\
$\quad$ White & 2.1 & 6.7 \\
$\quad$ Hispanic & 3.2 & 6.0 \\
$\quad$ Black & 10.7 & 32.4 \\
\hline Source: Bruce Western, "The Prison Boom and the Decline of American Citizen- \\
ship," Society 44, no. 5 (2007): 30-36.
\end{tabular}


The racialization and criminalization of immigrants have been a key factor in the successful establishment of a comprehensive state surveillance and violence apparatus. Systemic racism here deploys racialized differences as a basis of exclusion from full participation in society. Methods of preventing full participation in society are a means of maintaining sub-status citizenship for people of color in the United States. Statesanctioned violence through law enforcement agencies continues to uphold White Supremacy and non-White racial subjugation. The methods used to systematically oppress Black people have been adopted to solve the 'immigrant problem'.

Shaping the American identity has been hinged upon the exclusion of others, based on class and race. The Chinese Exclusion Act of 1882 was a watershed moment in U.S. immigration policy (Lee 2002). After extensive witness testimonies on effects of Chinese immigration, the act was signed--effectively barring Chinese immigration for a decade (Lee 2002). The Chinese Exclusion act marked the first significant restrictive immigration policy that would provide the structural components for immigration laws in the future (Lee 2002; Ngai 2004, 18). The association between Chinese immigrants and undesirability laid the groundwork for nativist approaches to Mexican immigrants (Ngai $2004,18,22)$. Exclusion on the basis of un-American values has also been expanded to include Muslims.

Immigration reform and policy have primarily targeted Mexican immigrants, using stricter and more violent enforcement of such policies. The pervasiveness of the Latino Threat Narrative funnels support into targeted, racialized enforcement of immigration 
policy (Chavez 2008; Goldsmith et. Al 2009; Inda 2005 p. 30; Kretesdemas 2008; Shashani and Green 2009 p. 35-43). Targeted enforcement relies on racial profiling, often targeting legal immigrants (Goldsmith et. A1 2009). Stricter restrictions from societal participation have continuously increased since California Prop 187 in 1994. The proposition which barred undocumented immigrants from receiving any form of social services, including schooling for children, has seen an upward trend of similarly restrictive policies (Silva 2018; 2019). On the federal level, incorporation of Immigration and Customs Enforcement (ICE) into Homeland Security has signaled that immigration is a threat to national security. These elements have often led to multi-institutional collaboration efforts to allow for detainment, detention, and deportation of immigrants (Varsanyi 2010). The consistent, targeted enforcement against Mexican and Central American immigrants through surveillance maintain the system of racial oppression through fear and violence.

State surveillance as a means of maintaining exclusion has been thoroughly expanded through Countering-Violent Extremism (CVE) policies targeting Muslim Americans. CVE relies on multi-level law enforcement agencies and community integration to unlawfully criminalize and target Muslims. Following the 9/11 terrorist attacks, expansive surveillance programs into "terrorist sleeper cells", or Muslim Americans who were deemed suspicious, un-awake terrorists. Under the PATRIOT act, massive surveillance programs into mosques, communities, and even Muslim student organizations have been rolled out (Ahmadi 2011; Cainkar 2004; Onwudiew 2005; Wong 
2006). The result of these surveillance projects has resulted in numerous Muslim Americans being detained and convicted of terrorism charges, only to later be overturned (Pitt 2011). The methods are undertaken to "weed out" Muslim terrorists have primarily relied on informants - many of whom funded for information. The latest case involving an arrest and charge for a Muslim is that of Hamid Hayat. A governmentally funded informant reported false information to law enforcement, which resulted in Hayat serving 14 years in federal prison (National Registry of Exonerations 2020). State surveillance programs provide an institutional guideline for the exclusion of Muslims with the premise that Islam and Muslims are antithetical to the social fabric of America.

Islamophobia in the United States has consistently risen since 9/11, affecting the lives of many Muslims, especially those easily identifiable as Muslim, i.e. Muslim women in headscarves. While Islamophobic rhetoric and action attempt to identify and target Muslims, it often relies on false stereotypes of what a Muslim "looks like", resulting in many Sikh Americans targeted because they are mistaken for Muslims (Thompson 2017). The post 9/11 vitriol for Muslims, which was exacerbated by the United States' invasion of Iraq in 2003, sought to picture the 'enemy' and it successfully did so, linking Arab identity with Muslim identity. This allowed for Orientalist stereotypes of "savage Arabs" to dominate the media and political sphere (Saleem et. Al 2017; Schmidt 2014, 138-189). Evidence of Orientalist language when discussing Arabs and Muslims illustrates a widely held belief that Arabs and Muslims are the same, evil 
foreign threats to American safety and security (Ryan 2004; Tehranian 2009; Nacos and Torres-Reyna 2007; Schmidt 2014).

The success in defining Muslims using Orientalist language allows for popular consent to illegal detainment and surveillance of entire communities. Similar to the "Black male predator", the "undesirable Chinese immigrant" and the "Latino Threat Narrative", the "Terrorist Muslim" prevents non-Whites from fully participating in society and polity.

Review

This section has outlined the ways in which institutions shape, manifest, and reinforce racial inequality. Discrimination in employment, redlining, inequality in education, state violence, and exclusion from citizenship have upheld the racial hierarchy of the United States. The section below, Social Structures of Disempowerment presents EdwardBonilla Silva's Theory of Color-Blind Racism 2017 to illustrate how social mechanisms reinforce racial inequality in instititutional and social spaces.

\section{Social Structures of Disempowerment}

The steps procured to maintain institutional subjugation cannot thrive without majority consent and complicity. As Theory of Systemic Racism asserts that institutionalized oppression is carried out by individuals, the Theory of Color-Blind Racism, advanced by Edward Bonilla-Silva, expands on this. Bonilla-Silva's Theory of Color-Blind Racism speaks of a new form of racism that has replaced the old, overt form. New racism, as Bonilla-Silva discusses, involves covert mechanisms and behaviors that 
act in a "now you see it, now you don't" sense (Bonilla-Silva 2017, 53). Whites uphold this new racism through four frames: abstract liberalism, naturalization, cultural racism, and minimization of racism (Bonilla-Silva 2017, 54).

\section{Abstract Liberalism}

Abstract liberalism, the most important frame, according to Bonilla-Silva, refers to Whites' usage of political ('equal opportunity') and economic liberalism ('individualism') as a means of explaining racial issues (Bonilla-Silva 2017; 56; Byrd 2011). Used in an abstract sense, evocations of liberalism illustrate Whites as moral and reasonable; i.e. in instances of opposing affirmative-action policies as violations of equal opportunity, all the while removing the context of state-sanctioned efforts to maintain inequality between Whites and non-Whites (Bonilla-Silva 2017; 56). Using abstract liberalism to stipulate individual choice and freedom engages in blaming the victim (nonWhites) for their less-than status.

Abstract liberalism explanations of inequality allow Whites to explain inequality without responsibility and to oppose race-based interventions that promote equity. In Bonilla-Silva's study of support of policy proposals for assistance, welfare, and social assistance policies were less supported by Whites than African Americans - and when these policies specified addressing African Americans, White support dropped even more (Bonilla-Silva 2017; 59). Justifications for opposing group-based policies for mediating inequality argued that such policies would discriminate against individuals (Whites) who “earned" their success (Bonilla-Silva 2017, 61). The use of meritocracy is another key 
component of abstract liberalism; assertions about the importance of merit in maintaining the system of equal opportunity reinforces White supremacy as it ignores Whites' groupbased privilege in all aspects of society (Bonilla-Silva 2017, 61; Byrd 2011).

\section{Naturalization}

The second frame of color-blind racism, the naturalization frame, allows Whites to explain racial differences as natural phenomena. Naturalization attempts to root differences in human nature and biology (Bobo 1999; Bonilla-Silva 2017, 61). The naturalization frame allows for the dismissal of structural efforts to maintain differences and inequality. Residential segregation, as an example of racial inequality, stems from a structure of bankers, lenders, and real estate agents who reinforce it (Wise 2010, 135 150). Evidence suggests that when people of color attempt to purchase homes in White neighborhoods, they are often barred from doing so through hesitant homeowners (unwilling to sell to non-Whites), lenders who offer sub-prime loans for non-Whites, and banks who disproportionately reject loans to non-Whites (Kantor and Nyustuen 1982). In addition, efforts for inclusive housing in majority White, affluent neighborhoods are met with opposition (Scally and Tighe 2015). Thus, the naturalization frame dismisses effects caused by individual and institutional action as naturally occurring phenomena.

\section{Cultural Racism}

The cultural racism frame places culture as the main reason for racial differences in the United States. Cultural racism views non-Whites' cultures as inferiorlazy, as breeding individuals who should be blamed for their status in society (Bonilla- 
Silva 2017, 68; Wise 2010, 128-145). Cultural racism displaces the institutional effects of racism and places them on factors attributable to non-Whites. Many Whites, for example, cite their opposition to assistance programs targeted at non-Whites, and specifically African Americans, as opposition to assisting communities whose culture permits underachieving (Bonilla-Silva 2017). Further, in educational settings, Whites — whether students, educators, or administrators - assume Black and Latina/o youth to underperform academically (Kozol 1991, 2005; Lareau 2003; Peguero, Popp, and Koo 2011; Phelan and Rudman 2010; Tyson 2002). The cultural racism frame also positions different ethnic and racial minorities in opposition to one another (Chou and Feagin 2008) - i.e. the creation of the "model minority" as evidence of the saliency of culture in success (Chou and Feagin 2008). The 'model minority' stereotype posits that Asian Americans have superior educational capabilities (Chou and Feagin 2008; Kao 2000; Lee 2009). This stereotype has also been utilized to uphold the notion of meritocracy in achieving success (Chou and Feagin 2008; Kao 2000; Lee 2009).

Along this vein of meritocracy, cultural racism is also deployed in explanations for anti-affirmative action policies (Fisher v. University of Texas 2008). In the case of Fisher v. University of Texas, Abigail Fisher, a White student, was declined admission to the University of Texas. In a case that reached the Supreme Court, Fisher's defense team argued that Fisher had been born the wrong race: White and that had she been born nonWhite, she would have been admitted to the university. The arguments presented in the case discard the evidence of non-White students who were higher-achieving, and the 
majority of White students who were under-achieving yet were still offered admission (Hannah-Jones, 2013). This case represents the cultural racism frame in that it views nonWhites were offered admissions to the university as inferior, and thus, as having stripped a White student of a well-deserved admission (Hannah-Jones, 2013). This case is also an example of the minimization of racism frame, wherein success and particularly, failures, are removed from the context of race.

\section{Minimization of Racism}

The minimization of racism frame asserts that race is no longer a contributing factor to minorities' position in society (Bonilla-Silva 2017, 57). This frame alleges that discrimination is a "thing of the past" and that "it's better today than ever" (Bonilla-Silva 2017, 57). When non-Whites argue discuss the effects of discrimination on their success, Whites, according to Bonilla-Silva, will likely employ the minimization of racism frame to retort that the minority individual is "playing the race card" to absolve themselves of responsibility for their failure (Bonilla-Silva 2017, 57). These retorts often come despite ample evidence of discrimination in employment (Mason 2005, 141-149; Turner et. A1 1991; Cain 1993; Bertrand and Mullainathan 2004; Pager 2007; Pager and Shepherd 2007), housing (Kain and Quigley 1970, 72; Weinberg 1978; Schafer 1979; Lang and Nakamura 1993; Hernandez 2009; Mitchell and Franco 2018), education (Smith 1995, 54-57; Picower 2009), healthcare (Nelson 2002; Johnson et. Al 2004; Flores, Olson, and Tomany-Korman 2005; Canino et. al 2009; Hambidge et. Al 2007; Penner et. Al 2014), and partaking in everyday tasks like shopping (Schreer, Smith, and Thomas 2009). The 
structural effects that allow for discrimination are non-existent, according to individuals who employ this frame (Bonilla-Silva 2017, 68, 70-71).

\section{The Elusiveness of Color-blind Racism}

The four frames presented by Bonilla-Silva — abstract liberalism, naturalization, cultural racism, and minimization of racism — are often deployed simultaneously. Bonilla-Silva's survey of college students and a Detroit-Area Study (1997), he found that White respondents often utilized a variation of the frames, as a combination of two or more creates an impenetrable argument that removes Whites from the racial reality (Bonilla-Silva 2017, 75). For instance, many respondents in Bonilla-Silva's surveys utilized the abstract liberalism frame with the minimization of racism frame as a means of arguing that they were in support of individual rights, and thus against group-based initiatives like affirmative action (Bonilla-Silva 2017, 75). The malleability of color-blind racism eludes responsibility as it does not always rely on absolutes-instead, it thrives.

Color-blind racism derives its power from its shape-shiftiness, and its ability to mask racist behavior under the guise of a post-racial society. One such manifestation is in the form of television, film, and comedy. Portrayals of non-Whites in TV series and films are often written and produced by White screenwriters and producers. In these mediums, the plots and punchlines primarily rely on stereotypes (Ibrahim 2014, 167-185; Kretsedemas 2014, 285-315), and when individuals are asked about the nature of nonWhites' portrayals, offensive stereotypes are justified as humorous because we live in a post-racial society (Ibrahim 2014, 167-185; Perez 2013). The depictions on-screen propel 
color-blind frames and reinforce preconceived notions in everyday life, especially in the form of microaggressions - statements or messages that express discrimination or insults toward non-Whites, regardless of intention (Sue et. Al 2009). Microaggressions often used alongside color-blind frames (Bonilla-Silva 2017, 50-57), have been demonstrated to negatively impact health and ones' self-efficacy (Nadal et. Al 2014; Sue et. Al 2009). The demonstrated impact of microaggressions on individual success bleeds into the overall effect of color-blind language on non-White group positionalities in the greater context of society.

\section{Conclusion}

The institutional barriers to equality, coupled with the shapeshifting color-blind frames, produce real obstacles to success and livelihood for non-White communities. The inequalities experienced on an institutional and social level no doubt post significant hardships for non-Whites; however, their effect on young individuals, especially as they form their ethnic, racial, and political identities requires deeper analysis. Chapter three examines the effects of the institutional and social barriers discussed here on the ethnic and racial identity formation of non-White youth. The institutional and social context for identity formation is a key component in understanding whether political empowerment is forged, and to what degree it may be harnessed to facilitate political participation. 


\section{CHAPTER THREE}

\section{Ethnic and Racial Identity Formation: Implications and Possibilities for Gaining Political Empowerment}

Ethnic and Racial Identity, henceforth ERI, is a key component to understanding the political empowerment of young individuals. ERI development informs adolescents and young adults' notions about their place in society as a member of an ethnic-racial group (Syed and Azmatia, 2008). This developmental process ultimately influences decision-making in early and late adulthood in many spheres including employment, and political participation (Umana-Taylor et. al, 2014). ERI, as conceptualized by UmanaTaylor et. al represents a developmental timeline composed of content and process at different points in time. Content refers to the attitudes and beliefs that individuals may hold about their ethnic-racial group, whereas process denotes the mechanisms through which individuals form their ERI (Umana-Taylor et. al, 2014). In the different stages of development—childhood, adolescence, and young adulthood—differing levels of cognitive capabilities, emotional competency, and daily life experience influence content. Meanwhile, the process that creates this content extends beyond the individual's abilities into immediate and broader socio-environments. Proximal (family, peers, immediate community) and distal (local, national, and global) influences comprise the socioenvironmental context for ERI formation.

In what follows, I will discuss ERI development for each stage and detail the impacts of proximal influences. I will then discuss the effects of distal influences when 
examining later stages of ERI formation. Finally, I use Social Cognitive Theory (Bandura, 1986) as an agency-building framework to examine the potentially empowering effects of social media use.

\section{Early and Middle Childhood}

Early and middle childhood comprise the first points in the ERI development timeline. In early childhood, children begin to gain awareness of their differences. Here, family socialization and interactions comprise the bulk of the child's understanding of themselves (Umana-Taylor et. al, 2014). In middle-childhood, cognitive abilities are advancing, leaving children with an understanding of hierarchy, in-group/out-groups, and public regard. Familial socialization and peer interactions play a key role in the middlechildhood understanding of ethnic identity. Studies show that familial ethnic-racial socialization promotes ERI formation (Hughes et. al, 2006; Umana-Taylor, GonzalesBacken, and Guimond, 2009) and, positive parent-child relationships spur identity formation and exploration (Huang and Stormshak, 2011). Moving into middle-childhood, children are introduced to peer networks and their influence. Studies show that 


\section{Figure 2: ERI Development Timeline}

\begin{tabular}{|c|c|c|c|c|c|c|c|c|}
\hline & \multicolumn{2}{|c|}{ Early childhood } & \multicolumn{2}{|c|}{ Middle childhood } & \multicolumn{2}{|c|}{ Adolescence } & \multicolumn{2}{|c|}{$\begin{array}{c}\text { Young } \\
\text { adulthood/Emerging } \\
\text { adulthood }\end{array}$} \\
\hline $\begin{array}{l}\text { Cognitive } \\
\text { milestones }\end{array}$ & $\begin{array}{l}\text { - Cognitive ability } \\
\text { - Refinement } \\
\text { Assimilation } \\
\text { Accommodation }\end{array}$ & & $\begin{array}{l}\text { - Refinement of c } \\
\text { abilities (e.g., eq } \\
\text { reasoning; socia } \\
\text { perspective-taki }\end{array}$ & $\begin{array}{l}\text { ggnitive } \\
\text { uity-based } \\
\text { I comparison, } \\
\text { ng abilities) }\end{array}$ & $\begin{array}{l}\text { - Abstract thinking } \\
\text { - Introspection } \\
\text { - Metacognition } \\
\text { - Further } \\
\text { development of } \\
\text { social-cognitive } \\
\text { abilities }\end{array}$ & & $\begin{array}{l}\text { - Deeper } \\
\text { reflection } \\
\text { resulting in } \\
\text { ability to } \\
\text { construct } \\
\text { narratives } \\
\text { - Greater } \\
\text { flexibility }\end{array}$ & \\
\hline Physiological & & & & & $\begin{array}{l}\text { - Puberty } \\
\text { (body image) }\end{array}$ & & & \\
\hline $\begin{array}{l}\text { Social and } \\
\text { environmental } \\
\text { contexts }\end{array}$ & $\begin{array}{l}\text { - Family } \\
\text { - Media }\end{array}$ & & $\begin{array}{l}\text { - Family } \\
\text { - Peers } \\
\text { - Media }\end{array}$ & & $\begin{array}{l}\text { - Family } \\
\text { - Peers } \\
\text { - Social demands } \\
\text { and transitions } \\
\text { - Navigate } \\
\text { expanded } \\
\text { social world } \\
\text { - Media }\end{array}$ & & $\begin{array}{l}\text { - Social world } \\
\text { may expand } \\
\text { for some but } \\
\text { contract for } \\
\text { others based } \\
\text { on social } \\
\text { position } \\
\text { - Emancipation } \\
\text { - Media }\end{array}$ & \\
\hline $\begin{array}{l}\text { Corresponding } \\
\text { ERI components }\end{array}$ & $\begin{array}{l}\text { Process } \\
\text { - Differentiation } \\
\text { of self and other } \\
\text { - Cognitive } \\
\text { development } \\
\text { applied to } \\
\text { ethnicity } \\
\text { and race }\end{array}$ & $\begin{array}{l}\text { Content } \\
\text { - Ethnic } \\
\text { labeling } \\
\text { - Ethnic } \\
\text { knowledge } \\
\text { - Ethnic } \\
\text { constancy }\end{array}$ & $\begin{array}{l}\text { Process } \\
\text { - Awareness } \\
\text { of bias } \\
\text { - Understanding } \\
\text { of social } \\
\text { hierarchy }\end{array}$ & $\begin{array}{l}\text { Content } \\
\text { - Salience } \\
\text { (triggers) } \\
\text { - Centrality } \\
\text { (importance) } \\
\text { - Affect } \\
\text { Own/in-group } \\
\text { Other/out-group } \\
\text { - Public regard }\end{array}$ & $\begin{array}{l}\text { Process } \\
\text { - Contestation } \\
\text { - Elaboration } \\
\text { - Negotiation } \\
\text { - Internalization of } \\
\text { cultural values } \\
\text { - Exploration/search } \\
\text { - Collective } \\
\text { self-verification }\end{array}$ & $\begin{array}{l}\text { Content } \\
\text { - Public regard } \\
\text { - Ideology } \\
\text { - Affect } \\
\text { (affirmation, } \\
\text { private regard) } \\
\text { - Salience } \\
\text { - Centrality } \\
\text { - Importance } \\
\text { - Understanding of } \\
\text { common fate/destiny } \\
\text { - Identity self-denial } \\
\text { - Certainty }\end{array}$ & $\begin{array}{l}\text { Process } \\
\text { - Further } \\
\text { elaboration, } \\
\text { narrowing, and } \\
\text { continuation of } \\
\text { adolescence } \\
\text { processes } \\
\text { - Transformation } \\
\text { (new } \\
\text { possibilities) }\end{array}$ & $\begin{array}{l}\text { Content } \\
\text { - Same as } \\
\text { adolescence }\end{array}$ \\
\hline
\end{tabular}

Figure 2 details the ERI developmental timeline created by Umana-Taylor et. al (2014).

around age 6 , children gain the ability to infer an individual's social beliefs, including their psychological perspectives (Selman, 1981). Further, studies on an individual's understanding of the reasons why someone does not like their ethnic-racial group is superficially developed at age 6 and around age 10, are extensively developed to where children identify stereotypes, prejudice, and racism as reasons why. Social perspectivetaking theory (Selman, 1980) and ethnic perspective-taking theory (Quintana 1994) both 
suggest that individuals become aware of the stereotypes held against their ethnic-racial group before they understand the broader institutional and societal implications.

Research on non-White children's developmental competence highlights that stigmatization, prejudice, and discrimination propel non-White children to develop an understanding of broader held stereotypes about their ethnic-racial group (Garcia-Coll et. al, 1996; Tatum 1997, 93-117; Miller and MacItosh, 1999). In a study ( $\mathrm{n}=867)$ of Black adolescents (ages 10-12) by Simons et. al (2003), 67\% reported being insulted because they were Black, and $47 \%$ were the target of racial slurs. In their study, Simons et. al (2003) found that racial discrimination was associated with depressive symptoms in these children. Studies have also shown that stereotypes also affect non-White children, especially in schooling. Wolf, Spencer, et. al (1996) found that teacher expectancy, especially the negative expectancy of children, can affect daily classroom behavior. Further, students' awareness of their teacher's expectancy affects their academic success, especially when students observe differential treatment in the classroom (Kuklinski and Weinstein, 2001). Evidence also suggests that minority children, Black and Latino students, in particular, face low expectations from their teachers, even when they have prior high academic achievements (Ferguson, 1998). These negative stereotypes affect student performance and overall response to academic environments. Proximal influences on ERI formation begin at a young age for minority children and continue to play an important role during adolescence. 


\section{Adolescence}

Adolescence is a unique time in identity formation because, in addition to developing an ERI, puberty, identity exploration, and relationship building are concurring changes. Socio-environmental factors are critical at this stage in ERI formation. Because adolescents have developed and continue to advance their social-cognitive skills, the impacts of racism and discrimination are significant. The Phenomenological Variant of Ecological Systems Theory (PVEST) presents a comprehensive theoretical model for understanding minority youth's cognitive development, contextualized within daily experiences (Spencer 2003; 2005; 2006).

PVEST is a multi-layered model that begins with net vulnerability level which refers to the contexts that can be potentially challenging for development. These risks, like racial discrimination and subordination, can be offset by support systems and these two taken together form any given individual's net vulnerability level (Spencer et. al 2003). Inadequate support systems and risks present in proximal relationships can increase net vulnerability for minority youth. For White youth, privilege can pose a vulnerability threat as it hinders the development of coping skills (Spencer et. al, 2001). The second PVEST level net stress engagement denotes the lived challenges that slow development. Like level one, social support can offset the stress from these experiences and serve as a protective buffer. However, these challenges can be experienced within proximal relationships, and thus, the social support that should stem from them is lacking. An individual's response to net stress engagement is PVEST's third level, reactive 
coping methods. The coping mechanisms deployed to deal with stressful experiences include positive adaptation from these situations but can also include maladaptive outcomes. These outcomes form the fourth level, emergent identities which are a culmination of prior experiences and coping mechanisms that affect adolescent ERI formation. The four components of PVEST lay the foundation for the penultimate level, life-stage specific coping outcomes. This final stage refers to the effects of identity on developing stable behavior and determining positive or negative coping mechanisms that affect long-term adversity and success.

The effect of discrimination and racism on cognitive development and psychological wellbeing is substantial. Seaton (2009) finds a negative effect of discriminatory and racist experiences on self-esteem in a study of Black adolescents. A decline in self-esteem during critical development years impact long-term success and increases the likelihood of behavioral issues (Seaton, 2009). In addition, perceptions of differential treatment from institutional actors (e.g. teachers) present adverse effects like decreased grade-point average and decreased academic self-perceptions (Eccles et. al 2004; Chavous et. al 2008). In terms of extra-familial relationships with peers that become more central to adolescents, perceptions of prejudice or stereotypical ideations can also adversely impact minority youth.

Research shows that self-control depletion occurs in interracial peer interactions that are perceived as racist or that may blatantly display racism (Baumeister and Muraven 2000; Bair and Steele, 2007). When self-control is exerted in racist situations, it 
subsequently decreases and negatively affects carrying out activities that require selfcontrol (Baumeister and Muraven 2000). In the academic setting, one study reported that $89 \%$ of Black adolescents described incidents where they were the target of racially motivated insults (D’Augelli and Hershberger, 1993). Another study revealed that minority students in predominantly White colleges reported being in racist incidents roughly once every two weeks; these students maintained that the majority of incidents involved peers (Swim et. al, 2003).

Beyond explicitly racist situations, evidence suggests that ambiguous racism has a more adverse effect on non-White adolescents because it requires greater cognitive effort to disentangle the incident and determine whether it was indeed racist (Salvatore and Shelton, 2007). ERI formation is a difficult terrain to navigate, especially when the immediate surrounding environment provides emotional and psychological strain. Conversely, support in proximal relationships can lead to an increase in adolescents' sense of empowerment and even increase their likelihood of political participation when they reach young adulthood (Diemer and Li, 2011).

\section{Young Adulthood}

Young adulthood and the transition to proper adulthood is still a time for cognitive and ERI development. While cognitive skills are primarily advanced in adolescence, the processes salient earlier on remain salient in adulthood. Additionally, young adulthood is unique in that most cognitive abilities are present and formed. During this time, complex thinking about ERI begins to explore the intersections of multiple identities, all of which 
are central to the young adult (Erikson, 1968; Bowleg, 2008; Syed, 2010). Questions about the intersection of political, gender, and class identity begin to emerge. These explorations are molded and shaped in a narrative that cohesively binds different identities into one, coherent achieved identity (Umana-Taylor et. al, 2014). Life-long salient experiences are ultimately sewn together to form the foundation of the achieved identity. They also inform future decisions to become civically engaged (Umana-Taylor et. al, 2014). A key factor of this achieved identity remains to be the influence of the distal socio-environmental contexts within which minority young adults are operating. Contextualizing ERI: Institutional and Social Structures of Racism

Institutional racism is a critical contextual piece of the identity formation puzzle because it forms the foundational basis of the society within which minority youth operate. Theory of Systemic Racism (Feagin, 2006) details the all-encompassing nature of racism in United States institutions and the ways in which they affect our lives in the immediate and long-term. To understand how institutional racism affects ERI, I outline the adverse effects of standardized testing, the impact of White educators' selfpositionality as saviors, and the disproportionate use of exclusionary punishment and policing in schools as adversely affecting ERI formation.

Color-blindness reigns in the Post-Civil Rights Era and dominates in academic spheres. I examine the effect of color-blindness using Edward Bonilla-Silva's Theory of Color-Blind Racism (2017) on ERI formation. I detail the impact of microaggressions 
and cultural racism in academic and peer-relationships and how they hinder positive selfidentity and their long-term impacts on mental health and overall success.

Racism in the educational system has been well documented (Smith 1995, 54-57; Feagin, 2006, 37; Furumoto 2005). Prior to the decision in Brown v. Board of Education of Topeka (1954), schools were segregated nationally. Even then, the ruling called for integration "with all deliberate speed" (349 U.S. 249, 1955). This intentional vagueness in the implementation of the ruling allowed for local school districts to avoid any immediate steps toward integration. Since then, school integration has not seen a major leap. Au contraire, many studies show that segregation remains a major issue across school districts (Chemerinsky, 2002; Wells, 2002; Orfield and Lee, 2007; Garcia, 2008; Orfield, 2009; Glenn, 2011; Frankenberg, Siegel-Hawley, and Wang, 2011; Knoester, 2011) and intra-schools (Knoester and Au, 2015).

The pushback against integration following the Brown v. Board (1954) decision has held long-term ramifications for the quality of education that minority children receive. This pushback has been systematically integrated in the form of linking highstakes standardized testing to funding that ultimately racially code schools and negatively impact minority children and impoverished regions (Popham 2011). The negative effect of high-stakes standardized testing, especially within and post the No Child Left Behind Act era has been well-documented (Chapman 1988; Sacks 2000; McNeil, 2001; Meier, 2002; Meier and Wood, 2004; Nichols and Berliner, 2007). Standardized tests place lowresource schools with high poverty rate children under pressure to perform, thus leading 
educators to teach to the test because resource allocation is tied to performance ( $\mathrm{Au}$, 2007, 2009). Because standardized tests have been marketed under the guise of neutrality and color-and-class-blindness despite their origins having been rooted in eugenic, pseudo-scientific measurements of intelligence (Selden, 1999), minority student underperformance in these tests has been linked to individual, parental, and cultural failure (Moore, 2005, 184) as opposed to the white supremacy undergirding the structure (Knoester and $\mathrm{Au}, 2015)$.

The perceived intellectual deficit of non-White students impacts student-teacher classroom dynamics and thereby affects ERI. Notions of non-White students, especially Black and Latino students as less intelligent than other students leads to differential teacher treatment (Ferguson, 1998; Kuklinski and Weinstein, 2001). This differential treatment stems from White educators' conscious/unconscious bias, understanding of race, and Whiteness and privilege. Studies show the impact of White educators' beliefs about communities of color and the Black community in particular. These studies documented the ways in which White educators view Black and P.O.C. communities as failing and themselves as having unique capabilities in saving young minority students from such failure (Cammamorta, 2011, 244; Anderson, 2013; Brown, 2013; Cann, 2015; White, 2016). The consequences of treating non-White students as lacking intelligence lead to underperformance in the classroom (Babad, 1998). Further, negative stereotypes about one's race view an increase in depressive symptoms (Simons et. al, 2003). 
An additional component of structural inequality in the educational system that affects ERI is the use of exclusionary punishment. Exclusionary punishment in the form of out-of-school suspensions has been found to disproportionately affect minority students and particularly Black students (Mendez, Knoff, and Ferron, 2002; Wallace et. al, 2008; Skiba, Shure, and Williams, 2012; Schollenberger, 2014). Exclusionary punishment is harmful to students because it hinders learning and causes greater racial gaps in academic achievement (Perry and Morris, 2014; Morris and Perry, 2016). In primary school children, this form of punishment disrupts routine and in turn results in an increase of aggressive behavior as a coping mechanism for stressful events (Attar, Guerra, and Tolan, 1994; Weissman, 2015). Although at the elementary level, children are still being acquainted with school norms and are thus less likely to have violent outbursts than middle and high schoolers.

Studies find that children from households with an incarcerated parent and children in poverty and facing familial instability are more likely to be suspended (Waldfogel, Craigie, and Brooks-Gunn, 2010; Macartney, 2011; Manning, Brown, and Stykes, 2014). Even when controlling for bad behavior, students with an incarcerated parent and those in poverty are more likely to face exclusionary punishment, suggesting closer monitoring from the educator based on perceptions of the student's family (Ferguson, 2001; Petras et. al, 2011). Further, schools with higher proportions of Black students also have a greater reliance on exclusionary punishment as the main form of discipline (Welch and Payne, 2010; Skiba et. al, 2014; Ramey, 2015). This reality is also 
connected to standardized testing performance as lower-performing schools have fewer resources and thus, less funding for alternative methods of discipline (Mukuria, 2002).

Exclusionary punishment in early childhood suggests an adverse effect on mental health. Because children are still developing their identities and cognitive abilities, stressful events like suspensions spur a negative emotional response especially if the student perceives their treatment as unfair or different from other students (Bowditch, 1993; Vavrus and Cole, 2002; Agnew, 2006). Along the vein of unfair treatment, educator's implicit bias can also be a contributing factor to exclusionary punishment for subjective infractions, e.g. disrespect (Skiba et. al, 2002; Morris and Perry, 2014; Owens and McLanahan, 2017). Regardless of perceptions of mistreatment, exclusionary punishment in early childhood leads to aggressive behavior as young kids have yet to enhance their emotional regulation and verbal communication skills (Agnew and Brezina, 2019; Jacobsen, Pace, and Ramirez, 2019). These disruptions of routine and stressinducing events can affect young children later on, especially during adolescence and adulthood suggesting that schools play an important role in either mitigating or advancing racial inequality.

Beyond childhood, exclusionary punishment in adolescence can increase the likelihood of adulthood struggles including criminal victimization, and incarceration. The 'school-to-prison' pipeline has been well studied and shows a high correlation between exclusionary punishment and the likelihood of contact with the criminal justice system (Wald and Losen, 2003; Skiba, Arredondo, and Williams, 2014; Hemez, Brent, and 
Mowen, 2020). Harsh discipline and punishment during adolescence can adversely impact mental health by increasing anxiety and stress (Welsh and Little, 2018). In addition, exclusionary punishment can also strain familial relationships between the adolescent and their family (Kupchik, 2016). Positive and supportive proximal relationships are crucial to ERI; when these relationships are strained, the critical influence and emotional bonds needed are compromised. Welsh and Little (2018) found, in a comprehensive study of the effects of exclusionary punishment on long-term life outcomes, that it leads to a greater likelihood of dropout and a lower likelihood of matriculation (p. 316-335).

Exclusionary punishment not only impacts student learning in the immediate, but it also hinders future success. Rosenbaum (2020) in a study comparing suspended youth and non-suspended youth over 12 years found that 5 years after suspension, youth were $8 \%$ less likely to have obtained a high school diploma than their non-suspended counterparts. Further, Black suspended youth were $96 \%$ less likely to have obtained a Bachelor's degree than similar non-suspended youth. After 12 years, suspended youth were also more likely to have been arrested. This suggests that exclusionary suspension severely impacts lifelong success. Rosenbaum also finds that Black youth were disproportionately affected by suspension (2020). The evidence illustrates the consequences of exclusionary punishment and its role in fostering racial inequality within school and into adulthood. 
During adolescence, peer relationships are critical to ERI formation. For nonWhite students, peer and educator relationships can be playgrounds for microaggressions and color-blind behavior that have adverse effects on identity and self-esteem (Nadal et. al, 2014). Bonilla-Silva's Theory of Color-Blind Racism allows us to understand the ways in which the color-blind wheels are turned in daily interactions. Bonilla-Silva presents four frames that Whites adopt to maintain their color-blind status and overall racial hierarchy. The four frames - abstract liberalism, cultural racism, naturalization, minimization of racism — work individually or in tandem. Abstract liberalism claims that success is merit-based, cultural racism attributes failure to minority cultures, naturalization suggests that racial differences are biologically rooted, and minimization of racism negates and invalidates racial experiences (Bonilla-Silva 2017, 56-70).

In the classroom, teachers adopt the cultural racism frame with assumptions that Black and Latino students are academically challenged (Kozol 1991, 2005; Lareau 2003; Peguero, Popp, and Koo 2011; Phelan and Rudman 2010; Tyson 2002). This frame, the naturalization frame, and the abstract liberalism frame also position minorities against each other by establishing the 'model minority' myth in the classroom and homogenizing Asian students as inherently academically gifted and as evidence of success through merit (Chou and Feagin, 2006). Amongst peers, White students adopt the cultural racism frame by assuming that non-White peers are beneficiaries of affirmative action (Bonilla-Silva $2017,75)$, thus attributing academic success to external factors. 
The effects of color-blindness on ERI formation ultimately resides in the assertion that diverse racial identities do not exist. Color-blindness denies variation and in doing so, negates the salience of racial experiences in identity formation (Umana-Taylor et. al, 2014). Further, color-blindness maintains systemic racism and centralizes Whiteness in all spheres. In adolescence, when cognitive abilities are heightened and physical and emotional changes are occurring as a byproduct of puberty, denial of one's racial identity through assertions of "I don't see color!" have negative immediate and long-term impacts on ERI. In the short term, color-blind racist interactions result in self-control depletion resources that are necessary for carrying out day-to-day activities (Baumeister and Muraven 2000). In the long-term, these interactions lead to mental health issues and even hinder career success (Baumeister and Muraven 2000).

Returning to the PVEST model (Spencer et. al, 2003), institutional racism and color-blindness will negatively impact minority youth's ERI formation. Negative contact with institutions, primarily in the educational context, increases minority youth's net vulnerability level and net stress engagement through inequitable resource allocation by the hand of high-stakes testing. Exclusionary punishment on the other hand increases net stress engagement by removing children and adolescents from their learning environments, disrupting routines, and placing youth at risk of contact with the criminal justice system. These realities influence reactive coping methods and lead to maladaptive responses such as aggressive behavior and a lowered capacity for graduation. These coping methods in turn affect minority adolescents' emergent identities and become 
salient factors in their ultimate life-stage specific coping outcomes hindering their ability to deal with difficulties and lessen their likelihood of economic success and civic participation. Similarly, color blindness can trigger stress, depressive symptoms, lower self-esteem, and increase anxiety in minority youth. During ERI formation, these negative emotional and mental health factors can impede the growth of a positive racial identity. Although institutional and color-blind practices negatively impact minority youth, building a sense of agency can mitigate some of the effects. The next section will adopt Social Cognitive Theory (Banudra, 1986) to analyze whether social media can serve as a politically empowering tool.

\section{Road to Building Agency and Empowerment}

ERI formation within the context of institutional racism and color-blindness presents implications for political efficacy and empowerment. Based on the ERI formation literature, stressful events like racist encounters and exclusionary punishment at a young age have long-lasting effects on life outcomes and decisions (Spencer et. al 2003; Gibbons et. al, 2004, 2007; Seaton, 2009; Rosenbaum, 2020). Albert Bandura’s Social Cognitive Theory (1986) presents a useful theoretical model for understanding the effects of environments on individuals' behavior and internal factors like efficacy. In this section, I will outline the core components of Social Cognitive Theory (Bandura, 1986) and apply it to examine how social media use can increase a sense of political efficacy and empowerment. 
Social Cognitive Theory - A Theory of Agency

Social Cognitive Theory (SCT) is a theory of psychosocial functioning based on triadic reciprocal causation, observational learning, and agency (Bandura, 1986, 1997). SCT first took form as the Social Learning Theory (SLT) (1977) and was later expanded to SCT to account for the theory's additional model of triadic reciprocal causation. Bandura's theory came as a response to the behaviorist camp in psychology which asserted that learning can only be done through direct experience (Bandura, 2011). SCT instead presented a model that focused on observational learning and later on expanded to include triadic reciprocal causation. Bandura's theory places focus on the multidirectionality of effect and centers the person, behavior, and environment (Bandura, 1999).

Triadic reciprocal causation focuses on the bidirectional influence of environment, the internal self, and behavior. Within this model, environments can be further broken into three subcategories: the imposed, selected and constructed (Bandura, 1997). The imposed environment refers to our physical and socio-structural contextshere, one has no control of the existence of the environment but has control over how to construe and understand what happens in it. Next, the selected environment refers to our social structures and personal relationships and activities we partake in. Finally, the constructed environment flows out of the imposed and selected and it is composed of the meanings we infer from both of those environmental structures. Further, the meanings we construct are not absent from the influence and reality of the socio-institutional structures 
that we live within. These three types of environments are not exclusive of one anotherin fact, the selected and constructed environments can be understood as functioning under the umbrella of our imposed structures (Bandura, 1999). The different environmental realities are one component of triadic reciprocal causation.

The individual and behavior, the second and third components of triadic reciprocal causation are defined by personal factors like self-efficacy and biology. In this model, the individual is observing and adapting to socio-structural events. Cognitive processes determine the salience of environmental factors and their lasting effect on behavior, efficacy, and agency (Bandura, 1999). In SCT, self-efficacy is the foundation of agency. Self-efficacy refers to one's beliefs about their ability to produce change through their actions (Bandura, 1999). Working hand in hand, observations of environmental factors can deplete a sense of self- and political efficacy. Expanded to group-level, high self-efficacy can foster collective agency and propel groups to partake in the political process if they believe their actions will bring forth change (Bandura, 1997). Contrastingly, socio-environmental contexts of racism that lead to a lack of political trust (Hughes and Demo, 1989; Bobo and Gilliam, 1990; Avery 2006; 2009) will continually generate a lower sense of self-efficacy. Observation learning, however, can mitigate some of these effects. Here, behavior - actions, and decisions - can be influenced by observing positive events in a variety of environments.

The second model in SCT, observational learning, posits that learning can occur through observations of models. Here, models refer to any individual or action we can 
observe. Observational learning occurs consciously and inadvertently in everyday life (Bandura, 1997). As opposed to learning through direct experience, observational learning occurs through an individual observing behavior and learning its consequences. For example, individuals can learn that fire is hot and can cause wounds through observation of a model (an individual) burning their hand. Bandura states that one does not need to experience burn wounds to understand that fire should not be touched. An important component of observational learning is identification with the model — viewing similarities between yourself and the model increases the likelihood of retaining and adopting their behavior (Bandura, 1999).

Bandura's Social Cognitive Theory presents a useful model for understanding how environmental factors affect agency and behavior bidirectionally. In addition, learning through observing others can be useful in building a sense of agency without the prerequisite of direct experience. Together, triadic reciprocal causation and observational learning can lend insight into the possibilities of social media use.

\section{Applying SCT: Social Media Use to Grow Political Efficacy and Empowerment}

Before delving into the application of SCT on social media use, it is important to understand the conditions under which empowerment can be harnessed. Empowerment is defined as the process whereby individuals and communities gain control over issues that are important to them (Rappaport, 1984; 1987). Conditions on the road to empowerment rely upon political efficacy (Florin and Wandersman, 1984; Zimmerman and Rappaport, 
1988; Hinkle et. al, 1996; Cole, Zucker, and Ostrove, 1998) and political alienation (Keiffer, 1984). Political efficacy generally refers to internal and external efficacy. Internal efficacy refers to one's beliefs about their qualifications for political participation while external efficacy denotes one's beliefs about system responsiveness (Craig et. al, 1990). Non-Whites have been found to have lower levels of political efficacy than Whites (Yancey, Rigsby, and McCarthy 1972; Rodgers 1974; Abramson and Aldrich 1982; Finkel 1986; Madsen 1987; Clark and Acocke 1989; Uhlaner, Cain, and Kiewiet 1989; Bobo and Gilliam 1990; Michelson 2000, 2003-2004; Wu 2003; Banducci, Donovan, and Karp 2004). In addition, minorities also experience stronger feelings of political alienation -disconnectedness from the political process (Citrin et. al, 1975) and lack of ability to wield political power (Reefe and Knoke, 1999). Coupled with this, the literature on political efficacy and political alienation and disillusion show that young people have lower levels of political efficacy and a higher sense of political alienation (Gneiwosz, Noack, Buhl 2009) and disillusion (Dalton, 2004) than adults. So far, this research has posited that systemic racism and color-blind racism prevent minority youth from becoming politically empowered within institutional structures. However, I contend that social media can be used as a mediating tool to develop a sense of political efficacy and weaken the gaps in political discussion and participation to ultimately foster a sense of political empowerment.

Social Media has grown significantly within the past two decades. Social Networking Sites (SNS) or Social Media, refer to web-based platforms that allow 
individual profiles connections with other users all within the platform (Boyd and Ellison, 2007). Since MySpace, social networking took a popular turn. MySpace provided a unique platform that converged music bands, young teens, and college-aged youth into online networking and unlike the then competitor site Friendster, it did not charge a user fee (Boyd and Ellison, 2007). During the earlier years of MySpace’s conception, Facebook took off as a private networking community for Harvard students only (Cassidy, 2006). By 2006, MySpace began to deal with a moral panic about sexual predators after several instances of sexual interactions between minors and adults were uncovered leading to fear about the safety of the site (Boyd, 2006). Meanwhile, Facebook was gaining traction with its innovative platform. Eventually, there would be mass migration from MySpace to Facebook, ensuring its success. While MySpace was in the midst of its image problem, Twitter was established as a microblogging platform in 2006 (Dijk, 2011). What began as a one-directional microblogging platform began to focus on user-integration in order to remain relevant like Facebook (Dijk, 2011). By 2009, Twitter's audience soared and became majority 35 and under (Lipsman, 2009). Eventually, Facebook and Twitter would remain as popular online hubs of communication. Other applications like Instagram have since become staples for wide audiences.

The rise of social media which has eventually become the primary method for individuals to communicate and create content has generated scholarship on its effect on political efficacy, civic engagement, and political participation. Political participation 
literature has examined whether social media can foster political interest and engagement to ultimately lead to offline participation like voting (Effing, Hillegersberg, and Huibers, 2011). Similarly, studies on political apathy and disaffection have grappled with whether social media can have a mediating effect on these inclinations (Yamamoto, Kushin, and Dalisay, 2017). Here, I use SCT to analyze the ways in which social media can increase individuals' sense of political efficacy and agency. Then, I examine the possibilities of social media in politically empowering minority youth.

Adopting SCT's framework, social media acting as a constructed environment can have a positive effect on agency and efficacy through observational learning. As SCT informs us, individuals can increase their sense of efficacy through observation of what models have attained (Bandura, 1997, 86). When we can identify with a model, whether it be racial and ethnic identity or political identity, there is a higher likelihood of successful enactment of the model's behavior. Thus, in online social media communities, observing successful online political expression can increase one's sense of efficacy and belief in their capability to enact what they observed (Velasquez, 2018). Studies have found that online political behavior of users within one's social media connections can push individuals toward online political expression and increase a sense of political efficacy (Burke, Marlow, and Lento, 2009; Dimitrova et. al, 2011; Bond et. al, 2012; Velasquez, 2012; Ekstrom and Ostman, 2013). In line with SCT, enactive experiences, like social media, can increase one's sense of political efficacy through an increase in perception of capability (Velasquez and LaRose, 2015). Studies have also found a 
positive relationship between social media use and offline participation, suggesting a political efficacy increase (Dimitrova et. al, 2011; Vissers and Stolle, 2014). This coincides with SCT's triadic reciprocal causation as the influence of the constructed social media environment affects personal factors like efficacy, the individual's behavior then changes in an attempt to influence larger socio-structural environmental factors through political participation. In sum, social media can positively affect political efficacy (Velasquez, 2018) and political participation (Yamamoto, Kushin, and Dalisay, 2017) both key components of political empowerment.

\section{Next Steps}

The umbrella theories presented detailed unique experiences of non-Whites and the interactions they have with institutions and with Whites. The Theory of Systemic Racism (Feagin 2006) illustrates the ways in which political and non-political institutions cannot operate in an un-racist manner as the construction of hierarchy and oppression was fundamental to their successful operation. Bonilla-Silva's Theory of Color-Blind Racism depicts the individual interactions that take place in Feagin's Theory of Systemic Racism. The experiences of Black, Indigenous, People of Color (BIPOC) are colored by the everyday individual and institutional interactions. Studies evidence the effects of perceived discrimination and racism on BIPOC and tell a tale of negative physiological and cognitive impact (Williams et. al 1997; Harrel, Hall, and Taliaferro 2003; Harrel et. al 2011). The social environmental effects of racism on the development of racial identity are conceptualized by the $21_{\text {st }}$ Century Study Group composed of a collective of scholars. 
The process of Ethnic and Racial identity formation relies on the content of every day to understand one's self in relation to the outside world. In the case of non-whites, the process of understanding bias begins in early-childhood and informs the cognitive development of young individuals (Umana-Taylor et. al 2014). Within the context of Feagin (2006) and Bonilla-Silva's 2017 world, non-white youth and young adults are impacted in an individual and institutional way. According to Umana-Taylor et. al (2014), content and context are crucial to the development of non-white children as they become adults. Thus, examining the effects of systemic and color-blind racism on young non-whites is essential as it allows us to capture the development of an individual's understanding of their positionality in society and the subsequent consequences for their political empowerment.

According to Bandura's Social Cognitive Theory (1986), cognitive, behavioral patterns, affective and biological events, and environment are interconnected and influence agency. Bandura moves away from understanding human behavior through unidirectional causation and asserts that human behavior can be understood through triadic reciprocal causation which states that cognitive, behavioral pattern, affective and biological events, and environment are all interacting bidirectionally. This interaction affects human agency and allows individuals to construe and interpret their environments. Through Social Cognitive Theory, the use of social media, which can comprise one's constructed environment, can positively affect one's sense of agency as it allows individuals to directly create their realities. I argue that this phenomenon can positively 
impact non-white youth's sense of political empowerment through increasing political efficacy.

In Bandura's Social Cognitive Theory, individual sense of agency positively impacts efficacy and when this individual is translated into a collective setting, collective efficacy is positively impacted, including political efficacy (Bandura 1999). The application of Social Cognitive Theory to social media use has shown a positive impact on political efficacy through observed online political behavior (Velasquez 2018). Individuals gain agency through observation and adoption of online political behavior, translating the increased agency from their constructed environments into their biological environment (Bandura 1999).

To apply the theoretical expectations laid out here, I detail five hypotheses that encompass various aspects of the overarching argument put forth in this project. The hypotheses below test claims about attitudes about racism, political efficacy, and social media within a youth population.

\section{Hypotheses}

Attitudes about Racism and Political Efficacy. Attitudes about racism are shaped by experiences and observed instances of racist incidents. Per Feagin's (2006) Theory of Systemic Racism and Bonilla-Silva's 2017 Theory of Color-Blind Racism, I expect that for attitudes about racism, race will matter by virtue of uniquely experiencing racism. Additionally, I expect that attitudes about racism remaining an issue will be inversely related to political efficacy, regardless of race, as suggested by context and social capital 
research which posits that political attitudes in one's community affect political efficacy (Anderson 2010). Finally, I expect that the effect of attitudes about racism on political efficacy will be more pronounced for non-Whites because they generally exhibit lower levels of political efficacy because of their unique relationship with racism.

H1: Non-White respondents will be more likely to view racism as a major problem than White respondents.

H2: Belief that racism remains a major problem will be negatively related to political efficacy regardless of race.

H3: The relationship between viewing racism as a major problem and political efficacy will be stronger for non-White respondents than White respondents.

Social Media and Political Efficacy. Social media and online participation literature show evidence for increased political efficacy and empowerment amongst users (Effing, Hillegersberg, and Huibers 2011; Li 2015). I expect that high social media use will have a positive relationship with political efficacy for both Whites and non-Whites. Social media can provide an equalizing effect for individuals who are traditionally less politically empowered and efficacious as it allows them to observe successful political interactions online (Velasquez, 2018). Based on this study by Velasquez, I expect that the effect of high social media use on political efficacy will be stronger for non-Whites.

H4: High social media users will have higher levels of political efficacy, regardless of race. 
H5: The positive relationship between high social media use and political efficacy will be stronger for non-White than Whites.

The claims above test the theoretical arguments posed in chapters two and three. I test whether non-Whites are more likely to report racism as a major issue, per Feagin's and Bonilla-Silva's theories of institutional and social structures of disempowerment. I test whether there is a negative relationship between attitudes about racism and political efficacy as previous studies have suggested (Barretto et. al, 2018) and also whether that negative relationship will be stronger for non-Whites. Next, I claim that social media can serve as an efficacy building tool (Bandura, 1986; Velasquez 2018). Finally, I assert that the positive relationship between high social media use and political efficacy will be stronger for non-Whites. Chapter four discusses data, empirical methods, and measures chosen to test these relationships. 


\section{CHAPTER FOUR}

\section{Data, Methods, and Measures}

\section{Data and Methods}

To test the hypotheses, I use data from the Youth and Participatory Politics (YPP) survey conducted by co-Principal Investigators Kathy Cohen at the University of Chicago and Joseph Kahne at the University of California, Riverside. The dataset was retrieved online from The Inter-University Consortium for Political and Social Research (ICPSR), available here: https://www.icpsr.umich.edu/web/civicleads/studies/37188. The survey is a nationally representative three-wave survey of young people that oversamples for Black and Latino youth. It was conducted to gauge young people's political and attitudes and behaviors and how they use digital media to facilitate on-line and offline participation and engagement (Youth Participatory Politics Project, 2018). Wave 2 and Wave 3 particularly focus on online engagement and its impact on young people's lives (Cohen and Kahne, 2018). For the scope of this research, I use data from Wave 2 and Wave 3 only. The survey for Wave 2 was administered between July 7, 2013, and November 7, 2013, and the survey for Wave 3 was administered between June 6, 2015, and November $14,2015$.

All waves of the survey were conducted through the Growth for Knowledge (GfK) group (formerly Knowledge Networks) by sampling households in their Knowledge Panel, a nationally representative probability-based web panel. To accommodate the possibility that GfK sampling would not reach the goal of targeted 
demographics, an additional probability-based sample was used from the U.S. Postal Service Delivery Sequence File. In Wave 2, most of the survey was completed online, however, a small portion of interviews were conducted by telephone $(N=129)$. In Wave 3 , the survey was conducted online only. Table 1 includes the demographic breakdown of respondents for both waves.

In Wave 2, a sample of 2343 U.S. residents was retrieved in three ways - direct sampling, a parent sample, and address based-sampling. The direct sample of 18-27-yearolds was drawn from the GfK's KnowledgePanel (KP), a probability-based Internet panel designed to be nationally representative. The second sample, the parent sample, used the same KP and was created by GfK contacting individuals they knew to be parents of people in the target age range (15-27). Upon contacting these households, one person within the target age range was selected at random to complete the survey. The final sample was put together using address-based sampling through the U.S. Postal Service Delivery Sequence File. To collect data for Wave 3, GfK attempted to contact eligible respondents from Wave 2 to complete the survey and received a total of 1,033 respondents from Wave 2. The Wave 3 sample extended the age range to 29 . 
Table 1. Survey Respondents by Race and Age Wave 2

\begin{tabular}{lcccc} 
& Under 18 & $18-24$ & $25-34$ & Total \\
\hline White & 110 & 168 & 78 & 356 \\
Black & 48 & 138 & 56 & 242 \\
Asian & 34 & 75 & 40 & 149 \\
Hispanic & 76 & 115 & 51 & 242 \\
Other/2+ races & 21 & 12 & 11 & 44 \\
\hline $\mathbf{N}$ & 289 & 508 & 236 & 1033 \\
\hline
\end{tabular}

Note: Frequencies are unweighted.

Table 1.1 Survey Respondents by Race and Age Wave 3

\begin{tabular}{lrrrr} 
& Under 18 & $18-24$ & $25-34$ & Total \\
\hline White & 50 & 171 & 135 & 356 \\
Black & 15 & 126 & 102 & 243 \\
Asian & 14 & 75 & 69 & 158 \\
Hispanic & 33 & 127 & 82 & 242 \\
Other/2+ Races & 12 & 15 & 7 & 34 \\
\hline $\mathbf{N}$ & 124 & 514 & 395 & 1033 \\
\hline
\end{tabular}

Note: Frequencies are unweighted.

I tested the hypotheses using Logistic and Ordinary Least Squares (OLS) regression. Logistic regression was utilized for $H 1$ that contained a binary dependent variable. OLS regression was used for the remaining four hypotheses. For each hypothesis I conducted two tests: first, a bivariate test to measure the primary effect of the independent variable on the dependent variable; second, I included a set of covariates to account for other factors in a full model. In addition, each test was run separately for the individual waves - the two waves allow us to analyze the change over time in respondents. The study also included weights and they were applied appropriately. 


\section{Measures}

\section{Dependent Variables}

The dependent variables of interest are attitudes about racism and political efficacy. Attitudes about racism is measured by one question from the survey that provided a statement and question along with four response options. The question stated, "We would like to know your views on race and immigration. Some people say that racism no longer exists in American society and politics. Would you say that...?". The response options included the following statements: "Racism remains a major problem in our society."; "Racism exists today but is no longer a major problem."; "Racism once existed, but no longer exists in our society."; and "Racism has never been a major problem in our society." I collapsed the responses and recoded the variable on a $0-1$ scale. Table 2 reports the breakdown of responses by race for each wave. The three responses indicating that 'racism is no longer a major problem', 'racism no longer exists', and 'racism has never been a problem' were collapsed because the number of observations for the 'racism no longer exists' (Wave $2 \mathrm{~N}=32$; Wave $3 \mathrm{~N}=11$ ) and 'racism has never been a problem' (Wave $2 \mathrm{~N}=15$; Wave $3 \mathrm{~N}=5$ ) options were too small for meaningful analysis. The recoded variable is 0 for "Racism is no longer/has never been a major problem" and 1 for "Racism remains a major problem". The question-wording in both Wave 2 and Wave 3 remained the same. 
Table 2. Belief that Racism is a Major Problem by Race Wave 2

\begin{tabular}{lccc} 
& Whites & Non-Whites & Total \\
\hline Racism is no longer/has never been a major problem & 235 & 262 & 497 \\
Racism remains a major problem & 67.53 & 39.70 & 49.31 \\
& 113 & 398 & 511 \\
\hline $\mathbf{N}$ & 32.47 & 60.30 & 50.69 \\
\hline
\end{tabular}

Note: First row has frequencies and second row has column percentages

Table 2.1. Belief that Racism is a Major Problem by Race Wave 3

\begin{tabular}{l|ccc} 
& Whites & Non-Whites & Total \\
\hline Racism is no longer/has never been a major problem & 207 & 209 & 416 \\
& 59.48 & 31.33 & 40.99 \\
Racism remains a major problem & 141 & 458 & 599 \\
& 40.52 & 68.67 & 59.01 \\
\hline $\mathbf{N}$ & 348 & 667 & 1015 \\
& 100.00 & 100.00 & 100.00 \\
\hline
\end{tabular}

Note: First row has frequencies and second row has column percentages

The questions chosen to represent political efficacy were those that most closely aligned with traditional efficacy measures put forth by Neimi, Craig, and Mattei (1988, 1991). Although previous works by Campbell et. al (1960) and Abrahamson (1983) measured political efficacy, the measures put forth by Neimi, Craig, and Mattei are widely used. While empowerment theory differs from political efficacy, the core components of empowerment theory can speak to some to political efficacy (Zimmerman and Rappaport 1988; Menon 1999). In addition, the political efficacy measure, although containing one question traditionally understood as internal efficacy and another as external efficacy, is used as a general political efficacy measure. To ensure that results would not be based on one question functioning majority of the time, I ran the regressions 
with each question. I found no evidence that only one aspect of efficacy mattered more, so the questions were combined into one efficacy measure.

The measure for political efficacy is comprised of two questions from the survey. In Wave 2, the questions ask respondents to indicate their level of agreement with two statements - first, "I consider myself well qualified to participate in politics.", and second, "Public officials don't really care about what people like me think." In Wave 3, the first statement remains the same from Wave 2; however, the second statement slightly changes to, "The leaders in government care very little about people like me.". The small change in phrasing is noted for clarity. Respondents were asked to respond using a Likert scale ranging from 'strongly disagree' to 'strongly agree'. Both items are coded 0-3, and the overall political efficacy measure contains a range of 0-6 with higher values indicating higher levels of political efficacy.3 The second component of the efficacy measure is reverse coded so that a higher value indicates a higher level of political efficacy. Both items were combined to create an additive index of political efficacy that ranges from 0 to 6 . The figure below highlights political efficacy level distribution across both waves.

\footnotetext{
${ }^{3}$ The responses from the question about public officials is reverse coded so that the overall efficacy measure indicates that higher values correspond with higher levels of efficacy.
} 

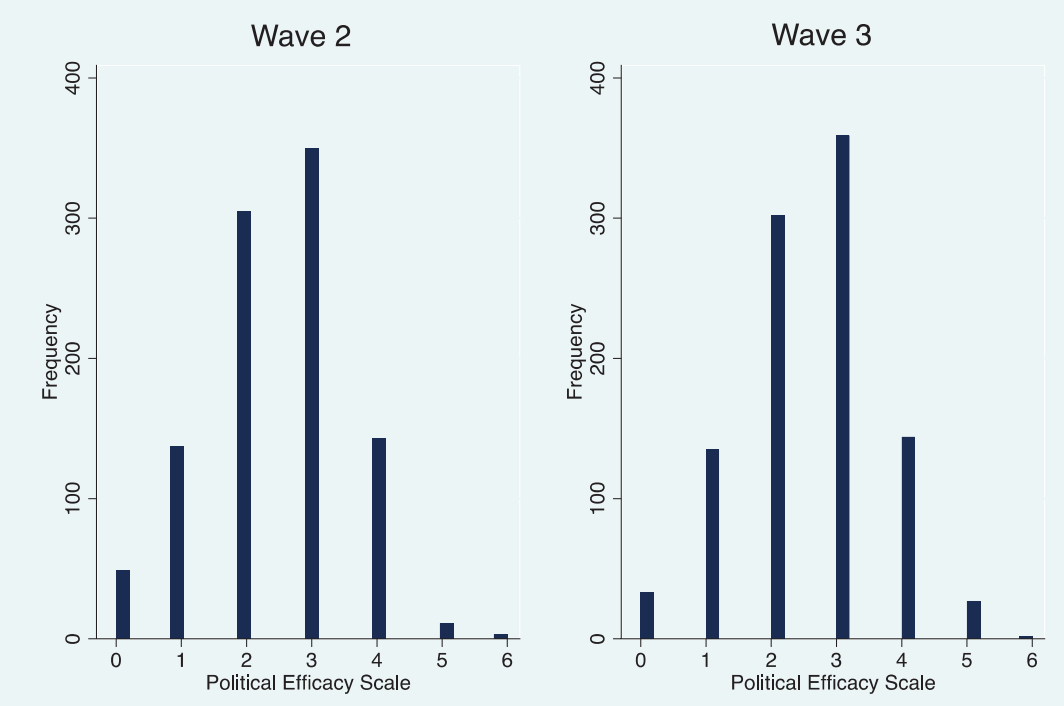

Figure 3. Political Efficacy Scale

Wave $2: M=2.89 \mathrm{SD}=1.24 \mid$ Wave $3: M=2.53 \mathrm{SD}=1.09$

\section{Key independent variables}

The main independent variables of interest are attitudes about racism, race, and social media scale. The attitudes about racism variable is the same measure used as a dependent variable. The race variable used in the analysis was collapsed into a binary White/nonWhite variable. This was done in line with the ways in which the theoretical foundations of this research were laid. Further, examining the theoretical argument and its effects for each ethnic and racial group would be better suited for a larger project. The survey codebook and questionnaire did not provide question-wording for supplemental variables like race. However, the options listed on the codebook were coded as such: Whites $(0)$ and non-Whites (1) - comprised of Black, Latino, Asian, and 2+/Mixed-Race respondents. The social media scale is measured with fourteen survey questions that 
asked respondents about their social media behavior. For example, respondents are asked if they have posted a status update or tweet about a political campaign, if they have followed someone on Twitter for political information, news, or opinions and if they created their own media to share online. Each item measures the frequency of the specific behavior with a five-point scale ranging from 'never' to 'daily'. These were coded 0 to 4 , culminating in an overall Social Media Scale range of 0-60. Figure 4 illustrates the social media use distribution for both waves.
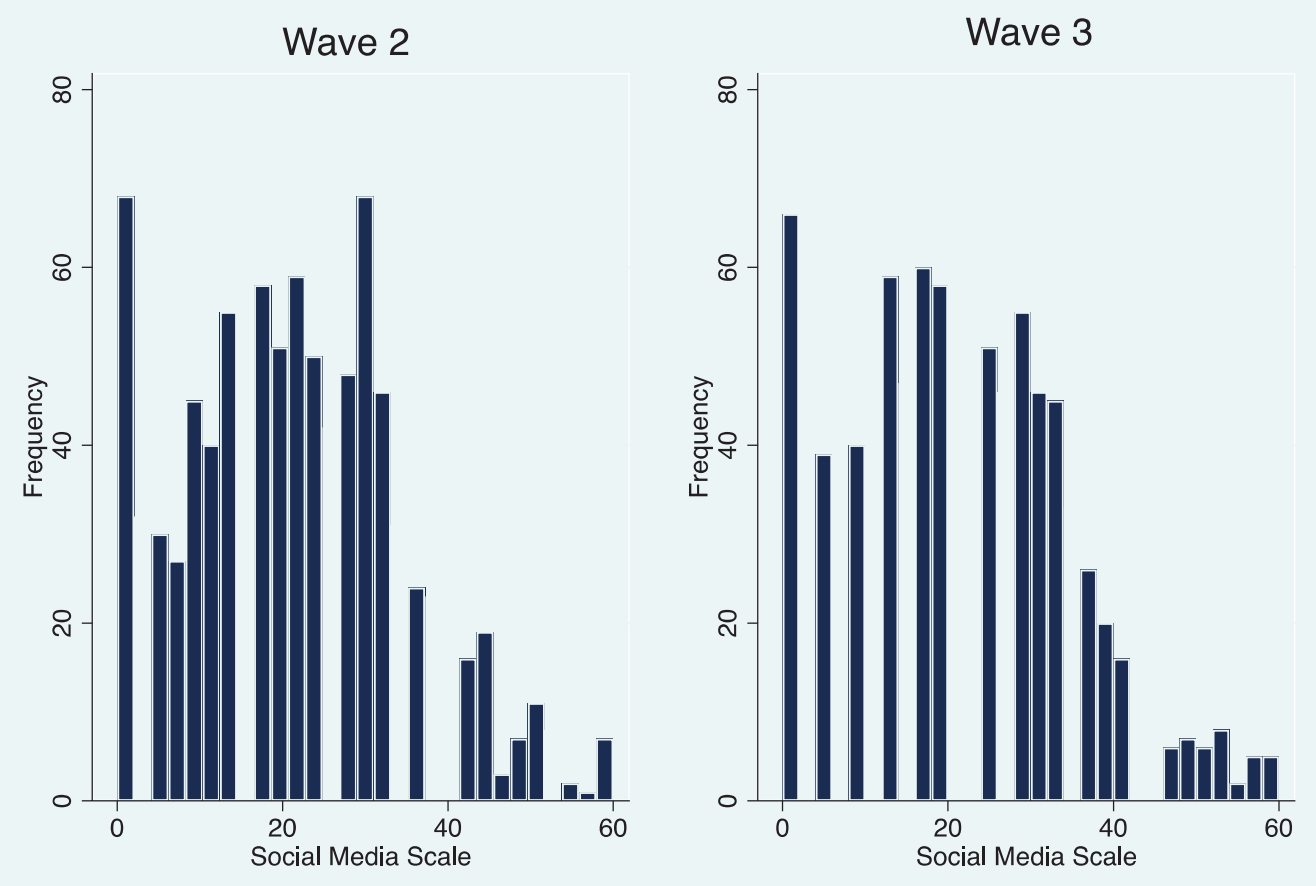

Figure 4. Social Media Scale

Wave 2: $M=21.83 \mathrm{SD}=13.12 \mid$ Wave $3: M=21.15 \mathrm{SD}=13.14$ 


\section{Control Variables}

In order to isolate the effects of attitudes about racism, race, and social media use, I control for a set of demographic factors that could affect the dependent variables. I control for a binary race variable coded (0) White and (1) for non-White4, education level ranging 0 to 3 from (0) 'less than high school', (1) high school, (2) some college, and (3) 'Bachelor's degree or higher'. Household income is coded 0 to 4 starting at (0) 'under $\$ 25,000$ ', (1) \$25,000-\$49,999, (2) \$50,000-\$74,999, (3) \$75,000-\$99,999, and (4) ‘ $\$ 100,000$ and above'. Gender is coded as (0) 'male' and (1) as 'female', a binary region variable differentiating (0) South and (1) non-South, and Democratic and Republican Party ratings ranging from 0 to 100 with increasing values denoting warmer views of the party. The political party thermometers are used as stand-ins for party identification because the survey does not contain any question asking for explicit party ID. The factors chosen are traditionally considered to affect political attitudes, participation, and efficacy (Brady, Verba, Scholzman, 1995).

\section{Conclusion}

In this chapter, I introduced the hypotheses, data, methods, and measures. First, the hypotheses laid the expectations that attitudes about racism will matter differently based on race; attitudes about racism will be negatively related to political efficacy, and

\footnotetext{
${ }^{4}$ While the theoretical argument presents a more detailed account of the impact of ethnic-racial identity, the empirical examination collapses and combines all minority youth. This was done because the data does not present large enough sample sizes for each ethnic/racial groups, and for remaining within the scope of the project.
} 
this relationship will be stronger for non-Whites. In terms of social media, social media use will have a positive relationship with political efficacy, and this relationship will be stronger for non-Whites. Next, I detailed the data used for analysis - the Youth Participatory Politics Survey, a three-wave - 2011, 2013, 2015 - nationally representative survey of young people that oversamples for Black and Latino youth in particular. Here, I presented the sampling process and the empirical methods. Finally, I laid out the measures used for analysis. In the next chapter, I will present the results based on the hypotheses. 


\section{CHAPTER FIVE}

\section{Results}

Attitudes about Racism by Race

I first claimed that non-White youth are more likely to view racism as a major problem. To test this, I ran a logistic regression on the binary dependent variable that asks whether racism remains a major problem on the independent binary White/non-White variable. I ran the logistic regression run for both waves-Wave 2 (2013) and Wave 3 (2015) and with two different models: a bivariate model testing only the independent variable on the dependent variable, and a full model with a set of controls.

The results in Table 3 show a significant relationship between race and attitudes about whether racism remains a major problem. Column 1 "Bivariate" under Wave 2 shows a significant relationship between the independent and dependent variable. Column 2 "Full Model" under Wave 2 shows that the relationship remains significant, even when controlling for a set of covariates. Again, in Wave 3, both column 3 "Bivariate" and column 4 "Full Model" highlight a significant relationship between just the dependent and independent variable that remains significant, even after introducing a set of controls. 
Table 3. Belief that Racism is a Major Problem Based on Respondent Race

\begin{tabular}{|c|c|c|c|c|}
\hline & \multicolumn{2}{|c|}{ Wave 2} & \multicolumn{2}{|c|}{ Wave 3} \\
\hline & Bivariate & Full Model & Bivariate & Full Model \\
\hline Non-White & $\begin{array}{l}1.30^{*} \\
(.18)\end{array}$ & $\begin{array}{l}1.21 * \\
(.20)\end{array}$ & $\begin{array}{l}1.16^{*} \\
(.18)\end{array}$ & $\begin{array}{l}.97 * \\
(.19)\end{array}$ \\
\hline Education (0-3) & & $\begin{array}{c}.02 \\
(.09)\end{array}$ & & $\begin{array}{l}-.15 \\
(.11)\end{array}$ \\
\hline Democrat (0-100) & & $\begin{array}{l}.003 \\
(.004)\end{array}$ & & $\begin{array}{l}.005 \\
(.004)\end{array}$ \\
\hline Republican (0-100) & & $\begin{array}{l}-.02 * \\
(.004)\end{array}$ & & $\begin{array}{l}-.01 * \\
(.004)\end{array}$ \\
\hline Income $(0-4)$ & & $\begin{array}{l}-.07 \\
(.07)\end{array}$ & & $\begin{array}{l}-.04 \\
(.07)\end{array}$ \\
\hline South & & $\begin{array}{l}-.27 \\
(.21)\end{array}$ & & $\begin{array}{l}-.15 \\
(.21)\end{array}$ \\
\hline Female & & $\begin{array}{l}.16 \\
(.19)\end{array}$ & & $\begin{array}{l}.35^{*} \\
(.19)\end{array}$ \\
\hline Constant & $\begin{array}{l}-.80 * \\
(.14)\end{array}$ & $\begin{array}{l}-.11 \\
(.34)\end{array}$ & $\begin{array}{l}-.42 * \\
(.13)\end{array}$ & $\begin{array}{l}.13 \\
(.37)\end{array}$ \\
\hline $\begin{array}{l}\text { Pseudo } \mathrm{R}_{2} \\
\mathrm{~N}\end{array}$ & $\begin{array}{c}.07 \\
1,008\end{array}$ & $\begin{array}{l}.13 \\
969\end{array}$ & $\begin{array}{c}.06 \\
1,015\end{array}$ & $\begin{array}{c}.09 \\
1,001\end{array}$ \\
\hline
\end{tabular}

$* \mathrm{p}<0.05,+\mathrm{p}<0.1$

Note: The dependent variable is Belief that Racism is a problem coded 0 for not a problem, and 1 for belief it is a problem. Cell entries are logit coefficients with standard errors in parentheses.

In order to examine the coefficients from the logistic regression, I converted the coefficients to estimate the probability that the dependent variable will equal one when comparing White and non-White respondents. The marginal effects for the full models in both waves are presented in Figure 3. The marginal effects report for Wave 2 at NonWhite $=0$ is .33 and at Non-White $=1$ is .60 . In Wave 3 , the marginal effect at 
Non-White $=0$ is .41 and at Non-White $=1$ is 0.64 . From Wave 2 to Wave 3 , the probability of viewing racism as a major problem increased .08 for Whites and .04 for non-Whites.

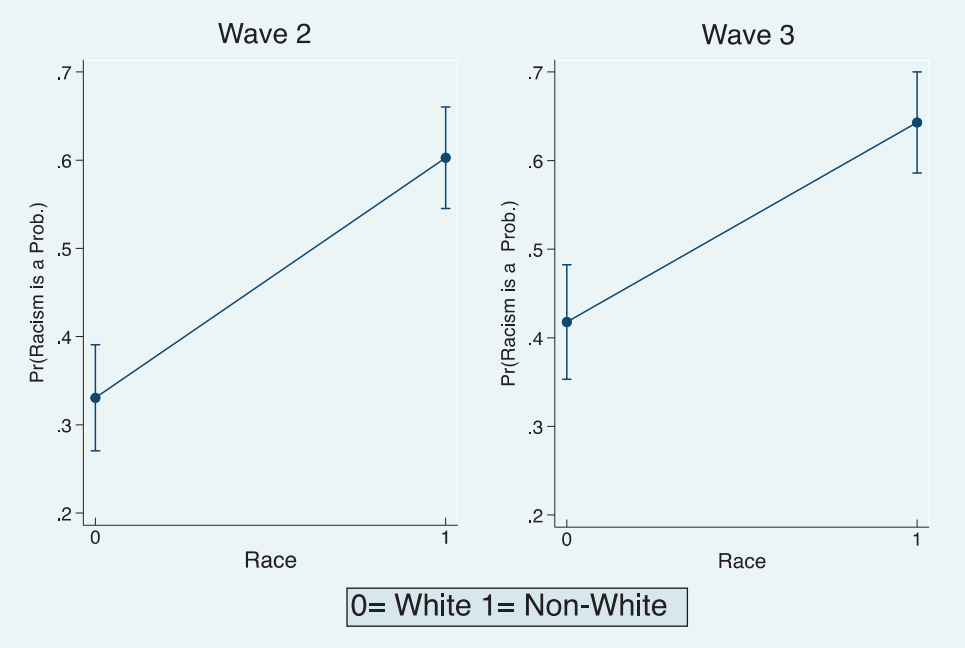

Figure 3. Probability of Viewing Racism as a Major Problem by Race Note: the figure reports the marginal effects for the full models only.

In addition to the marginal effects for the main variable of interest, I also computed the marginal effects of the covariates that were statistically significant. In both Wave 2 and Wave 3, Republican Party thermometer (0-100) showed a negative relationship between warmer Republican Party ratings and viewing racism as a major problem. I included political party thermometers in the models because partisan identity affects beliefs about political issues. In Wave 2, respondents least favorable of the Republican Party had a .59 probability of viewing racism as a major problem while those 
who were most favorable only had a .22 probability of holding the same opinion. Similarly, in Wave 3, respondents that felt least favorable about the party had a .62 probability of contending that racism remains a major issue. Meanwhile, those with the most favorable Republican Party rating had a .34 probability of believing racism remains a major problem. The results from both waves suggest that the more favorably one views the Republican Party, the less likely they are to view racism as a major problem.

In the full model in Wave 3, gender is also statistically significant. I included gender in the model as a covariate because gender identity affects life experiences. Based on the marginal effects report, males on average had a .47 probability of viewing racism as a major issue, while women had a .64 probability of holding the same opinion. The difference between men and women suggests that women are .17 more likely to view racism as a major issue as opposed to men.

The results from the logistic regression and marginal effects test suggest that nonWhite youth are more likely to believe that racism remains a major problem. This finding is consistent across the Bivariate and Full Models across the two waves. The increase of .08 for Whites and .04 for non-Whites from Wave 2 to Wave 3 suggest that over time, all respondents, regardless of race are more likely to report that racism remains a major problem. Based on the results in Table 3 and Figure 3, we find support for hypothesis 1's claim that non-Whites are more likely to view racism as a major issue. 
Effect of Belief that Racism is a Major Problem and Political Efficacy

To test the second claim, that viewing racism as a major problem will have a negative relationship with political efficacy, I used OLS regression.5 The dependent variable, political efficacy ranges from 0-6 with higher values denoting higher levels of efficacy. I ran the OLS regression with a Bivariate and Full Model for both waves. Table 4 illustrates the OLS results. In column 1 "Bivariate" under Wave 2, the relationship between viewing racism as a major problem and political efficacy is statistically significant and operating in the proper direction. When we turn to column 2 "Full Model" in Wave 2, the relationship remains significant, even after adding a set of controls. However, when we examine column 3 "Bivariate" under Wave 3, the relationship is not significant. After adding a set of controls to column 4 "Full Model", the relationship is still not significant and takes on the wrong value.

\footnotetext{
${ }^{5}$ In addition to OLS, I ran an Ordered-Logit regression to ensure that the OLS estimates were accurate. The Ordered-Logit results were substantively the same as the OLS estimates. The additional Ordered-Logit tests were conducted for every other hypothesis to ensure accurate estimates. OLS regression estimates are reported because they present clearer and simpler results.
} 
Table 4. Impact of Viewing Racism as a Major Problem on Political Efficacy Wave 2 Wave 3

\begin{tabular}{|c|c|c|c|c|}
\hline & Bivariate & Full Model & Bivariate & Full Model \\
\hline Racism is a prob. & $\begin{array}{l}-.24 * \\
(.10)\end{array}$ & $\begin{array}{l}-.21 * \\
(.10)\end{array}$ & $\begin{array}{l}-.01 \\
(.10)\end{array}$ & $\begin{array}{c}.09 \\
(.10)\end{array}$ \\
\hline Non-White & & $\begin{array}{r}-.002 \\
(.11)\end{array}$ & & $\begin{array}{l}-.09 \\
(.10)\end{array}$ \\
\hline Education (0-3) & & $\begin{array}{l}.08+ \\
(.04)\end{array}$ & & $\begin{array}{l}.14^{*} \\
(.05)\end{array}$ \\
\hline Democrat (0-100) & & $\begin{array}{l}.01 * \\
(.002)\end{array}$ & & $\begin{array}{l}.006^{*} \\
(.002)\end{array}$ \\
\hline Republican (0-100) & & $\begin{array}{l}.003+ \\
(.002)\end{array}$ & & $\begin{array}{l}.006^{*} \\
(.002)\end{array}$ \\
\hline Income $(0-4)$ & & $\begin{array}{c}.04 \\
(.03)\end{array}$ & & $\begin{array}{l}.09^{*} \\
(.03)\end{array}$ \\
\hline South & & $\begin{array}{l}.10 \\
(.10)\end{array}$ & & $\begin{array}{l}.17 \\
(.11)\end{array}$ \\
\hline Female & & $\begin{array}{l}-.18+ \\
(.10)\end{array}$ & & $\begin{array}{l}-.12 \\
(.10)\end{array}$ \\
\hline Constant & $\begin{array}{c}2.53^{*} \\
(.07)\end{array}$ & $\begin{array}{l}1.92 * \\
(.17)\end{array}$ & $\begin{array}{c}2.52^{*} \\
(.07)\end{array}$ & $\begin{array}{l}1.56^{*} \\
(.19)\end{array}$ \\
\hline $\begin{array}{l}\mathrm{N} \\
\mathrm{R}_{2}\end{array}$ & $\begin{array}{c}988 \\
.01\end{array}$ & $\begin{array}{l}957 \\
.06\end{array}$ & $\begin{array}{l}998 \\
.003\end{array}$ & $\begin{array}{l}987 \\
.08\end{array}$ \\
\hline
\end{tabular}

$* \mathrm{p}<0.05,+\mathrm{p}<0.1$
Note: The dependent variable is political efficacy (0-6). The coefficients are unstandardized OLS coefficients. The "Racism is a prob."

The OLS coefficient in Column 2 "Full Model” under Wave 2 shows a .21

decrease on the political efficacy scale when one view racism as a major problem.6

\footnotetext{
${ }^{6}$ To ensure greater accuracy in reporting, I deconstructed the political efficacy variable into "Internal Efficacy" and "External Efficacy" and re-ran the regressions with each type of efficacy. In doing this, I was able to determine that the results in Wave 2 were not stemming from one portion of the scale. In addition, this allowed me to examine whether the results in Wave 3 were dampened because of one form of efficacy. The findings from the regressions specified with either internal or external efficacy suggest similar findings from the overall efficacy scale. The tests specifying the type of efficacy were also run for each hypothesis that contained efficacy as the dependent variable.
} 
However, the result vanishes in Wave 3 column 4 showing partial support for the claims laid in Hypothesis 2.

When we turn to the covariates in the full models in column 2 and 4 for both Wave 2 and Wave 3, we find that several of the same covariates are statistically significant. In both waves, education is positively related to efficacy showing that a 1unit increase in education level corresponds with a .08 increase on the political efficacy level scale in Wave 2 and a .14 increase in Wave 3. Partisan identity is also significant across both waves. In Wave 2, a 1-unit increase in the 100-point Democratic Party thermometer rating scale will view increase a .01 increase in the efficacy scale. Meanwhile, the same increase in the Republican Party rating will result in a .003 increase on the efficacy scale. In Wave 3, a 1-unit increase for both Democrats and Republicans show a .006 increase on the political efficacy scale. In Wave 3 only, a 1-unit increase in income suggests an increase of .09 on the efficacy scale. Meanwhile, in Wave 2, women view a .18 decrease on the same scale.

The OLS estimates presented in Table 4 paint a picture of mixed results. In Wave 2 - 2013- the results show a .21 decrease on the 7-point efficacy scale, supporting the claims laid in Hypothesis 2. Turning to Wave 3 -2015 - however, the OLS estimates in the full model illustrate a non-statistically significant result. 
Racial Differences in the Relationship between Attitudes about Racism and Political Efficacy

To examine the relationship in hypothesis 2 more closely, in hypothesis 3 I expect that the relationship between attitudes about racism and political efficacy will be stronger for non-White respondents. To test this expectation, I ran an OLS regression with a product term of the variable "Racism is a prob." multiplied by the variable "Non-White". The full models here contain the same set of covariates as in Table 4 with the sole difference being the introduction of the product term to test whether an interaction effect is present. 
Table 5. Interaction of Attitudes about Racism and Race: Impact on Political Efficacy

Wave 2

Wave 3

\begin{tabular}{|c|c|c|c|c|}
\hline & Bivariate & Full Model & Bivariate & Full Model \\
\hline Racism is a prob. * Non-White & $\begin{array}{l}-.11 \\
(.10)\end{array}$ & $\begin{array}{l}.08 \\
(.21)\end{array}$ & $\begin{array}{l}-.03 \\
(.10)\end{array}$ & $\begin{array}{l}.18 \\
(.18)\end{array}$ \\
\hline Racism is a prob. $(0-1)$ & & $\begin{array}{l}-.25 \\
(.16)\end{array}$ & & $\begin{array}{l}.03 \\
(.10)\end{array}$ \\
\hline Non-White & & $\begin{array}{l}-.04 \\
(.15)\end{array}$ & & $\begin{array}{l}-.18 \\
(.14)\end{array}$ \\
\hline Education $(0-3)$ & & $\begin{array}{l}.08+ \\
(.04)\end{array}$ & & $\begin{array}{l}.14^{*} \\
(.05)\end{array}$ \\
\hline Democrat (1-100) & & $\begin{array}{l}.007^{*} \\
(.002)\end{array}$ & & $\begin{array}{l}.006^{*} \\
(.002)\end{array}$ \\
\hline Republican (1-100) & & $\begin{array}{l}.003+ \\
(.002)\end{array}$ & & $\begin{array}{l}.006^{*} \\
(.002)\end{array}$ \\
\hline Income $(0-4)$ & & $\begin{array}{l}.04 \\
(.03)\end{array}$ & & $\begin{array}{l}.09 * \\
(.03)\end{array}$ \\
\hline South & & $\begin{array}{l}.11 \\
(.10)\end{array}$ & & $\begin{array}{l}.17 \\
(.11)\end{array}$ \\
\hline Female & & $\begin{array}{l}-.18^{*} \\
(.09)\end{array}$ & & $\begin{array}{l}-.12 \\
(.09)\end{array}$ \\
\hline Constant & $\begin{array}{l}2.50^{*} \\
(.06)\end{array}$ & $\begin{array}{l}1.94 * \\
(.18)\end{array}$ & $\begin{array}{l}2.52 * \\
(.06)\end{array}$ & $\begin{array}{l}1.59^{*} \\
(.20)\end{array}$ \\
\hline $\begin{array}{l}\text { Observations } \\
\text { R-squared }\end{array}$ & $\begin{array}{l}988 \\
.002\end{array}$ & $\begin{array}{l}957 \\
.06\end{array}$ & $\begin{array}{c}998 \\
0.000\end{array}$ & $\begin{array}{l}987 \\
0.08\end{array}$ \\
\hline
\end{tabular}

$* \mathrm{p}<0.05,+\mathrm{p}<0.1$

Note: The models contain a product term of Racism is a prob. and Non-White. The product term tests whether there is an interaction between attitudes about racism and race. The dependent variable is political efficacy (0-6). Coefficients are unstandardized OLS coefficients and standard errors are reported in parentheses.

In column 1 "Bivariate", under Wave 2, the product term is not statistically significant and remains non-significant in column 2 "Full Model". In Wave 3, both the 
bivariate and full model do not show a statistically significant relationship. The results show a null effect and thus, no support for Hypothesis 3's claim that non-Whites who view racism as a major problem will have lower levels of efficacy than Whites that hold the same belief.

Relationship between Social Media Use and Political Efficacy

Recall the claim in $H 4$ that high social media users will have higher levels of political efficacy. To test this, I ran OLS regression across both waves with both a Bivariate model and a Full Model with controls. The covariates in the model are the same covariates used in Table 4 and 5. Table 6 reports the estimates from the OLS regression. Column 1 "Bivariate" under Wave 2 returns a positive, statistically significant result which indicates that higher social media use is positively related to political efficacy. However, once I included a set of controls in column 2 "Full Model", the relationship diminishes and is no longer statistically significant. Next, when looking at column 3 "Bivariate", the relationship between "Social Media Scale" and political efficacy is statistically significant and, looking at column 4 "Full Model", this effect remains even when adding a set of controls. The coefficient for the social media scale (0-60) shows that a 1 -unit increase in social media use results in a .01 increase on the political efficacy scale. 
Wave 2

Wave 3

\begin{tabular}{|c|c|c|c|c|}
\hline & Bivariate & Full Model & Bivariate & Full Model \\
\hline Social Media Scale (0-60) & $\begin{array}{l}.008+ \\
(.004)\end{array}$ & $\begin{array}{c}.005 \\
(.004)\end{array}$ & $\begin{array}{l}.009 * \\
(.004)\end{array}$ & $\begin{array}{l}.01^{*} \\
(.004)\end{array}$ \\
\hline Non-White & & $\begin{array}{l}-.04 \\
(.11)\end{array}$ & & $\begin{array}{l}-.09 \\
(.11)\end{array}$ \\
\hline Education (0-3) & & $\begin{array}{l}.08+ \\
(.05)\end{array}$ & & $\begin{array}{l}.15^{*} \\
(.05)\end{array}$ \\
\hline Democrat (1-100) & & $\begin{array}{l}.008^{*} \\
(.002)\end{array}$ & & $\begin{array}{l}.006^{*} \\
(.002)\end{array}$ \\
\hline Republican (1-100) & & $\begin{array}{l}.004 * \\
(.002)\end{array}$ & & $\begin{array}{l}.006^{*} \\
(.002)\end{array}$ \\
\hline Income $(0-4)$ & & $\begin{array}{l}.06 \\
(.04)\end{array}$ & & $\begin{array}{l}.08^{*} \\
(.03)\end{array}$ \\
\hline South & & $\begin{array}{c}.20 \\
(.10)\end{array}$ & & $\begin{array}{l}.20+ \\
(.11)\end{array}$ \\
\hline Female & & $\begin{array}{l}-.24^{*} \\
(.10)\end{array}$ & & $\begin{array}{l}-.15 \\
(.10)\end{array}$ \\
\hline Constant & $\begin{array}{c}2.30^{*} \\
(.10)\end{array}$ & $\begin{array}{l}1.68^{*} \\
(.20)\end{array}$ & $\begin{array}{c}2.33 * \\
(.09)\end{array}$ & $\begin{array}{l}1.42 * \\
(.19)\end{array}$ \\
\hline $\begin{array}{l}\mathrm{N} \\
\mathrm{R}_{2}\end{array}$ & $\begin{array}{c}934 \\
.01\end{array}$ & $\begin{array}{c}905 \\
.08\end{array}$ & $\begin{array}{c}986 \\
.01\end{array}$ & $\begin{array}{r}975 \\
.09\end{array}$ \\
\hline
\end{tabular}

$* \mathrm{p}<0.05,+\mathrm{p}<0.1$

Note: Dependent variable is political efficacy (0-6). Coefficients are unstandardized OLS coefficients.

Figure 5 illustrates the estimated effects for Wave 2 and Wave 3. Although Wave 2 was not statistically significant, I graphed the results for comparison. Because the survey uses the same set of respondents from Wave 2 (2013) and Wave 3 (2015), the graph illustrates that over time, social media use can have a significant positive effect on political efficacy. 

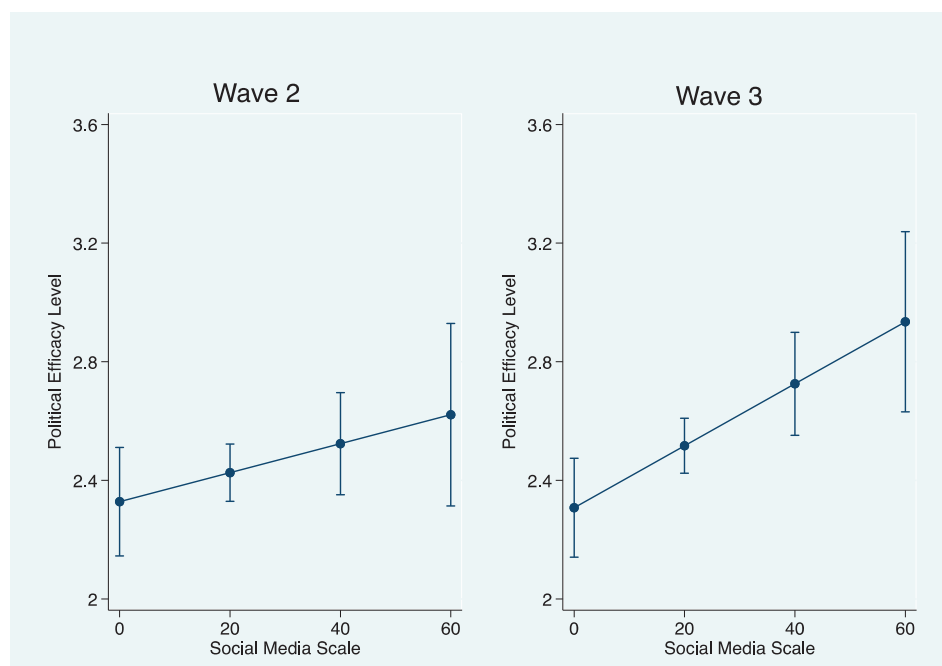

\section{Figure 5. Estimated Effects of Social Media Usage on Political Efficacy}

Note: the graph shows results for the Full Models only.

The relationship between social media use and political efficacy is slightly more complex than hypothesized. While we see that the effect in Wave 2 is not statistically significant, the results are suggestive of the effect of social media over time as Wave 3 shows us. Based on the results, we find partial support for $H 4$.

Turning to the covariates in Table 6, several are statistically significant and operating similarly to previous models (Table 3 and 4). Education, income, and partisanship are all positively related to the political efficacy, consistent with what we should expect of these relationships. Gender also operates in a manner consistent with what we should expect—female respondents are less efficacious than male respondents.

Next, I tested the expectation that the impact of social media use on efficacy will be stronger for non-White respondents with OLS regression. To tease out the specific 
impact of social media use, I split the sample by race and ran two sets of regressions and the same set of covariates as previous models. Table 7 reports the OLS estimates from Wave 2. Here, I set up two bivariate models and two full models, controlling for a set of covariates. Column 1 "Bivariate White" is the bivariate model with White respondents only. The result in this column is not statistically significant, suggesting that at the bivariate level, there is no relationship between social media use and political efficacy for Whites. Moving to column 3 'Full White', the full model specified for Whites, the relationship remains non-significant. 
Table 7. Efficacy Level Based on Social Media Usage with Sample Split by Race

Wave 2

\begin{tabular}{|c|c|c|c|c|}
\hline & $\begin{array}{c}\text { Bivariate } \\
\text { White }\end{array}$ & $\begin{array}{l}\text { Bivariate non- } \\
\text { White } \\
\end{array}$ & Full Whitehite & Full Non-White \\
\hline Social Media Scale (0-60) & $\begin{array}{l}.0005 \\
(.007)\end{array}$ & $\begin{array}{c}.01 * \\
(.004)\end{array}$ & $\begin{array}{c}.001 \\
(.006)\end{array}$ & $\begin{array}{l}.009 * \\
(.004)\end{array}$ \\
\hline Education $(0-3)$ & & & $\begin{array}{l}.10 \\
(.06)\end{array}$ & $\begin{array}{l}.06 \\
(.06)\end{array}$ \\
\hline Democrat $(0-100)$ & & & $\begin{array}{l}.01 * \\
(.003)\end{array}$ & $\begin{array}{l}.004+ \\
(.002)\end{array}$ \\
\hline Republican (0-100) & & & $\begin{array}{l}.004 \\
(.003)\end{array}$ & $\begin{array}{l}.004 \\
(.002)\end{array}$ \\
\hline Income $(0-4)$ & & & $\begin{array}{l}.11 * \\
(.05)\end{array}$ & $\begin{array}{l}-.02 \\
(.04)\end{array}$ \\
\hline South & & & $\begin{array}{l}.25 \\
(.16)\end{array}$ & $\begin{array}{l}.09 \\
(.12)\end{array}$ \\
\hline Female & & & $\begin{array}{l}-.25+ \\
(.15)\end{array}$ & $\begin{array}{l}-.16 \\
(.12)\end{array}$ \\
\hline Constant & $\begin{array}{l}2.34 * \\
(.14)\end{array}$ & $\begin{array}{l}2.18^{*} \\
(.13)\end{array}$ & $\begin{array}{l}1.51^{*} \\
(.27)\end{array}$ & $\begin{array}{l}1.90^{*} \\
(.25)\end{array}$ \\
\hline $\begin{array}{l}\mathrm{N} \\
\mathrm{R}_{2}\end{array}$ & $\begin{array}{l}328 \\
.002\end{array}$ & $\begin{array}{r}606 \\
.02\end{array}$ & $\begin{array}{l}318 \\
.18\end{array}$ & $\begin{array}{l}587 \\
.05\end{array}$ \\
\hline
\end{tabular}

$* \mathrm{p}<0.05,+\mathrm{p}<0.1$

Note: Dependent variable is political efficacy (0-6). Coefficients are unstandardized OLS coefficients. "Bivariate White" refers to the bivariate model with White respondents only. "Bivariate Non-White" is the bivariate model with Non-white respondents only. "Full White" is the model with controls with White respondents only. "Full Non-White" is the model with controls with Non-white respondents only.

The non-White respondents in Column 2 "Bivariate NW", the bivariate model shows a statistically significant relationship. In column 4 "Full Non-White", the full model for non-White respondents, the effect present in the bivariate model remains, even after controlling for a set of covariates. The OLS estimates shows that for non-Whites, a 1-unit increase on the social media use scale (0-60) corresponds with a .009 increase on the political efficacy scale. 
Wave 3 was tested in the same fashion as Wave 2-using OLS regression with a split sample by race, illustrated in Table 7.1. Column 1 "Bivariate White" highlights the results for the bivariate model for Whites and shows a non-statistically significant result. Looking at column 3, "Full White", the full model for Whites also shows a nonstatistically significant relationship. Column 2 "Bivariate Non-White" represents the bivariate model for non-Whites and shows a statistically significant relationship at this level. Column 4 "Full Non-White", the full models for non-Whites retains the statistically significant relationship even when adding a set of controls.

Table 7.1: Efficacy Level Based on Social Media Usage with Sample Split by Race

\begin{tabular}{|c|c|c|c|c|}
\hline & $\begin{array}{c}\text { Bivariate } \\
\text { White }\end{array}$ & $\begin{array}{c}\text { Bivariate Non- } \\
\text { White } \\
\end{array}$ & Full White & Full Non-White \\
\hline Social Media Scale (0-60) & $\begin{array}{c}.003 \\
(.006)\end{array}$ & $\begin{array}{c}.02^{*} \\
(.004)\end{array}$ & $\begin{array}{c}.005 \\
(.006)\end{array}$ & $\begin{array}{c}.02 * \\
(.004)\end{array}$ \\
\hline Education (0-3) & & & $\begin{array}{l}.17^{*} \\
(.07)\end{array}$ & $\begin{array}{l}.08 \\
(.06)\end{array}$ \\
\hline Democrat $(0-100)$ & & & $\begin{array}{l}.006^{*} \\
(.003)\end{array}$ & $\begin{array}{l}.006^{*} \\
(.002)\end{array}$ \\
\hline Republican (0-100) & & & $\begin{array}{l}.002 \\
(.003)\end{array}$ & $\begin{array}{l}.01 * \\
(.002)\end{array}$ \\
\hline Income $(0-4)$ & & & $\begin{array}{l}.09+ \\
(.05)\end{array}$ & $\begin{array}{l}.09^{*} \\
(.04)\end{array}$ \\
\hline South & & & $\begin{array}{l}.26 \\
(.17)\end{array}$ & $\begin{array}{l}.21+ \\
(.12)\end{array}$ \\
\hline Female & & & $\begin{array}{l}-.19 \\
(.14)\end{array}$ & $\begin{array}{l}-.07 \\
(.12)\end{array}$ \\
\hline Constant & $\begin{array}{l}2.50^{*} \\
(.12)\end{array}$ & $\begin{array}{l}2.12^{*} \\
(.11)\end{array}$ & $\begin{array}{l}1.64 * \\
(.28)\end{array}$ & $\begin{array}{l}1.11^{*} \\
(.22)\end{array}$ \\
\hline $\mathrm{N}$ & 340 & 646 & 336 & 639 \\
\hline $\mathrm{R}_{2}$ & .001 & .043 & .08 & .13 \\
\hline
\end{tabular}

$*_{p}<0.05,+\mathrm{p}<0.1$ 
Note: Dependent variable is political efficacy (0-6). Coefficients are unstandardized OLS coefficients. "Bivariate White" refers to the bivariate model with White respondents only. "Bivariate Non-White" is the bivariate model with Non-white respondents only. "Full White" is the model with controls with White respondents only. "Full Non-White" is the model with controls with Non-white respondents only. The Social Media Scale coefficient represents the change in political efficacy levels, based on an individual's frequency of social media use with a split race-sample.

Figure 6 illustrates the overall impact of social media use on both White and nonWhites respondents based on the full models only. Although the OLS estimates for Whites were not statistically significant, they have been included in the graph to illustrates the extent of the impact for non-Whites especially. In Wave 2, for non-White respondents, there is a .55 increase in the political efficacy scale when one changes from never using social media to the highest social media use level. In Wave 3, also for nonWhites, there is a .91 increase in political efficacy level when one moves from never using social media to the highest social media use level. 

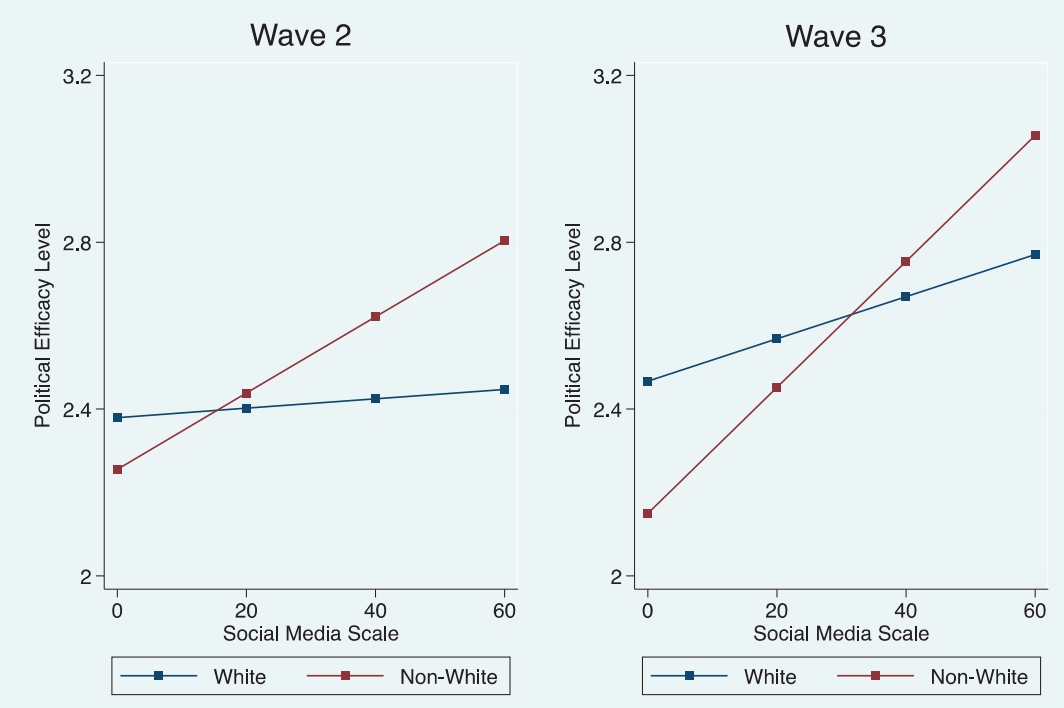

Figure 6. Political Efficacy Levels Based on Social Media Usage by Race Note: The dependent variable political efficacy contains a range of 0 to 6 .

Comparing the impact of social media use on political efficacy on non-Whites from Wave 2 to Wave 3, the differences suggest a stronger effect over time. For highest social media users, there is .36 increase in political efficacy levels over time from Wave 2 to Wave 3, in addition to the larger difference between these users and respondents who never used social media. The figure results suggest that over time, high social media use will have a greater impact on political efficacy. Meanwhile, for Whites, there is no statistically significant relationship between social media use and political efficacy. Based on these findings, we find support for Hypothesis 5.

\section{Conclusion}


This chapter has presented the tests of the hypotheses presented in Chapter 4. First, I tested the claim that non-Whites are more likely to view racism as a major problem than Whites. The results from the Table 3 logistic regression support the hypothesis. Here, we view that across both Wave 2 - 2013 - and Wave 3 - 2015, nonWhites were more likely to view racism as a major problem. The results from the marginal effects show that in Wave 2, the predicted probability of Whites viewing racism as a major issue as .33 and non-Whites as .60. In Wave 3, the predicted probability for Whites is .41 and for non-Whites, .64. From Wave 2 to Wave 3, however, the likelihood of individuals viewing racism as a major problem rose .08 for Whites and .04 for nonWhites. Based on the results from the logit estimator and marginal effects, hypothesis 1 is supported.

Hypothesis 2 stated that viewing racism as a major problem will be negatively related to political efficacy. The OLS estimates in Table 4 illustrated mixed results. The full model in Wave 2 shows a .21 decrease on the political efficacy when one views racism as a major problem. In Wave 3 however, there is no statistically significant relationship. Next, hypothesis 3 tested whether the impact of viewing racism as a major problem on political efficacy would differ between Whites and non-Whites. Table 5 reports the results tested using a product term of attitudes about racism and race. The findings show no-statistically significant relationships across both waves.

Turning to social media use, hypothesis 4 tested the claim that high social media users will have higher levels of political efficacy. Table 6 reports mixed results. First, in 
Wave 2, 2013, there is no statistically significant relationship. In Wave 3, 2015, however, a 1-unit increase in social media coincides with a statistically significant .01 increase on the political efficacy scale. Based on the OLS estimates, there is partial support for hypothesis 4 .

Hypothesis 5 tested whether the positive relationship between social media use and political efficacy would be stronger for non-Whites. Table 7 and 7.1 report the results for Wave 2 and Wave 3. Wave 2 shows that for non-Whites, there is .009 increase on the efficacy scale and in Wave 3, there is .02 increase on the scale. Across both waves, the results for Whites were not statistically significant. The results support the claims laid in hypothesis 5. Chapter 6 will discuss the results presented here. 


\section{CHAPTER SIX}

\section{Discussion and Future Steps}

\section{Review}

This project asked why are minority youth lacking political empowerment? I argued that institutional and social structures of racism maintain racial subjugation and disempowerment. Using Joe Feagin's Theory of Systemic Racism (2006), I detailed how the economic, education, housing, healthcare, and policing institutions work in tandem to reinforce racism. Slavery, centuries-long lack of access to economic opportunities (Lively 1992, 2-6; Shapiro 2004, 31; Darity 2005, 14-16; Feagin 2006, 42), and discriminatory hiring (Wilson, Tienda, and Wu 1995; Tomaskovic-Devey, Thomas, and Johnson et. Al 2005; Pager and Shepherd 2007). Inequitable resource allocation based on high-stakes testing (Smith 1995, 54-57; Furumoto 2005; Kim, Losen, and Hewitt 2010) exclusionary punishment (Polakow-Suransky 2001; Fuentes 2013; Heitzeg 2016) maintains racial inequality in education. Redlining (Kain and Quigley 1970, 72; Weinberg 1978; Schafer 1979; Lang and Nakamura 1993; Hernandez 2009; Mitchell and Franco 2018), white flight from diversifying neighborhoods (Crowder 2000; Trounstine 2016), and opposition to inclusionary housing in affluent areas (Maney and Abraham 2008, 66-82; Tighe 2012; Tighe and Goetz 2019) maintain housing segregation and unequal access to a quality life. In healthcare, historical medical experimentation on black bodies (Feagin 2006, 24; Washington 2006, 157-189), differential medical treatments based on race (Nelson 2002; Johnson et. Al 2004; Flores, Olson, and Tomany-Korman 2005; Canino et. al 2009; 
Hambidge et. Al 2007; Penner et. Al 2014), and polluted regions where minorities live (Dubary and Lebrun 2012) systemically threaten the likelihood of living. Lastly, police brutality (Nelson 2001; White and Fradella 2016, 17-40), mass incarceration (Alexander 2011), racialization and restriction of immigration (Lee 2002; Ngai 2004, 18;) and surveillance targeting Muslims (Cainkar 2004; Onwudiew 2005; Wong 2006; Ahmadi 2011) serve to uphold White Supremacy and keep non-Whites as second-class citizens.

Second, I argued that social structures of disempowerment reinforce White Supremacy on an individual level. Using Bonilla-Silva's Theory of Color-Blind Racism 2017, I detailed how the four frames of color-blindness play out. Abstract Liberalism uses the myth of meritocracy to explain racial differences and opposition to race-based equity policies (Bonilla-Silva 2017; 56; Byrd 2011). In the second frame, Naturalization roots racial differences in biology (Bobo 1999; Bonilla-Silva 2017, 61), effectively dismissing the structural effect of inequality. Next, Cultural Racism situates non-Whites' position in society as a result of cultural inferiority (Bonilla-Silva 2017, 68; Wise 2010, 128-145). Finally, the Minimization of Racism invalidates and negates the experiences of non-Whites ((Bonilla-Silva 57). Together, these frames uphold White Supremacy and racial subjugation on an individual level.

Next, I outlined the racial-ethnic identity formation process focusing on the different developmental periods and the effects that racism has on early and middle childhood (Selman, 1980; Garcia-Coll et. al, 1996; Tatum, 1997; Miller and MacItosh, 1999) adolescence (Simons et. al, 2003; Eccles et. al 2004; Chavous et. al 2008; Seaton, 
2009), and young adulthood (Erikson, 1968; Bowleg, 2008; Syed, 2010). I then contextualized the cognitive development process within institutional (Chemerinsky, 2002; Wells, 2002; Orfield and Lee, 2007; Garcia, 2008; Orfield, 2009; Glenn, 2011; Frankenberg, Siegel-Hawley, and Wang, 2011; Knoester, 2011) and social structures of disempowerment (Kozol 1991, 2005; Tyson 2002; Lareau 2003; Phelan and Rudman 2010; Peguero, Popp, and Koo 2011; Nadal et. al, 2014). I detail the extent of the effect these structures have on healthy identity formation and understanding of societal positionality. Finally, using Albert Bandura's Social Cognitive Theory, I proposed social media as a potential tool for gaining political empowerment, first through increasing political efficacy (Bandura, 1986; Velasquez, 2018).

To test the theoretical expectations, I used panel data from the nationally representative Youth Participatory Politics Survey that oversamples for minority youth. Here, I used logistic and OLS regression to test my hypotheses. I hypothesized that nonWhite youth are more likely to view racism as a major issue, that attitudes about racism will be negatively related to political efficacy and, the negative relationship will be stronger for non-Whites. In terms of social media, I claimed that social media use will be positively related to political efficacy, and the positive relationship will be stronger for non-Whites. My findings support the claim that non-Whites are more likely to contend that racism is a major issue. Meanwhile, the negative relationship between attitudes about racism and political efficacy is only significant for one period - 2013. Further, there is no statistically significant racial difference in the way that attitudes about racism affect 
political efficacy. Finally, higher social media use suggests a positive effect on political efficacy, particularly for non-Whites.

Below, I discuss the findings from Chapter five, focusing on whether the results align with the theoretical expectations. Finally, I discuss the limitations and future areas of study.

\section{Discussion}

This study presents evidence for several issues related to attitudes about racism, political efficacy, and social media use. First, I found that non-Whites are more likely to believe that racism remains a major problem in society. Second, attitudes about racism remaining a major issue are negatively related to political efficacy in the same manner for Whites and non-Whites. Finally, non-Whites become more efficacious with higher social media while Whites do not.

First, as noted above, racial identity has a significant bearing on an individual's propensity to believe racism remains a major issue. The tests used to measure the impact of identity collapsed the racial identity variable into a binary White/non-White variable. While the theoretical foundation expanded on the importance of this identity, the tests reflect a starting point into its examination. The tests presented here offer preliminary insight into the impact of racial identity relying on a shared non-White experience of exclusion and racism. While the data contained a diverse ethnic-racial sample, there were not large enough sample sizes to test the hypotheses on every racial-ethnic identity 
makeup. Further, this project presents a first-glance into a test of the theoretical argument and more specified ethnic-racial identity variables are more appropriate for a larger project.

The findings in Table 3 illustrate a marked difference between Whites and nonWhites and their likelihood to view racism as a major problem. In the 2nd Wave, 2013, the predicted probability of non-Whites viewing racism as a major problem is .60 while for Whites, it is .33-here, there is a .27 increase in the predicted probability of viewing racism as a major issue when one moves from White to non-White. Similarly, in Wave 3, 2015 , the predicted probability of Whites viewing racism as a major issue is .41 while there for non-Whites it is .64. Overall, there is an increase in the probability of viewing racism as a major issue from Wave 2 to Wave 3, regardless of race. Interestingly, Wave 3 of the survey was administered in the year leading up to the 2016 presidential election. Perhaps one reason for the overall increase for Whites and non-Whites can be informed by some of the narratives put forth by Donald Trump and his campaign which stoked White Supremacist and nativist fires (Huber, 2016). This finding is in line with the theoretical arguments laid out in chapters two and three.

Hypothesis one fits within Feagin's Theory of Systemic Racism (2006) that details how institutions propagate racism and the lived experiences of BIPOC in these institutions. Contact with institutions and observing and experiencing racism within those structures affect a minority child's development and understanding of social hierarchies. It is also consistent with Bonilla-Silva's 2017 Theory of Color-Blind Racism which 
posits that Whites are more likely to adopt a color-blind ideology. In this instance, Whites' having a lower probability of viewing racism as a major problem coincides with the dominant post-Civil Rights Era narrative that the United States is a post-racial society (Bonilla-Silva 2017, 12). Further, the all too common experiences with color-blind cloaked microaggressions and racism are internalized by non-White youth. Based on the argument laid out in chapter three, the experiences affect identity formation and have lifelong consequences for success (Rosenbaum, 2020) and mental health (Welsh and Little, 2018). Finally, non-Whites being .27 more likely to believe racism remains an issue aligns with many of racist encounters during adolescence that stem from peer relationships (Swim et. al, 2003). This reality seeps into the inverse where White peers can blanket racist ideas under color-blindness, pointing to the effectiveness of color-blind racism in simultaneously purporting racism and denying its existence (Bonilla-Silva 2017, 53).

This study found that attitudes about racism can negatively affect political efficacy, regardless of demographic characteristics. The findings in Table 4 highlight mixed results. In Wave 2, we view a .21 decrease on the 7-point political efficacy scale when one believes that racism remains a major problem. However, in Wave 3, there is a non-significant finding. The findings in Wave 2 are consistent with literature that suggests that perceptions of injustice have a negative relationship with political efficacy (Barreto al, 2018). Additionally, perceptions of institutions' efforts to remedy racism affect political efficacy (Barretto et. al, 2018). Wave 3 was not statistically significant 
pointing to a limitation in the hypothesized effects and in the timeframe of analysis. This non-significance provides an interesting contrast to the finding in hypothesis one that showed an increase in both Whites and non-Whites viewing racism as a major issue. Situating this finding within literature could point to the mobilizing effect of perceptions of injustice (Corcoran, Pettinicchio, Young, 2015). This finding is limited though in its explanation of political efficacy in particular. Connecting the literature to the political context of the timeframe within which Wave 3 was administered (July 2015 - November 2015) shows that anti-Trump protests were propping up around the nation against his racist campaign start (NBC News 2015) suggesting an efficacy-building experience stemming from participation in and observation of these protests (Klandermans, 1984). However, the extent to which Klandermans' argument can be applied to the findings of this study is very limited and speculative.

Turning to hypothesis 3 , which claimed that the effect of viewing racism as a major problem on political efficacy would be stronger for non-Whites. The null results in Table 6 show that there is no support for hypothesis 3 . This perhaps stems from the limitation of having only two efficacy measures. It could also point to additional limitations of understanding which identity factors are salient in their effect on political efficacy. Increasingly, intersectionality defines youth identity and in the case of testing the effect of attitudes about racism on efficacy, other identity-related factors are not accounted for that could point to whether a difference between Whites and non-Whites truly exists. Connecting this finding to present-day (2020), recent Black Lives Matter and 
anti-police brutality protests show a diverse range of protesters - including a large portion of White youth. Future studies could find even more similarities between White and minority youth.

After examining the effects of race on attitudes about racism and the effect of those attitudes on political efficacy, I turned to social media use. I contended that social media use can serve as a conduit for gaining political empowerment by first increasing a sense of political efficacy as other studies have found (Burke, Marlow, and Lento, 2009; Dimitrova et. al, 2011; Bond et. al, 2012; Velasquez, 2012; Ekstrom and Ostman, 2013). The findings in Table 6 paint an interesting picture. Here, we find that Wave 2 does not show a statistically significant relationship between social media use and political efficacy. However, as we move to Wave 3, the relationship becomes significant with a 1 unit increase on the social media use scale (0-60) coinciding with a .01 increase on the political efficacy scale. The findings in Wave 3 are consistent with the literature on the empowering effect of social media use (Burke, Marlow, and Lento, 2009; Dimitrova et. al, 2011; Bond et. al, 2012; Velasquez, 2012; Ekstrom and Ostman, 2013; Velasquez, 2018). Further, because the data analyzes the same respondents over two periods in time, the results showing a change from a non-significant relationship in Wave 2 to a significant one in Wave 3 provide an interesting starting point for future research to provide clearer findings on whether social media use over time can increase efficacy. However, in this study, a significant limitation of only having two periods of time for 
analysis limits our ability to confidently conclude that social media use can increase efficacy over time. Based on the findings, there is partial support for hypothesis 4.

Lastly, I examined whether the positive impact of social media use on political efficacy would be stronger for non-Whites per Bandura's Social Cognitive Theory (1986) and studies that find this to be the case (Velasquez, 2018). The findings in Table 7 and 7.1 show support for this hypothesis. Here, I find that in both periods in time, non-Whites grow more efficacious the more they use social media. Additionally, I find that increases in political efficacy were even higher from 2013 to 2015, especially for high social media users. This finding aligns with SCT's models of observational learning and triadic reciprocal causation. In this case, observational learning, which states that individuals are more likely to adopt certain behaviors and increase their sense of efficacy if they identify with a model that is displaying those behaviors, comes into play. As social media becomes more heavily dominated by younger audiences, the likelihood of their peers adopting this form of media increases. When they successfully adopt social media and increase use, their sense of efficacy increases, per the observational learning model (Bandura, 1986). The findings here also relate to SCT's triadic reciprocal causation in that the positive influence of social media as a constructed environment in increasing efficacy (Bandura, 1986; Velasquez, 2018). Here, social media use corresponds with Bandura's claims about triadic reciprocal causation and observational learning in their potential to increase agency. This finding ultimately speaks to the potential that social media has in countering some of the inequalities that decrease political efficacy and 
potentially serving as a potentially empowering tool. However, the limitations of having only two moments in time for analysis, future research that examines social media use's effect on political efficacy over a longer period can elucidate whether the empowering potential is conclusive.

This chapter has discussed the results presented in chapter five, focusing on the implications of the findings. I find that race matters for attitudes about racism, as extensively detailed in chapters two and three. Racist encounters during institutional interactions and within those contexts inform an individual's perceptions of whether racism still exists. In terms of race, minority children are more likely to identify prejudicial and racist encounters (Garcia-Coll et. al, 1996; Tatum, 1997; Miller and MacItosh, 1999). Non-White children and adolescents' experiences with racially based differential treatment in the educational system is but one example of the effects of institutional contact on perceptions of racism (Babad, 1998; Kuklinski and Weinstein, 2001). Further, non-White adolescents' encounters with racism from peers speak to the social structures of racism that uniquely affect this group (Swim et. al, 2003). Conversely, color-blind racism leads Whites to believe that racism no longer remains a major issue, despite their potential to partake in it (Bonilla-Silva 2017). Next, there is partial support for the claim that attitudes about racism affect political efficacy. The significant finding in Wave 2 coincides with theories that purport perceptions of injustice negatively affect political efficacy (Barretto et. al, 2018). The non-significant relationship in Wave 3 points to a limit in the overall meaning we can extrapolate from the findings as 
we are only observing two moments in time. The results from hypothesis 3 are not supported as the effect of believing that racism is a major issue on political efficacy does not function differently between Whites and non-Whites. This finding perhaps points to another limitation in the study's limited efficacy measures. Further, the effects of other salient identity factors are not accounted for. Next, hypothesis 4 results show partial support for the claim that social media is positively related to political efficacy. The positive relationship was significant in Wave 3, but not in Wave 2. This partial finding requires a study over a longer period to extract meaningful conclusions about the true effect of social media use on political efficacy. Finally, the positive relationship between social media use and political efficacy is significant for non-Whites, but not for Whites. This aligns with studies that highlight the equalizing effect of social media (Velasquez, 2018). It also coincides with SCT's triadic reciprocal causation and observational learning models, both of which claim that identifying with models can lead to replicated behaviors. In turn, this replicated behavior leads to a positive change in an individual's perceptions of their environment, ultimately leading to higher levels of political efficacy (Bandura, 1986). The findings in this study show mixed results based on the theoretical expectation. Study limitations and future steps for research are discussed next. 


\section{Limitations and Future Steps}

Despite the implications discussed above, it is important to note the limitations of this study. The primary limitation is the lack of empowerment measures in the data. Because of this, the analysis focused on political efficacy as an important condition for political empowerment. However, although efficacy is a core component of empowerment, inferences about the actual effect of social media use on empowerment are limited. Another limitation of the study is the limited questions about political efficacy. A general limitation of studying the effects of social media is in the rapid growth and change associated with social media use. Thus, making relevant inferences based on severalyears old data can miss the magnitude of the effects present-day. Future areas of research should focus on testing the effects of social media use on political empowerment using empowerment measures. Further, using questions with a primed identity frame like race can help elucidate the isolated effects of racial identity. Finally, collecting data over a longer period can better inform the assumptions and inferences we draw from the findings.

This work adds to our understanding of the unique ways in which institutional racism and color-blindness affect minority youth. The theoretical argument laid out here connects institutional and social structures of racism with the process of ethnic-racial identity formation to detail the extent of their effect on cognitive development and political empowerment,. It also opens the door to examining the different ways in which we can empower minority youth, taking particular care to the empowering possibilities of 
social media. The ultimate hope for this project is that it sparks discussion and research into how institutions and social structures of racism uniquely affect minority youth. This is particularly important as our society continues to diversify and as increasingly diverse generational cohorts enter the electorate. This project aims to move beyond a theoretical exercise - it details the multi-faceted nature of systemic and color-blind racism and in doing so, situates the absence and exclusion of certain populations from the electorate. Reaching past shallow notions of 'apathetic youth' to uncover the 'why' is crucial if we seek to empower them.

\section{References}

Abramson, P. R., \& Aldrich, J. H. (1982). The decline of electoral participation in America. American Review, 76, 502.

Adriana J. Umaña-Taylor, Stephen M. Quintana, Richard M. Lee, William E. Cross Jr., Deborah Rivas-Drake, Seth J. Schwartz, Moin Syed, Tiffany Yip, Eleanor Seaton and Ethnic and Racial Identity in the 21st Century Study Group. "Ethnic and Racial Identity During Adolescence and Into Young Adulthood: An Integrated Conceptualization". Child Development, 85 (1): 21-39.

Agnew, Robert. 2006. Pressured into crime: An overview of general strain theory. New York, NY: Oxford University Press.

Agnew, Robert, and Timothy Brezina. 2019. "General Strain Theory.” In Handbook on Crime and Deviance. Eds. M. Krohn, N. Hendriz, G. Hall Penly, and A. Lizotte. Springer: Cham.

Ahmadi, Shafiqa. 2011. "The Erosion of Civil Rights: Exploring the Effects of the Patriot 
Act on Muslims in American Higher Education." Rutgers Race and the Law Review, 12(1): 1-56.

Alexander, Michelle. 2011. The New Jim Crow. Ohio State Journal of Criminal Law, 9(1): 7-26.

Alpert, Geoffrey P., John M. Macdonald, and Roger G. Dunham. 2005. "Police Suspicion and Discretionary Decision Making During Citizen Stops." Criminology, 43(2): 407-434. DOI:10.1111/j.0011-1348.2005.00012.x

Anderson, A. 2013. "Teach for America and the dangers of deficit thinking." Critical Education, 4(11).

Anderson, Mary R. 2010. "Community Psychology, Political Efficacy, and Trust." Political Psychology, 31(1): 59-84.

Attar, Beth K., Nancy G. Guerra, and Patrick H. Tolan. 1994. "Neighborhood disadvantage, stressful life events and adjustments in urban elementary-school children." Journal of Clinical Child Pscyhology, 23(4): 391-400.

Au, Wayne. 2007. "High-Stakes Testing and Curricular Control: A Qualitative Metasynthesis."Educational Researcher, 36(5): 258-267.

Au, Wayne. 2009. "High-Stakes Testing and Discursive Control: The Triple Bind for Non-Standard Student Identities." Multicultural Perspectives, 11(2): 65-71.

Avery, James M. "The Sources and Consequences of Political Mistrust among African Americans." American Politics Research, 34(5): 653-682.

Avery, James M. 2009. "Political Mistrust Among African Americans and Support for the Political System.” Political Research Quarterly, 62(1): 132-145.

Bair, Allison N., and Jennifer R. Steele. 2007. "Examining the consequences of exposure to racism for the executive functioning of Black students." Journal of Experimental Social Psychology, 46(1): 127-132.

Banducci, S., Donovan, T., \& Karp, J. (2004). Minority Representation, Empowerment, and Participation. Journal of Politics, 66(2), 534-556.

Bandura, Albert. 1986. Social foundations of thought and action: A social cognitive Theory. Englewood Cliffs, NJ: Prentice-Hall. 
Bandura, Albert. 1997. Self-efficacy: The exercise of control. New York: Freeman.

Bandura, Albert. 1999. "Exercise of agency in personal and social change." In Behavior and cognitive therapy today: Essays in honor of Hans J. Eysenck. Eds. E. Sanavio. Oxford: Anonima Romana. 1-29

Bandura, Albert. 2011. "But what about the gigantic elephant in the room?" In Most unappreciated: 50 prominent social pscyhologists talk about hidden gems. Oxford: Oxford University Press. 51-59.

Barreto, Matt, Jonathan Collins, Gregory Leslie, and Tye Rush. 2018. "Perceived Racial Efficacy and Voter Engagement Among African-Americans: A Cautionary Tale from 2016." Western Political Science Association.

Bellin, Jeffrey. 2014. ""The Inverse Relationship between the Constitutionality and Effectiveness of New York City Stop and Frisk." Boston University Law Review, 94(5): 1495-1550.

Belkhir, Jean Ait, and Michel Duyme. 1998. "Intelligence and Race, Gender, Class: The Fallacy of Genetic Determinism: Rethinking Intelligence from the Position of the Oppressed.” Race, Gender, \& Class, 5(3): 136-178.

Bertrand, Marianne, and Sendhil Mullainathan. 2004. "Are Emily and Greg More Employable Than Lakisha and Jamal? A Field Experiment on Labor Market Discrimination." American Economic Review, 94 (4): 991-1013.

Bobo, Lawrence. 1999. "Prejudice as Group Position: Microfoundations of a Sociological Approach to Racism and Race Relations." Journal of Social Issues, 55(3): 445472.

Bobo, Lawrence, and Franklin D. Gilliam. 1990. "Race, Sociopolitical Participation, and Black Empowerment.” American Political Science Review, 84(2): 377-393.

Bond, R. M., Fariss, C. J., Jones, J. J., Kramer, A. D. I., Marlow, C., Settle, J. E., \& Fowler, J. H.2012. A 61-million-person experiment in social influence and political mobilization. Nature, 489: 295-298.

Bowditch, Christine. 1993. "Getting Rid of Troublemakers: High School Disciplinary Procedures and the Production of Dropouts." Social Problems, 40(4): 493-509. 
Bonilla-Silva, Edward. 2017. "Racism Without Racists”, 5th ed. US: Rowman \& Littlefield.

Bowleg, Lisa. 2008. "When Black + Lesbian + Woman $\neq$ Black Lesbian Woman: The Methodological Challenges of Qualitative and Quantitative Intersectionality Research." Sex Roles, 59: 312-325.

Boyd, Danah. 2006. "Friends, Friendsters, and MySpace Top 8: Writing Community Into Being on Social Network Sites.” First Monday 11:12, December. http://www.firstmonday.org/issues/issue11_12/boyd/index.html

Boyd, D. M. \& Ellison, N. B. (2007). Social Network Sites: Definition, History and Scholarship. Journal of Computer-Mediated Communication, 13(1).

Brady, H. E., Verba S., Scholzman, K.L. (1995). Beyond SES: A resource model of political participation. American Political Science Review, 89, 272-294.

Bridges, Khiara. 2011. Reproducing Race: An Ethnography of Pregnancy as a Site of Racialization. London: University of California Press. 210-216.

Brown, A. 2013. "Waiting for superwoman: White female teachers and the construction of the "neoliberal savior" in a New York City public school." Journal for Critical Education Policy Studies, 11: 123-164.

Burke, Moira, Cameron Marlow, and Thomas Lento. 2009. "Feed me: motivating newcomer contribution in social network sites.” CHI, 945-954.

Byrd, Carson W. 2011. "Conflating Apples and Oranges: Understanding Modern Forms of Racism.” Sociology Compass, 5: 1005-1017.

Byrd, W. Michael, and Linda A. Clayton. An American Health Dilemma: Race, Medicine, and Healthcare in the United States. 2. New York: Routledge

Cain, Glen G. Clear and convincing evidence: Measurement of discrimination in America, eds. Michael Fix and Raymond J. Struyk. Washington, D.C.: The Urban Institute Press.

Cainkar, Louise. 2004. "The impact of the September 11 attacks and their aftermath on 
Arab and Muslim communities in the United States." GSC Quarterly, 13.

Cammarota, J. 2011. "Blindsided by the avatar: White saviors and allies out of Hollywood and in education." Review of Education, Pedagogy, and Cultural Studies, 33: 242-259.

Cann, C. N. 2015. "What school movies and TFA teach us about who should teach urban youth: Dominant narratives as public pedagogy." Urban Education, 50: 288-315.

Canino, Glorisa, Elizabeth L. McQuaid, and Cynthia S. Rand. 2009. "Addressing asthma health disparities: A health multilevel challenge." Journal of Allergy and Clinical Immunology, 123(6): 1209-1217.

Cassidy, J. 2006. Me media. The New Yorker. May 15, 2006

Chaix, Basile. 2009. "Geographic life environments and coronary heart disease: a literature review, theoretical contributions, methodological updates, and a research agenda." Annual Review of Public Health, 30: 81-105.

Chapman, P.D. 1988. Schools as sorters: Lewis M. Terman, applied psychology, and the intelligence testing movement, 1890-1930. New York, NY: New York University Press.

Chavez, Leo R. 2008. The Latino Threat: Constructing Immigrants, Citizens, and the Nation. Stanford: Stanford University Press.

Chavous, T. M., Rivas-Drake, D., Smalls, C., Griffin, T., \& Cogburn, C. 2008. “ender matters, too: The influences of school racial discrimination and racial identity on academic engagement outcomes among African American adolescents." Developmental Psychology, 44(3): 637-654.

Chitewere, Tendai, Janet K. Shim, Judith C. Barker and Irene H. Yen. 2017. "How Neighborhoods Influence Health: Lessons to be learned from the application of political ecology." Health \& Place, 45: 117-123.

Chemerinsky, Erwin. 2002. "The Segregation and Resegregation of American Public Education: The Court's Role," North Carolina Law Review, 81(4): 1597-1622.

Chou, Rosalind S., and Joe Feagin. 2008. Myth of the Model Minority: Asian Americans Facing Racism, Second Edition. New York: Routledge. 
Citrin, Jack, Herbert McClosky, J. Merrill Shanks, and Paul M. Sniderman. 1975 "Personal and Political Sources of Political Alienation." British Journal of Political Science, 5(1): 1-31.

Clarke, H., \& Acock, A. (1989). National elections and political attitudes: The case of political efficacy. British Journal of Political Science, 19, 551.

Cole, Elizabeth R., Alyssa N. Zucker, Joan M. Ostrove. 1998. "Political Participation and Feminist Consciousness Among Women Activists of the 1960s." Political Psychology, 19(2): 349-371.

Cohen, Cathy J., and Kahne, Joseph. Youth Participatory Politics Survey Project, United States, 2013 and 2015 Panel Data. Ann Arbor, MI: Inter-university Consortium for Political and Social Research [distributor], 2018-12-03. https://doi.org/10.3886/ICPSR37188.v1

Corcoran, Katie E., David Pettinicchio, and Jacob T. N. Young. 2015. "Perceptions of Structural Injustice and Efficacy: Participation in Low/Moderate/High-Cost Forms of Collective Action." Sociological Inquiry, 85(3): 429-461.

Craig, S. C., Niemi, R. G., \& Silver, G. E. (1990). Political efficacy and trust: A report on the NES pilot study items. Political Behavior, 12, 289-314. doi:10.1007/BF00992337

Crowder, Kyle. 2000. "The Racial Context of White Mobility: An Individual-Level Assessment of the White Flight Hypothesis.” Social Science Research, 29(2): 223-257. DOI: https://doi.org/10.1006/ssre.1999.0668

D’Augelli, Anthony R., and Scott L. Hershberger. 1993. “African American Undergraduates on a Predominantly White Campus: Academic Factors, Social Networks, and Campus Climate." The Journal of Negro Education, 62(1): 67-81.

Dalton, R. 2004. Democratic Challenges, Democratic Choices: The Erosion of Political Support in Advanced Industrial Democracies. Oxford: Oxford University Press.

Darity, William Jr. 2005. "Stratification Economics: The Role of Intergroup Inequality." Journal of Economics and Finance, 29 (2): 144-153.

Diemer, Matthew A., Cheng-Hsien Li. 2011. "Critical Consciousness Development 
Political Participation Among Marginalized Youth.” Child Development, 82(6): 1815-1833.

Dimitrova, D. V., Shehata, A., Strömbäck, J., \& Nord, L. W. 2011. The effects of digital media on political knowledge and participation in election campaigns: Evidence from panel data. Communication Research.

Dimsky, Gary A., and Patrick L. Mason. 2005. "Racial Inequality and African Americans' Disadvantage in Credit and Capital Markets." In African Americans in the US Economy, eds. Cecilia Conrad, James Stewart, John Whitehead and Patrick L. Mason, 141-149. Oxford: Rowman and Littlefield Publishers Inc. 151156.

Dijk, Teun A. van. 2011. Discourse and Communication. Berlin, Germany: Walter de Gruyter \& Co.

Dubay, Lisa C., and Lydie A. Lebrun. 2012. "Health, Behavior, and Health Care Disparities: Disentangling the Effects of Income and Race in the United States." International Journal of Health Services, 42(4): 607-625.

Eccles, Jacquelynne S. 2004. "Schools, academic motivation, and stage-environment fit." Eds. R.M. Lerner and L. Steinger. Handbook of Adolescent Psychology, 2nd ed. Hoboken, NJ: Wiley. 125-153.

Effing, Robin, Jos van Hillegersberg, and Theo Huibers. 2011. "Social Media and Political Participation: Are Facebook, Twitter and YouTube Democratizing Our Political Systems." International Conference on Electronic Participation, 6847: 22-35.

Ellen, Ingrid Gould, Tod Mijanovich, and Keri-Nicole Dillman. 2016. "Neighborhood Effects on Health: Exploring the Links and Assessing the Evidence." Journal of Urban Affairs, 23(3-4): 391-408.

Ekstrom, MMats, and Johan Ostman. 2013. "Family talk, peer talk and young people's civic orientation." European Journal of Communication, 28(3): 294-308.

Erikson, E.H. 1968. Identity: Youth and Crisis. New York, NY: Norton.

Esaiasson, Peter. 2014. "NIMBYism - A re-examination of the phenomenon." Social Science Research, 48: 85-95. 
Feagin, Joe. 2006. Systemic Racism: A Theory of Oppression. London: Taylor \& Francis Group. ProQuest Ebook Central.

Feagin, Joe R., and Clairece B. Feagin.1978. Discrimination American Style: Institutional Racism and Sexism. Englewood Cliffs, NJ: Prentice Hall

Feagin, Joe, and Sean Elias. 2013. "Rethinking racial formation theory: a systemic racism critique." Ethnic and Racial Studies, 36 (6): 931-960.

Ferguson, R.F. 1998. Teachers' perceptions and expectations and the black-white test score gap. In The black-white test score gap. Eds. C. Jenks and M. Phillips. Washington, D.C.: Brookings Institution Press.

Ferguson, Ann Arnett. 2001. Bad Boys: Public Schools in the Making of Black Masculinity. Ann Arbor: University of Michigan Press.

Finkel, S. E. (1986). Reciprocal effects of participation and political efficacy: A panel Analysis. American Journal of Political Science, 29, 891-913. doi:10.2307/2111186

Fisher v. University of Texas 2008

Flores, Glenn, Lynn Olson, and Sandra C. Tomany-Korman. 2005. "Racial and Ethnic Disparities in Early Childhood Health and Health Care." Pediatrics, 115(2): 183193.

Florin, Paul R., Abraham Wandersman. 1984. "Cognitive Social Learning and Participation in Community Development." American Journal of Community Psychology, 12(6): 659-706.

Floyd v. City of N.Y., 959 F. Supp. 2 d 540 (S.D.N.Y. 2013)

Frankenberg, Erica, Genevieve Siegel-Hawley, and Jia Wang. 2011. "Choice without Equity: charter school segregation.” Education Policy Analysis Archives, 19(1): 350 .

Fuentes, Annette. 2013. Lockdown High: When the Schoolhouse Becomes the Jailhouse. London: Verso.

Furumoto, Rosa. 2005. "No Poor Child Left Unrecruited: How NCLB Codifies and 
Perpetuates Urban School Militarism.” Equity \& Excellence in Education, 38(3): 200-210. DOI: 10.1080/10665680591002579

Garcia-Castanon, Marcela, Allison Rank, Matt A. Barreto. 2011. "Plugged In or Tuned Out? Youth, Race, and Internet Usage in the 2008 Election”. Journal of Political Marketing, 10: 115-138.

Garcia-Coll, Cynthia, Keith Crnic, Gontran Lamberty, Barbara Hanna Wasik, Renee, Jenkins Heidie Vasquez Garcia, and Harritt Pipe McAdoo. 1996. “An Integrative Model for the Study of Developmental Competencies in Minority Children." Child Development, 67(5): 1891-1914.

Garcia, David R. 2008. "The Impact of School Choice on Racial Segregation in Charter Schools.” Educational Policy, 22(6): 805-829.

Gerber, A. S., Green, D. P. and Shachar, R. (2003), Voting May Be Habit-Forming: Evidence from a Randomized Field Experiment. American Journal of Political Science, 47: 540-550. doi:10.1111/1540-5907.00038

Gibbons, Frederick X., Gerrard, M., Cleveland, M. J., Wills, T. A., \& Brody, G. 2004. "Perceived discrimination and substance use in African American parents and their children: A panel study." Journal of Personality and Social Psychology, 86: $517-529$

Gibbons, Frederick X., Hsiu-Chen Yeh, Meg Gerrard, Michael J. Cleveland, Carolyn Cutrona, Ronald L. Simons., and Gene H. Brody. 2007. "Early experience with racial discrimination and conduct disorder as predictors of subsequent drug use: A critical period hypothesis." Drug and Alcohol Dependence, 88(1): S27-S37.

Glenn, Charles L. 2011. Contrasting Models of State and School: A Comparative Historical Study of Parental Choice and State Control. New York, NY: The Continuum International Publishing Group.

Gniewosz, Burkhard, Peter Noack, and Monika Buhl. "Political Alienation in Adolescence: Associations with Parental Role Models, Parenting Styles, and Classroom Climate." International Journal of Behavioral Development 33 (4): 337-46. doi:10.1177/0165025409103137.

Gneiwosz, Burkhard, Peter Noack, and Monika Buhl. 2009. "Political alienation in 
adolescence: Associations with parental role models, parenting styles, and classroom climate." International Journal of Behavioral Development, 33(4): 337-346.

Goldsmith, Pat, Mary Romero, Raquel Rubio-Goldsmith, Manue Escobedo, and Laura Khoury. 2009. "Ethno-Racial Profiling and State Violence in a Southwest Barrio." Aztlan: A Journal of Chicano Studies, 34(1): 93-123.

Hale, Nathan L., Kevin J. Bennett and Janice C. Probst. 2010. "Diabetes Care and Outcomes: Disparities Across Rural America." Journal of Community Health, 33: 365-374.

Hambridge, Simon J., Caroline Bublitz Emsermann, Steven Federico, and John F. Steiner. 2007 . "Disparities in Pediatric Preventive Care in the United States, 1993-2002." Arch Pediatr Adolesc Med., 161(1): 30-36.

Hannah-Jones, Nikole. 2016. “What Abigail Fisher's Affirmative Action Was Really About." ProPublica. June, 23, 2016. https://www.propublica.org/article/acolorblind-constitution-what-abigail-fishers-affirmative-action-case-is-r

Harcourt, Bernard E. 2001. Illusion of Order: The Promise of Broken Windows Policing. Cambridge, MA: Harvard University Press.

Harrell, Camara Jules P., Tanisha I. Buford, Brandi N. Cage, Travette McNair Nelson, Sheronda Shearon, Adrian Thompson, and Steven Green. 2011. "Multiple Pathways Linking Racism to Health Outcomes.” DuBois Review, 8(1): 143-157.

Harrell, Camara Jules P., Sadiki Hall, and James Taliaferro. 2003. "Physiological Responses to Racism and Discrimination: An Assessment of the Evidence." American Journal of Public Health, 93(2): 243-247.

Heitzeg, Nancy A. 2016. The School-to-Prison Pipeline: Education, Discipline, and Racialized Double Standards. Santa Barbara: Praeger. 10.

Hemez, Paul, John J. Brent, and Thomas J. Mowen. 2020. "Exploring the School-toPrison Pipeline: How School Suspensions Influence Incarceration During Young Adulthood." Youth Violence and Juvenile Justice, 18(3): 235-255.

Hernandez, Jesus. 2009. "The Residual Impact of History: Connecting Residential Segregation, Mortgage Redlining, and the Housing Crisis." Kirwan Institute for the Study of Race and Ethnicity. 
Hilmers, Angela, Davis C. Hilmers and Jayna Dave. 2012. "Neighborhood Disparities in Access to Healthy Foods and Their Effects on Environmental Justice." American Journal of Public Health, 102(9): 1644-1654.

Hinkle, Steve, Lee Fox-Cardamone, Julia A. Haseleu, Rupert Brown, and Lois M. Irwin. 1996 . "Grassroots political action as an intergroup phenomenon." Journal of Social Issues, 52(1), 39-51.

Huang, Cindy Y., and Elizabeth A. Stormshak. 2011. "A longitudinal examination of early adolescence ethnic identity trajectories." Cultural Diversity and Ethnic Minority Psychology, 17(3): 261-270.

Huber, Lindsay Perez. 2016. "Make America Great again: Donald Trump, Racist Nativism and the Virulent Adherence to White Supremacy Amid U.S. Demographic Change." Charleston Law Review, 10(2): 215-250.

Hughes, Diane, James Rodriguez, Emilie P. Smith, Deborah J. Johnson, Howard C., Stevenson, and Paul Spicer. "Parents' ethnic-racial socialization practices: A review of research and directions for future study." Developmental Psychology, 42(5): 747-770.

Hughes, Michael, and David H. Demo. 1989. "Self-Perceptions of Black Americans: Self-Esteem and Personal Efficacy." American Journal of Sociology, 95(1): 132159.

Huston, James L. 2003. Calculating the Value of the Union: Slavery, Property Rights, and the Economic Origins of the Civil War. Chapel Hill: University of North Carolina Press. 25-29.

Ibrahim, Dina. 2014. “Maybe Brown People Aren't So Scary If They're Funny: Audience Readings of Arabs and Muslims on Cable Television Comedies." In The Colorblind Screen: Television in Post-Racial America. Eds. Sarah Nilsen, Sarah E. Turner. NY: NYU Press. 167-185.

Inda, Jonathan Xavier. 2005. Targeting Immigrants: Government, Technology, and Ethics. MA: Blackwell Publishing.

Jacobsen, Wade C., Garret T. Pace, and Nayan G. Ramirez. 2019. "Punishment and 
Inequality at an Early Age: Exclusionary Discipline in Elementary School.” Social Forces, 97(3): 973-998.

Jha, Ashish K., Douglas O. Staiger, F. Lee Lucas and Amitabh Chandra. 2007. "Do racespecific models explain disparities in treatments after acute myocardial infarction?" American Heart Journal, 153(5): 785-791.

Johnson, Rachel L., Somnath Saha, Jose J. Arbelaez, Mary Catherine Beach, and Lisa A. Cooper. 2014. "Racial and ethnic differences in patient perceptions of bias and cultural competence in health care." Journal of General Internal Medicine, 19: 101-110.

Kain, John F., and John M. Quigley. 1970. "Measuring the Value of Housing Quality." Journal of American Statistical Association, 65(330): 532-548.

Kain, John F., and John M. Quigley. 1972. "Housing Market Discrimination, Home Ownership, and Savings Behavior." The American Economic Review, 62(3): 263277.

Kantor, Amy C., and John D. Nystuen. 1982. "De Facto Redlining: A Geographic View." Economic Geography, 58(4): 309-328.

Kao, G. 2000. “Group images and possible selves among adolescents: Linking stereotypes to expectations by race and ethnicity." Sociological Forum, 15: 407430 .

Keiffer, Charles H. 1984. "Citizen Empowerment: A Developmental Perspective." Prevention in Human Services, 3(2-3): 9-36.

Kim, Catherine Y., Daniel J. Losen, and Damon T. Hewitt. 2010. The School to Prison Pipeline:Structuring Legal Reform. New York and London: New York University Press.

Klandermans, Bert. 1984. "Mobilization and Participation: Social-Psychological Expansions of Resource Mobilization Theory." American Sociological Review, 49(5): 583-600.

Knoester, Matthew. 2011. "Is the Outcry for More Pilot Schools Warranted? Democracy, Collective Bargaining, Deregulation, and the Politics of School Reform in Boston." Educational Policy, 25(3): 387-423. 
Knoester, Matthew, and Wayne Au. 2015. "Standardized testing and school segregation: like tinder for fire?" Race, Ethnicty and Education, 20(1): 1-14.

Kozol, Jonathan. 1991. Savage Inequalities: Children in America’s Schools. New York, NY: Crown.

Kretesdemas, Philip. 2008. "Immigration Enforcement and the Complication of National Sovereignty: Understanding Local Enforcement as an Exercise in Neoliberal Governance." American Quarterly, 60(3): 553-573.

Kretsedemas, Philip. 2014. "Mainstreaming Latina Identity: Culture-Blind and Colorblind Themes in Viewer Interpretations of Ugly Betty." In The Colorblind Screen: Television in Post-Racial America. Eds. Sarah Nilsen, Sarah E. Turner. NY: NYU Press. 285-315.

Kuklinski, Margaret R., Rhona S. Weinstein. 2001. "Classroom and Developmental Differences in a Path Model of Teacher Expectancy Effects." Child Development, 72(5): 1554-1578.

Kupchik, Aaron. 2016. The Real School Safety Problem: The Long-Term Consequences of Harsh School Punishment. Oakland: University of California Press.

Lang, William W., and Leonard I. Nakamura. 1993. "A Model of Redlining.” Journal of Urban Economics, 33(2): 223-234.

Lareau, Annette. 2003. Unequal childhoods: Class, race, and family life. Berkeley: University of California Press.

Larson, Nicole I., Mary T. Story and Melissa C. Nelson. 2009. "Neighborhood Environments: Disparities in Access to Healthy Foods in the U.S." American Journal of Preventative Medicine, 36(1): 74-81.

Lawrence, Regina G. 2000. The Politics of Force: Media and the Construction of Police Brutality. London: University of California Press

Lee, Erika. 2002. "The Chinese Exclusion Example: Race, Immigration, and American Gatekeeping, 1882-1924.” Journal of American Ethnic History, 21(3): 36-62.

Lee, S. 2009. Unraveling the model-minority stereotype: Listening to Asian American Youth 2nd ed. New York, NY: Teachers College Press. 
Li, Zongchao. 2015. "Psychological empowerment on social media: Who are the empowered users?” Public Relations Review, 42: 49-59.

Lipsman, Andrew 2009 “ Breaking News (and Making News): Twitter surges 131\% in March to 9.3 million U.S. visitors!", Comscore, 15 April

Lively, Donald E. 1992. The Constitution and Race. New York: Praeger. 2-6.

Lucas, F.L., Therese A. Stukel, Arden M. Morris, Andrea E. Siewers and John D. Birkemeyer .2006. "Race and Surgical Mortality in the United States." Annals of Surgery, 243(2): 281-286.

Macartney, Suzanne E. 2011. Child Poverty in the United States 2009 and 2010: Selected Race Groups and Hispanic Origin. Washington, DC: US Census Bureau.

Madsen, Douglas. 1987. "Political Self-Efficacy Tested." American Political Science Review, 81(2): 571-582.

Major, Brenda, Wendy Berry Mendes and John F. Dovidio. 2013. "Intergroup relations and health disparities: A social psychological perspective." Health Psychology, 32(5): 514-524. https://doi.org/10.1037/a0030358

Maney, Gregory M., and Margaret Abraham. 2008. "Whose Backyard? Boundary Making in NIMBY Opposition to Immigrant Services." Social Justice, 35(4): 6682.

Manning, Wendy D., Susan L. Brown, and J. Bart Stykes. 2014. "Family Complexity among Children in the United States." The ANNALS of the American Academy of Political and Social Science, 654(1): 48-65.

Mapping Police Violence. 2019. https://mappingpoliceviolence.org/

Mason, Patrick L. 2005. "Persistent Discrimination in the Labor Market." In African Americans in the US Economy, eds. Cecilia Conrad, James Stewart, John Whitehead and Patrick L. Mason, 141-149. Oxford: Rowman and Littlefield Publishers Inc.

McNeil, Linda. 2000. Contradictions of School Reform: Educational Costs of Standardized Testing. New York: Routledge. 
Mendez, Linda M. Raffaele, Howard M. Knoff, and John M. Ferron. 2002. "School demographic variables and out-of-school suspension rates: A quantitative and qualitative analysis of a large, ethnically diverse school district." Educational Practiced and Problems, 39(3): 259-277.

Menon, S. T. (1999). "Psychological empowerment: definition, measurement, and validation." Canadian Journal of Behavioural Science, 31(3): 161.

Messer, Chris M. 2011. "The Tulsa Race Riot of 1921: Toward an Integrative Theory of Collective Violence." Journal of Social History, 44(4): 1217-1232.

Meier, Deborah. 2002. In Schools We Trust: Creating Communities of Learning in an Era of Testing and Standardization. Boston, MA: Beacon Press.

Meier, Deborah, and George Wood. 2004. Many Children Left Behind: How the No Child Left Behind Act Is Damaging Our Schools. Boston, MA: Beacon Press.

Michelson, Melissa R. 2003. "Getting Out the Latino Vote: How door-to-door canvassing influences voter turnout in rural Central California." Political Behavior 25(3): 247-263.

Michelson, Melissa R. 2000. "Political Efficacy and Electoral Participation of Chicago Latinos.” Social Science Quarterly 81(1): 136-150

Michelson, Melissa R. 2003. "Political Efficacy Among California Latinos." Latino(a) Research Review 5(2-3): 5-15

Miller, David B., and Randall MacIntosh. 1999. "Promoting resilience in urban African American adolescents: Racial socialization and identity as protective factors." Social Work Research, 23(3): 159-169.

Mitchell, Bruce, and Juan Franco. 2018. "HOLC "Redlining” Maps: The Persistent Structure of Segregation And Economic Inequality." National Community Reinvestment Coalition.

Moore, H.A. 2005. "Testing Whiteness: No Child or No School Left Behind?" Washington University Journal of Law and Policy, 18: 173-201.

Morris, Edward W., and Brea L. Perry. 2016. "The Punishment Gap: School Suspension 
and Racial Disparities in Achievement." Social Problems, 63(1): 68-86.

Mukuria, Gathago. 2002. "Disciplinary Challenges: How Do Principals Address this Dilemma?" Urban Education, 37(3): 432-452.

Muraven, M. and R.F. Baumeister. 2000. "Self-regulation and depletion of limited resources: Does self-control resemble a muscle?" Psychological Bulletin, 126(2): $247-259$.

Nacos, Brigitte Lebens, and Oscar Torres-Reyna. 2007. Fueling our Fears: Stereotyping, Media Coverage, and Public Opinion of Muslim Americans. UK: Rowman and Littlefield Publishers, Inc.

Nadal, Kevin L., Yinglee Wong, Katie E. Griffin, Kristin Davidoff, and Julie Sriken. 2014. "The Adverse Impact of Racial Microaggressions on College Students' Self-Esteem.” Journal of College Student Development, 55(5): 461-474.

National Registry of Exonerations. 2020. "Hamid Hayat." National Registry of Exonerations. URL: https://www.law.umich.edu/special/exoneration/Pages/casedetail.aspx? caseid $=56$ $\underline{83}$

NBC News. 2015. "Dallas Latinos Protest Against Donald Trump.” NBC News. September, 8, 2015. URL: https://www.nbcnews.com/news/latino/dallas-latinosprotest-against-donald-trump-n423311

Nelson, Alan. 2002. Unequal treatment: confronting racial and ethnic disparities in health care.” Eds. B.D. Smedley, A.Y. Stith, and A.R Nelson. Journal of the National Medical Association, 94(8): 666-668.

Nelson, Jill. 2001. "Introduction.” In Police Brutality: An Anthology. US: W.W. Norton \& Company.

Ngai, Mae M. Impossible Subjects: Illegal aliens and the making of modern America. Princeton, Oxford: Princeton University Press.

Nichols, Sharon L., and David C. Berliner. 2007. Collateral Damage: How High-Stakes Testing Corrupts America's Schools. Cambridge, MA: Harvard Education Press.

Niemi, R. G., Craig, S. C., \& Mattei, F. (1991). Measuring internal political efficacy in The 1988 National Election Study. The American Political Science Review, 1407-1413. doi:10.2307/ 1963953 
Omi, Michael, and Howard Winant. 1994. "Racial Formation in the United States: From the 1960s to the 1990s," 2nd ed. New York: Routledge. viiii

Onwudiew, Ihekwoaba D. 2005. "Defining terrorism, racial profiling and the demonisation of Arabs and Muslims in the USA." Community Safety, 4(2): 4-11.

Orfield, Gary. 2009. "Reviving the Goal of an Integrated Society: A 21 st Century Challenge." The Civil Rights Project.

Orfield, Gary, and Chunmei Lee. 2007. "Historic Reversals, Accelerating Resegregation, and the Need for New Integration Strategies." The Civil Rights Project. 3-49.

Owens, Jayanti, and Sara McLanahan. 2017. "The Origins of the Racial Gap in School Suspension and Expulsion." Working Papers WP 17-15 ff, Center for Research on Child Wellbeing.

Pager, Devah. 2007. "The Use of Field Experiments for Studies of Employment Discrimination: Contributions, Critiques, and Directions for the Future." The Annals of the American Academy of Political and Social Science, 690 (1): 104133.

Pager, Devah, and Hana Shepherd. 2007. "The Sociology of Discrimination: Racial Discrimination in Employment, Housing, Credit, and Consumer Markets." The Annual Review of Sociology, 34: 181-209.

Peguero, A.A., Popp, A. M., Koo, D.J. 2011. "Race, ethnicity, and school-based adolescent victimization. Crime and Delinquency."

Penner, Louis A., and Nao Hagiwara. 2014. "Racism and Health." In The Wiley Blackwell Encyclopedia of Health, Illness, Behavior, and Society. Eds. W.C. Cockerham, R. Dingwall, and S. Quah. DOI: 10.1002/9781118410868.wbehibs290

Penner, Louis A., Irene V. Blair, Terrance L. Albrecht, and John F. Dovidio. 2014. "Reducing Racial Health Care Disparities: A Social Psychological Analysis." Policy Insights from the Behavioral and Brain Sciences, 1(1): 204-212.

Perez, Raul. 2013. "Learning to make racism funny in the 'color-blind' era: Stand-up comedy students, performance strategies, and the (re)production of racist jokes in public." Discourse and Society, 24(4): 478-503. 
Perry, Brea L., and Edward W. Morris. 2014. "Suspending Progress: Collateral Consequences of Exclusionary Punishment in Public Schools." American Sociological Review, 79(6): 1067-1087.

Petras, H., K.E. Masyn, J.A. Buckley, N.S. Ialongo, and S. Kellman. 2011. "Who is most at risk for school removal? A multilevel discrete-time survival analysis of individual and context-level influence." Journal of Educational Psychology, 103(1): 223-237.

Phelan, J.E., Rudman, L.A. 2010. "Reactions to ethnic deviance: The role of backlash in racial stereotype maintenance." Journal of Personality and Social Psychology, 99(2): 265-281.

Picower, Bree. 2009. "The unexamined Whiteness of teaching: how White teachers maintain and enact dominant racial ideologies." Race Ethnicity and Education, 12(2): 197-215.

Pitt, Cassady. 2011. "U.S. PATRIOT Act and Racial Profiling: Are There Consequences of Discrimination?" Michigan Sociological Review, 25: 53-69.

Polakow-Suransky, Sasha. 2001. "America's Least Wanted: Zero Tolerance Policies and the Fate of Expelled Students." In The Public Assault on America's Children: Poverty, Violence and Juvenile Justice, eds. Valarie Polakow-Suransky. New York: Teacher's College Columbia University.

Popham, James W. 2011. “Assessment Literacy Overlooked: A Teacher Educator's Confession." The Teacher Educator, 46(4): 265-273.

Probst, Janice C., Charity G. Moore, Saundra H. Glover and Michael E. Samuels. 2004. "Person and Place: The Compounding Effects of Race/Ethnicity and Rurality on Health." American Journal of Public Health, 94(10): 1695-1703.

Quintana, Stephen M. 1994. "A model of ethnic perspective-taking ability applied to Mexican-American children and youth." International Journal of Intercultural Relations, 18(4): 419-448.

Ramey, David M. 2015. "The Social Structure of Criminalized and Medicalized School Discipline." Sociology of Education, 88(3): 181-201. 
Rappaport, Julian. 1984. "Seeking justice in the real world: A further explication of value contexts.” Journal of Community Psychology, 12: 208-216.

Rappaport, Julian. 1987. "Terms of Empowerment/Exemplars of Prevention: Toward a Theory for Community Psychology." American Journal of Community Psychology, 15(2): 122-142.

Rentschler, Thomas. 2006. "No child left behind: Admirable goals, disastrous outcomes." Widener Law Review, 12(2): 637-664.

Reef, Mary Jo, and Davide Knoke. 1999. "Political Alienation and Efficacy.”In Measures of Political Attitudes. Eds. John P. Robinson, Phillip R. Shaver, and Lawrence S. Wrightsman, New York: Academic Press.

Richardson, Lynne D., and Marlaina Norris. "Access to Health and Health Care: How Race and Ethnicity Matter." Mount Sinai Journal of Medicine: A Journal of Translational and Personalized Medicine, 77(2).

Rodgers, H. (1974). Toward Explanation of the Political Efficacy and Political Cynicism of Black Adolescents: An Exploratory Study. American Journal of Political Science, 18(2), 257-282. doi:10.2307/2110702

Rosenbaum, Janet. 2020. "Educational and Criminal Justice Outcomes 12 Years After School Suspension." Youth and Society, 52(4): 515-547.

Rosenstone, Steven J., and John Mark Hansen. 1993. Mobilization, Participation, and Democracy in America. New York: Macmillan.

Ryan, Michael. 2004. "Framing the War Against Terrorism: U.S. Newspaper Editorials and Military Action in Afghanistan." Gazette: The International Journal of Communication Studies, 66(5): 363-382.

Sabin, Janice A., Brian A. Nosek, Anthony G. Greenwald and Frederick P. Rivara. 2009. "Physicians' Implicit and Explicit Attitudes About Race by MD Race, Ethnicity, and Gender." Journal of Health Care for the Poor and Underserved, 20(3): 896913.

Sacks, Peter. 2000. "Standardized minds: The high price of America's testing culture and what we can do to change it." National Association of Secondary School Principals, 84(616): 118-121. 
Saleem, Muniba, Sara Prot, Craig A. Anderson, and Anthony F. Lemieux. 2017. "Exposure to Muslims in Media and Support for Public Policies Harming Muslims." Communication Research, 44(6): 841-869.

Salisbury, Neal. 1982. Manitou and Providence: Indians, Europeans, and the Making of New England 1500-1643. New York: Oxford

Salvatore, Jessica, and J. Nicole Shelton. 2007. "Cognitive Costs of Exposure to Racial Prejudice.” Association for Psychological Science, 18(9): 810-815.

Scally, Corianne Payton, and J. Rosie Tighe. 2015. "Democracy in Action?: NIMBY as Impediment to Equitable Affordable Housing Siting." Housing Studies, 30(5).

Schafer, Robert. 1979. "Racial Discrimination in the Boston Housing Market." Journal of Urban Economics, 6(2): 176-196.

Schmidt, Silke. 2014. (Re-)Framing the Arab/Muslim. Bielefeld: Knowledge Unlatched. 138-189.

Schreer, George E. Saundra Smith, and Kirsten Thomas. 2009. "Shopping While Black": Examining Racial Discrimination in a Retail Setting." Journal of Applied Psychology, 39(6): 1432-1444.

Seaton, Eleanor K., Tiffany Yip, Robert M. Sellers. “A Longitudinal Examination of Racial Identity and Racial Discrimination Among African American Adolescents." Child Development, 80(2): 406-417.

Selden, S. 1999. Inheriting shame: The story of eugenics and racism in America. New York: Teachers College Press.

Selman, R.L. 1980. The growth of interpersonal understanding - Developmental and clinical analyses. New York: Academic Press.

Shahani, Aarti, and Judith Greene. 2009. "Local Democracy on ICE.” Justice Strategies. $35-43$.

Shapiro, M. Thomas. 2004. The Hidden Cost of Being African American: How Wealth Perpetuates Inequality. New York: Oxford Press.

Shapiro, Thomas M., and Jessica L. Kenty-Drane. 2005. “The Racial Wealth Gap.” In 
African Americans in the US Economy, eds. Cecilia Conrad, James Stewart, John Whitehead and Patrick L. Mason, 175-181. Oxford: Rowman and Littlefield Publishers Inc.

Shapiro, Thomas, Tatjana Mschede, and Sam Osoro. 2013. "The Roots of the Widening Racial Wealth Gap: Explaining the Black-White Economic Divide." Institute on Assets and Social Policy.

Shollenberger Tracey L. 2014. "Racial Disparities in School Suspension and Subsequent Outcomes: Evidence from the National Longitudinal Survey of Youth." In Closing the School Discipline Gap: Equitable Remedies for Excessive Exclusion, eds. Losen DJ. New York: Teachers College Press. 31-43.

Silva, Andrea. 2018. "Direct-Democracy Rules: The Effect of Direct Democracy on State Immigration Legislation.” PS: Political Science and Politics, 51(2): 298-303.

Silva, Andrea. 2019. "How California's Prop. 187 is still shaping immigration policy 25 years after it passed." Monkey Cage. November, 25, 3:00 a.m. PST. URL: https://www.washingtonpost.com/politics/2019/11/25/how-californias-prop-isstill-shaping-immigration-policy-years-after-it-passed/

Skiba, Russell. J., Lauren Shure, and Natasha Williams. 2012. "Racial and Ethnic Disproportionality in Suspension and Expulsion." in Disproportionality in Education and Special Education, eds. A.L. Noltemeyer and C.S. Mcloughlin. Springfield, IL: Charles C. Thomas Publisher. 89-118.

Skiba, R J., C. Chung, M. Trachok, A. Sheya, and R. Hughes. 2014. "Parsing Disciplinary Disproportionality: Contributions of Infraction, Student, and School Characteristics to Out-of-School Suspension and Expulsion." American Educational Research Journal, 51(4): 640-670.

Skiba, Russell J., Mariella I. Arredondo, and Natasha T. Williams. 2014. "More Than a Metaphor: The Contribution of Exclusionary Discipline to a School-to-Prison Pipeline." Equity and Excellence in Education, 47(4): 546-564.

Simons, R. L., Chen, Y.-F., Stewart, E. A., \& Brody, G. H. 2003. "Incidents of discrimination and risk for delinquency: A longitudinal test of strain theory with an African American sample.” Justice Quarterly, 20, 827-854. 
Smith, Robert. 1995. Racism in the Post-Civil Rights Era: Now You See It Now You Don't. Albany: State University of New York Press. 54-57.

Spencer, M. B. 2005. "Crafting identities and assessing opportunities Post-Brown." American Psychologist, 60: 821-830.

Spencer, M. B. 2006. Phenomenology and ecological systems theory: Development of diverse groups. In Handbook of child psychology, vol. 1: Theoretical models of human development. Eds. W. Damon \& R. Lerner. 6th ed. New York: Wiley. 829-893.

Spencer, M. B., Fegley, S. G., \& Harplani, V. (2003). "A theoretical and empirical examination of identity as coping: Linking coping resources to the self processes of African American youth." Applied Developmental Science, 7: 181-188.

Spencer, M. B., Silver, L. J., Seaton, G., Tucker, S. R., Cunningham, M., \& Harpalani, V. 2001. Race and gender influences on teen parenting: An identity-focused culturalecological perspective. In Adolescence and education. Eds. T. Urdan \& F. Pajares. Vol. Greenwich, CT: Information Age Publishers. 231-268.

Sue, Derald Wing, Annie I. Lin, Gina C. Torino, Christina M. Capodilupo, and David P. Rivera. 2009. "Racial microaggressions and difficult dialogues on race in the classroom." Cultural Diversity and Ethnic Minority Psychology, 15(2): 183-190.

Syed, Moin, and Margarita Azmitia. 2008. "A narrative approach to ethnic identity in emerging adulthood: Bringing life to the identity status model." Developmental Psychology, 44(4): 1012-1027.

Swim, J.K., E.D. Scott, G.B. Sechrist, B. Campbell, and C. Strangor. 2003. "The role of intent and harm in judgments of prejudice and discrimination." Journal of Personality and Social Psychology, 84(5): 944-959.

Tatum, Beverly Daniel. 1997. "The Development of White Identity "I'm not ethnic, I'm just normal."' In Why are all the Black kids sitting together in the cafeteria? and other conversations about race /. New York: BasicBooks. 93-113.

Tehranian, John. 2009. Whitewashed: America's Invisible Middle Eastern Minority. New York: New York UP.

Terry v. Ohio, 392 U.S. 1 (1968) 
Thomas, Jacqueline Rabe. 2019. "Separated by Design: How Some of America's Richest Towns Fight Affordable Housing." MotherJones. May, 23, 2019. URL: https://www.motherjones.com/politics/2019/05/separated-by-design-how-someof-americas-richest-towns-fight-affordable-housing/

Thompson, A.C. 2017. "Sikhs in America: A History of Hate.” ProPublica. August, 4, 2017. URL: https://www.propublica.org/article/sikhs-in-america-hate-crimevictims-and-bias

Tighe, J. Rosie. 2012. "How race and class stereotyping shapes attitudes toward affordable housing." Housing Studies, 27(7): 962-983.

DOI:10.1080/02673037.2012.725831

Tighe, J. Rosie, and Edward G. Goetz. 2019. "Comment on "Does the Likely Demographics of Affordable Housing Justify NIMBYism".” Housing Policy Debate, 29(2): 369-373.

Tomaskovic-Devey, Donald, Melvin Thomas, and Kecia Johnson. 2005. "Race and the Accumulation of Human Capital across the Career: A Theoretical Model and Fixed-Effects Application." American Journal of Sociology, 111(1): 58-89.

Trounstine, Jessica. 2016. Segregation by Design: Local Politics and Inequality in American Cities. New York: Cambridge University Press.

Turner, Margery Austin, Michael Fix, and Raymond J. Struyk. 1991. Opportunities Denied, Opportunities Diminished: Racial Discrimination in Hiring. Washington, D.C.: The Urban Institute Press. 5-12.

Tyson, K. 2002. "Weighing in: Elementary-age students and the debate on attitudes toward school among black students." Social Forces, 80(4): 1157-1189.

Umana-Taylor, Adriana J., Melinda A. Gonzales-Backen, and Amy B. Guimond. 2009. “Latino Adolescents' Ethnic Identity: Is There a Developmental Progression and Does Growth in Ethnic Identity Predict Growth in Self-Esteem?" Child Development, 80(2): 391-405.

Uhlaner, Carole J., Bruce E. Cain, and D. Roderick Kiewiet. "Political Participation of Ethnic Minorities in the 1980s.” Political Behavior, 11(3): 195-219.

Urban Institute. 2019. “The Black Butterfly: Racial Segregation and Investment Patterns 
In Baltimore." The Urban Institute.

Varsanyi, Monica W. 2010. Taking Local Control: Immigration Policy Activism in U.S. Cities and States. Stanford: Stanford University Press.

Vavrus, Frances, and Kim Marie Cole. 2002. ““I Didn't Do Nothin'”: The Discursive Construction of School Suspension." The Urban Review, 34: 87-111.

Velasquez, Alcides. 2012. Social media and online political discussion: The effect of Cues and informational cascades on participation in online political communities. New Media \& Society, 14(8): 1286-1303.

Velasquez, Alcidez, and Andrea Quenette. 2018. "Facilitating Social Media and Offline Political Engagement During Electoral Cycles: Using Social Cognitive Theory to Explain Political Action Among Hispanics and Latinos." Mass Communication and Society, 21(6): 763-784.

Velasquez, A., \& LaRose, R. (2015). Social media for social change: Social media political efficacy and activism in student activist groups. Journal of Broadcasting \& Electronic Media, 59(3), 456-474. https://doi.org/10.1080/08838151.2015.1054998

Vissers, Sara, and Dietlind Stolle. 2014. "The Internet and new modes of political participation: online versus offline participation." Information, Communication, and Society, 17(8): 937-955.

Wald, J., \& Losen, D. J. 2003. "Defining and redirecting a school-to-prison pipeline." New Directions for Youth Development, 99: 9-15.

Waldfogel, Jane, Terry-Ann Craigie, and Jeanne Brooks-Gunn. 2010. "Fragile Families and Child Wellbeing." Future Child, 20(2): 87-112.

Wallace, John M., Sara Goodkind, Cynthia M. Wallace, and Jerald G. Bachman. "Racial, Ethnic, and Gender Differences in School Discipline among U.S. High School Students: 1991-2005." Negro Education Review, 59(1-2): 47-62.

Washington, Harriet A. 2006. Medical Apartheid: The Dark History of Medical Experimentation on Black Americans from Colonial Times to the Present. US: Doubleday. 157-215. 
Weinberg, Daniel H. 1978. "Further Evidence on Racial Discrimination in Home Purchase." Land Economics, 54(4): 505-513.

Weissman, M. 2015. Prelude to prison: Student perspectives on school suspension. Syracuse, NY: Syracuse University Press.

Welch, Kelly, and Allison Ann Payne. 2010. "Exclusionary School Punishment: The Effect of Racial Threat on Expulsion and Suspension." Youth Violence and Juvenile Justice, 10(2): 155-171.

Wells, Amy Stuart. 2002. Where Charter School Policy Fails: The Problems of Accountability and Equity. New York, NY: Teachers College Press.

Welsh, Richard O., and Shafiqua Little. 2018. "The School Discipline Dilemma: A Comprehensive Review of Disparities and Alternative Approaches." Review of Educational Research, 88(5): 752-794.

Western, Bruce. 2007. "The Prison Boom and the Decline of American Citizenship." Society, 44(5): 30-36.

White, Michael D., and Henry F. Fradella. 2016. Stop and Frisk: The Use and Abuse of a Controversial Policing Tactic. New York: New York University Press. 1-15.

White, T. 2016. “Teach For America's paradoxical diversity initiative: Race, policy, and Black teacher displacement in urban public schools." Education Policy Analysis Archives, 24(16): 1-37.

Williams, David R., Yan Yu, James S. Jackson, and Norman B. Anderson. 1997. "Racial Differences in Physical and Mental Health: Socio-economic Status, Stress and Discrimination." Journal of Health Psychology, 2(3): 335-351.

Wilson, Franklin D., Marta Tienda, and Lawrence Wu. 1995. "Race and unemployment: Labor market experiences of black and white men, 1968-1988." Work and Occupations. 22(3): 245-70

Wise, Tim. 2010. Colorblind: The Rise of Post-Racial Politics and the Retreat from Racial Equity. San Francisco: City Lights Books. 135-150.

Wolfe, C., Major, B., Spencer, S., Schmader, T., Wolfe, C., \& Crocker, J. (1998). Coping 
With negative stereotypes about intellectual performance: The role of psychological disengagement. Personality \& Social Psychology, 24, 34-50.

Wolfinger, Raymond E., and Steven J. Rosenstone. 1980. Who Votes? New Haven: CT, Yale University Press.

Wong, Kam C. 2006. "The USA PATRIOT Act: A Policy of Alienation.” Michigan Journal of Race and Law, 12(1): 161-202.

Wu, C.-L. (2003). Psycho-Political Correlates of Political Efficacy: The Case of the 1994 New Orleans Mayoral Election. Journal of Black Studies, 33(6), 729-760. https://doi.org/10.1177/0021934703033006002

Yamamoto, Masahiro, Matthew James Kushin, and Francis Dalisay. 2017. "Social Media and Political Disengagement Among Young Adults: A Moderated Mediation Model of Cynicism, Efficacy, and Social Media Use on Apathy." Mass Communication and Society, 20(7): 149-168.

Yancey, William L., Leo Rigsby, and John D. McCarthy. 1972. "Social Position and Self- Evaluation: The Relative Importance of Race." American Journal of Sociology, 78(2): 338-359.

Zimmerman, Marc A., Julian Rappaport. 1988. "Citizen Participation, Perceived Control, And Psychological Empowerment." American Journal of Community Psychology, 16(5): 725-748.

Zukin, Cliff, Scott Keeter, Molly Andolina, Krista Jenkins, and Michael X. Delli Carpini. 2006. New Engagement: Political Participation, Civic Life, and the Changing American Citizen. New York: Oxford University Press. 


\section{Appendix A}

\section{Dependent Variables}

Attitude about racism (0-1)

Question wording: "Some people say that racism no longer exists in American society. Would you say that...?"

Answer options: (0) racism exists today but it is no longer a major problem, (0) racism once existed but no longer exists in our society, (0) racism has never been a major problem in our society, (1) racism remains a major problem in our society.

\section{Political efficacy (0-6)}

Question wording:

1. "I consider myself well qualified to participate in politics."

2. "Public officials do not care very much about what people like me think." (Wave 2) "The leaders in government care very little about people like me." (Wave 3).7 Answer options for statement one: (0) strongly disagree, (1) disagree, (2) agree, (3) strongly agree.

Answer options for statement two: (0) strongly agree, (1) agree, (2) disagree, (3) strongly disagree.

\section{Independent Variables}

Attitude about racism (0-1)

Question wording: "Some people say that racism no longer exists in American society. Would you say that...?"

\footnotetext{
7 The question wording for the second statement slightly changes between Wave 2 and Wave 3 . Both are
} noted. 
Answer options: (0) racism exists today but it is no longer a major problem, (0) racism once existed but no longer exists in our society, (0) racism has never been a major problem in our society, (1) racism remains a major problem in our society.

Race (0-1)

Categories: (0) Whites, (1) non-Whites-Black, Latino, Asian, Mixed/2+Races

Social Media Scale (0-60)

Question wording:

1. Interact with friends/family by sending messages, sharing status updates, or chatting online using social network services like Twitter or Facebook.

2. Interact with friends/family by sharing links or forwarding information or media through social network services like Twitter or Facebook.

3. Interact with friends/family by tagging friends and family members in posts, photos, or videos on social networking sites.

4. Interact with friends/family by commenting on something a friend of family member posted on a social networking site.

5. Interact with friends/family by visiting websites and other online material that friends or family members have posted or circulated.

6. Participate in an online forum or group related to your interests.

7. Post, link to, or forward information or media related to your interests.

8. Give help, advice, or suggestions to others online related to your interests.

9. Use the internet to organize an online group, discussion, or website.

10. Post an online comment, review, or critique of someone else's media.

11. In the past 12 months, how often have you forwarded, re-tweeted or posted someone else's article/blog/picture/video about a political campaign/candidate/issue?

12. In the past 12 months, how often have you created and circulated your own article/blog/picture/video about a political campaign/candidate/issue to an online site?

13. In the past 12 months, how often have you commented online or tweeted about an article/blog/picture/video you saw about a political campaign/candidate/issue?

14. In the past 12 months how often have you posted a status update or sent an email/tweet/instant message about a political campaign/candidate/issue? 
15. In the past 12 months, how often have you followed someone on Twitter for political information, news, or opinions?

Answer options: (0) never, (1) less than one a month, (2) at least once a month, (3) at least once a week, (4) daily

\section{Control Variables}

Education (0-3)

Categories: (0) less than high school, (1) high school, (2) some college, (3) Bachelor's

degree or higher

Democratic Party Thermometer (0-100)

Question wording: We would like to get your feelings toward the president and political parties. We'd like you to rate them on a scale from 0 to 100 using something we call the feeling thermometer. Ratings between 50 degrees and 100 degrees mean that you feel favorably, and ratings between 0 degrees and 50 degrees mean that you don't feel favorably. Using this scale, please type in the number or click on the thermometer to indicate how you rate the Democratic Party."

Answer options: 0-100

\section{Republican Party Thermometer (0-100)}

Question wording: We would like to get your feelings toward the president and political parties. We'd like you to rate them on a scale from 0 to 100 using something we call the feeling thermometer. Ratings between 50 degrees and 100 degrees mean that you feel favorably, and ratings between 0 degrees and 50 degrees mean that you don't feel favorably. Using this scale, please type in the number or click on the thermometer to indicate how you rate the Republican Party."

Answer options: 0-100 
Income (0-4)

Categories: (0) under $\$ 25,000$, (1) $\$ 25,000-\$ 49,999$, (2) $\$ 50,000-\$ 74,999$, (3) $\$ 75,000$ $\$ 99,999$, (4) \$100,000 and above

Region (0-1)

Categories: (0) Northeast, Midwest, West, (1) South

Gender (0-1)

Categories: (0) male, (1) female 


\section{Appendix B}

\section{Descriptive Statistics Tables}

Wave 2

\begin{tabular}{lccccc}
\hline Variable & $\mathrm{N}$ & Mean & Std.Dev. & Min & Max \\
\hline Non-White (0-1) & 1033 & .66 & .48 & 0 & 1 \\
Female (0-1) & 1033 & .55 & .49 & 0 & 1 \\
Income (0-4) & 1033 & 1.78 & 1.45 & 0 & 4 \\
South (0-1) & 1033 & .33 & .47 & 0 & 1 \\
Education (0-3) & 1033 & 1.42 & 1.12 & 0 & 3 \\
Democrat (1-100) & 985 & 50.52 & 29.30 & 0 & 100 \\
Republican (1-100) & 983 & 35.70 & 27.80 & 0 & 100 \\
Racism is a prob. (0-1) & 1008 & .51 & .5 & 0 & 1 \\
Social Media Scale (0-60) & 948 & 21.83 & 13.12 & 0 & 60 \\
Efficacy (0-6) & 998 & 2.45 & 1.10 & 0 & 6 \\
& & & & & \\
\hline
\end{tabular}

Wave 3

\begin{tabular}{lccccc}
\hline Variable & $\mathrm{N}$ & Mean & Std.Dev. & Min & Max \\
\hline Non-White (0-1) & 1033 & .66 & .5 & 0 & 1 \\
Female (0-1) & 1033 & .55 & .5 & 0 & 1 \\
Income (0-4) & 1033 & 1.80 & 1.5 & 0 & 4 \\
South (0-1) & 1028 & .33 & .5 & 0 & 1 \\
Education (0-3) & 1032 & 1.74 & 1 & 0 & 3 \\
Democrat (1-100) & 1019 & 51 & 29 & 0 & 100 \\
Republican (1-100) & 1022 & 35.7 & 27 & 0 & 100 \\
Racism is a prob. (0-1) & 1015 & .60 & .50 & 0 & 1 \\
Social Media Scale (0-60) & 1004 & 21.15 & 13.14 & 0 & 60 \\
Efficacy (0-6) & 1002 & 2.53 & 1.1 & 0 & 6 \\
& & & & & \\
\hline
\end{tabular}

